


\section{A CATALOG OF COMPARTMENT FIRE MODEL ALGORITHMS AND ASSOCIATED COMPUTER SUBROUTINES}

David W. Stroup

U.S. DEPARTMENT OF COMMERCE

National Bureau of Standards

National Engineering Laboratory

Center for Fire Research

Gaithersburg, MD 20899

August 1987

U.S. DEPARTMENT OF COMMERCE, Malcolm Baldrige, Secretary NATIONAL BUREAU OF STANDARDS, Ernest Ambler, Director 

LIST OF FIGURES . . . . . . . . . . . . . . . . . . . . . . . . . . . . . iv

PREFACE . . . . . . . . . . . . . . . . . . . . . . . . . . v

ABSTRACT . . . . . . . . . . . . . . . . . . . . . . . . . . . 1

I. INTRODUCTION . . . . . . . . . . . . . . . . . . . . . . . 2

I.1. FIRE DYNAMICS . . . . . . . . . . . . . . . . . . . . . . . 3

I.2. FIRE MODEL TYPES . . . . . . . . . . . . . . . . . . . . . 4

I.3. CATALOG ORGANIZATION . . . . . . . . . . . . . . . . . . . . . 6

I.4. THE VARIABLE CROSS-REFERENCING SCHEME . . . . . . . . . . . . . 8

I.5. AN EXAMPLE OF USING THE CATALOG . . . . . . . . . . . . . . . . 12

I.6. REFERENCES . . . . . . . . . . . . . . . . . . . . . . . 14

1. ALGORITHMS RELATED TO THE BURNING OBJECT . . . . . . . . . . . . . . . 1-1

2. ALGORITHMS RELATED TO CONDUCTION HEAT TRANSFER . . . . . . . . . . . . $2-1$

3. ALGORITHMS RELATED TO CONVECTION HEAT TRANSFER . . . . . . . . . . . . $3-1$

4. ALGORITHMS RELATED TO THE HOT LAYER . . . . . . . . . . . . . . . . . . 4-1

5. ALGORITHMS RELATED TO THE PLUME . . . . . . . . . . . . . . . . . . . 5-1

6. ALGORITHMS RELATED TO RADIATION HEAT TRANSFER . . . . . . . . . . . . . 6-1

7. ALGORITHMS RELATED TO THE VENT . . . . . . . . . . . . . . . . . . . . 7-1

8. MISCELLANEOUS ALGORITHMS . . . . . . . . . . . . . . . . . . . . . . $8-1$

APPENDIX A. VARIABLE CROSS-REFERENCE . . . . . . . . . . . . . . . . . . . A-1

APPENDIX B. LISTING OF ALGORITHM/SUBROUTINE WRITE-UPS . . . . . . . . . . B-1 


\section{LIST OF FIGURES}

$\underline{\text { Page }}$

Figure 1-1. General diagram of a room fire. . . . . . . . . .

Figure 1-2. Diagram of the flame cone model 1-ANGLE - 4

Figure 1-3. Diagram of the flame cone model 1 - HEIGHT - 5

Figure 2-1. General diagram of a room fire........... . 2-2

Figure 2-2. Schematic of heat conduction into a slab . . . . . 2-TMPW01-11

Figure 3-1. General diagram of a room fire........... . 3-2

Figure 4-1. General diagram of a room fire... . . . . . . . 4-2

Figure 5-1. General diagram of a room fire... . . . . . . . 5-2

Figure 6-1. General diagram of a room fire... . . . . . . . 6-2

Figure 7-1. General diagram of a room fire... . . . . . . . 7-2

Figure 8-1. General diagram of a room fire.......... . 8-2. 
PREFACE TO THE FIRST EDITION OF THE

CATALOG OF COMPARTMENT FIRE MODEL ALGORITHMS AND ASSOCIATED SUBROUTINES

The main objective of the Compartment Fire Modeling Research (CFMR) Group of the Center for Fire Research (CFR) National Bureau of Standards is to develop computer software for a well-documented, user-friendly, modular and easily updated Consolidated Compartment Fire Model Computer Code, and to use this software to implement applications of the Code which would include a benchmark or reference compartment fire model application. As part of the documentation phase of this activity, a Catalog of Compartment Fire Submodel Algorithms and Associated Subroutines is being compiled. The Catalog will contain algorithms for calculating various physical/chemical fire phenomena and associated computer subroutines, written in FORTRAN 77 . The Catalog subroutine entries are intended to be transportable and usable in compartment fire model computer programs other than the Consolidated Compartment Fire Model Computer Code. Modularity is the key objective in the development of this Catalog. The document that follows represents the first edition of the Catalog.

The routines contained in this first edition of the Catalog have been derived from the NBS/Harvard $5 . \mathrm{N}$ and $6 . \mathrm{N}$ Compartment Fire Model computer programs. Future updates of the Catalog will include algorithms from other fire models and newly developed ones. The Catalog is in loose-leaf form and it is presented in a format that will allow. new or revised algorithm/subroutine entries to be issued and added conveniently.

The algorithms in this first edition of the Catalog were drawn mainly from two sources. They are "The Physical Basis of the Harvard Fire Code" by H.E. Mitler and "Documentation for CFC V, the Fifth Harvard Computer Fire Code" by H.E. Mitler and H.W. Emmons. The algorithm presentation format adopted here was based in part on the latter of these publications. Not all of the physical algorithms from the NBS/Harvard fire model programs have been included in this edition of the catalog. The phenomena which have not been documented fall into two categories: radiation heat transfer and venting. Work is underway to complete algorithm write-ups associated with these phenomena and to include them in a future Catalog update.

The basis of the FORTRAN subroutines for all entries of this edition of the Catalog is the recently completed, one-room computer code, FIRST, which is a consolidation of several advanced versions of the original Harvard CFC $V$ code. To achieve minimum criteria of modularity, some very minor modifications to the FIRST subroutines were required in all cases. In this sense, the subroutine entries in this edition are untested. The subroutine modifications included elimination of entry points, common statements and/or debug information, all of which were peculiar to the FIRST code. The user of this Catalog can refer to the FIRST code for an exact listing of the original software.

Considerable thought has been devoted to the development of a usable and convenient variable cross-referencing scheme. This should allow a catalog user to identify easily the physical input data (e.g. room dimensions, material 
properties, etc.) and the subroutines required to calculate additional inputs for use in a particular subroutine of interest. One desired objective was a scheme which, while assuring modularity, allowed for independence in nomenclature from one algorithm/subroutine catalog entry to the next. The scheme adopted consists of the common definition (in words) of a particular physical/chemical quantity, the subroutine variable or variables used to indicate the quantity, the equation notation used to indicate the quantity, and the names of the subroutines in which the calculations are carried out. Although uniformity in subroutine name and equation variable naming is desireable, the cross-referencing scheme does not make this a strict requirement. This method of cross-referencing variables will avoid the need to define specific common subroutine variable names and/or nomenclature. While there is an attempt to make unambiguous the common definition of a particular physical quantity, its meaning is clarified further from the context of the write-ups of individual algorithms which make use of the variable. This catalog is intended to be a dynamic publication. As suggestions for improvements are received, they will be evaluated and incorporated into the catalog philosophy.

Leonard Y. Cooper, Head

Compartment Fire Modeling Research 


\title{
A Catalog of Compartment Fire Model Algorithms and Associated Computer Subroutines
}

\author{
David W. Stroup
}

\section{ABSTRACT}

The Compartment Fire Modeling Research group of the Center for Fire Research, National Bureau of Standards has been charged with the development of a "benchmark" compartment fire model. As part of this activity, a catalog of available fire model algorithms has been compiled. The catalog contains algorithms which calculate various physical/chemical fire phenomena. The description of each algorithm includes the input(s), output(s), and calculations performed. In addition, each algorithm has a computer subroutine written for it in FORTRAN 77. The variables used as input and output throughout the catalog are cross-referenced. This enables a catalog user to determine which routines would be required to calculate a particular fire phenomena. Updates and revisions will be issued periodically.

Keywords: algorithms; building fires; cataloging; combustion physics; compartment fires; computer programs; fire chemistry; fire models; mathematical models; zone models. 


\section{INTRODUCTION}

Many mathematical models and associated computer programs have been developed to predict enclosure fire dynamics $[1-15]^{1}$. These models differ in many respects. They differ in the number and complexity of fire cumpartments which may be analyzed; the amounts of computer time and memory required; the number and detail of individual physical phenomena accounted for; the amount of documentation available; and the degree of "user-friendliness". Regardless of the many differences, all of these models attempt to describe the same basic fire phenomena. It is possible to break existing fire models up into "elemental" pieces. These "elemental" pieces describe the physical/chemical effects associated with the fire phenomena.

It is the purpose of this catalog to present the available physical/chemical algorithms and corresponding subroutines in a form which may be used by fire researchers who wish to develop or improve fire modeling computer programs. Researchers may use routines from the catalog according to their needs and take advantage of the progress made by others. The catalog contains descriptions of the methodologies used to calculate each of the fire related physical/chemical phenomena. In addition, a FORTRAN 77 computer subroutine which implements the method is included with each algorithm write-up.

Numbers in brackets refer to literature references listed at the end of this section. 
This catalog provides fire researchers with convenient access to each others' work. It eliminates the need for researchers to continually redevelop the same algorithms. For the most part, only the most accurate and efficient algorithms and subroutines are included in the catalog. The catalog is published in a form for easy inclusion in a loose-leaf binder. This will allow for the inclusion of future catalog updates. These updates will include improvements of old algorithms and issuing of new ones as necessary. To be successful, this catalog will require user support and feedback which is heartily encouraged.

\section{I.1. FIRE DYNAMICS}

The physical and chemical processes simulated by the algorithms and subroutines in this catalog are relevant to compartment fire-generated phenomena. The generic fire scenario of interest can be briefly described as follows. An unwanted ignition is assumed to occur within an enclosed space. The fire may start in a couch, for example, or stacked commodities in a warehouse. Regardless of the method and location of ignition, the applicable physical/chemical phenomena discussed below will be the same.

Heat from the initial flame pyrolyzes the material of fire origin. The resulting vapors rise into the flame zone, ignite, and maintain the flame. The elevated temperature products of combustion are driven out of the combustion zone by buoyancy. In this way, a plume of upward moving elevated temperature gases is formed above the fire. The gas entrains some of the surrounding air and the mixture rises to the ceiling. When the plume impinges on the ceiling, 
it spreads out and forms a relatively thin, hot, sooty layer. As the fire grows, this layer will thicken and the relatively sharp interface between it and the cool ambient air layer below will continuously drop. Eventually, the layer falls below the top of the highest vent, whereupon buoyancy-generated cross-vent pressure differentials will drive some of the hot layer gases out of the room. In addition to energy losses from the flow of hot gases out of the vent(s), the layer also loses energy by radiation and convection to the floor, ceiling, walls, and other objects within the room.

Due to heating from the elevated room temperature environment, combustible objects in the room remote from the fire may eventually reach their ignition temperature, and ignite. If such ignitions begin to occur, they may follow one another very rapidly, until all combustible objects within the room are burning. This transition period between ignition of the first "target item" and full room involvement is called "flashover." It generally only lasts a few seconds. Following flashover, the fire may spread from the room of origin to other parts of the building, thus presenting a severe danger to life and property.

\section{I.2. FIRE MODEL TYPES}

Many attempts have been made to model the above fire phenomena mathematically. Fire models may be divided into two main groups. The first group is composed of probabilistic models. Models in this group "calculate" fire development based on the probability of one event following another. Routines from these models will not be discussed in this catalog. 
The other group consists of deterministic models. In general, these models solve differential and/or algebraic equations to determine the. time-varying fire characteristics. The deterministic models may be further sub-divided into categories which describe the assumptions used to solve the problem. The first of these groups is "field" models. Field fire models describe events within an enclosure volume by a set of coupled partial differential equations, which are applicable throughout the volume, and which stipulate boundary conditions at the surfaces of the volume. Field models are generally very complex and require large amounts of computer time and memory.

The other group consists of the "zone" models. The zone type fire models divide the room into zones, usually three. The three zones are an upper zone which includes the smoke layer, a lower zone which contains relatively cool and uncontaminated air, and a combustion/plume zone which transports the smoke from the fire below to the upper smoke layer. Models developed using the zone concept range from very simple to very complex.

The focus of attention of this catalog is on the physical/chemical algorithms which would be used in zone-type models and, possibly, in hybrid models which combine both zone-type and field-type descriptions of the fire-generated compartment environment. 


\section{I.3. CATALOG ORGANIZATION}

This catalog of compartment fire model algorithms is intended to be used as a reference by persons desiring to develop their own fire models or enhance existing ones. Each algorithm write-up, contained in the catalog, explains the methodology for calculating a fire related parameter. The format, used to present each algorithm, has been chosen to be as "user-friendly" as possible. The catalog is being issued in a form for easy inclusion in a loose-leaf binder. This will make it easy to update, and updates, including new and improved algorithms, will be issued periodically. The catalog is divided into seven sections. They are: 1. Burning Object

2. Conduction Heat Transfer

3. Convection Heat Transfer

4. Hot Layer

5. Plume

6. Radiation Heat Transfer

7. Vents

8. Miscellaneous

Each section contains one or more algorithms, organized in alphabetical order, which calculate result(s) related to that section heading. An individual algorithm is only described once. However, if the algorithm could logically be expected to be found under two or more headings, reference to the complete algorithm description may be found under each appropriate heading. 
Each algorithm is described individually. The algorithm's name and brief title appears at the top of each page. The first section, Description, describes the methodology used in the algorithm. In addition, the major limitations of the algorithm are listed as are any other details which may be important to someone wishing to incorporate the algorithm into a fire model. The second section, Output, lists the output variable(s), with a brief description of the meaning of each variable. The number of output variables from a given subroutine are generally limited to one. This enables a catalog user to build a complete fire model using relatively small pieces of the phenomena. It also makes it possible to include alternate algorithms for modeling the same phenomena. The third section, Input, includes a list of the required input variables along with a brief description of each variable. Each input variable is identified as to whether it is a physical constant, input data, or calculated physical variable. The appropriate SI units are listed next to each input variable. Variables are numbered and cross-referenced so the user can easily find required input which is calculated by. routines elsewhere in the catalog.

A fourth section, Calculations, presents the step-by-step procedure or algorithm used to calculate the result. The meaning of each calculation is briefly described next to the calculation. The fifth section, References, is a listing of reference sources where the user may obtain more information about the theory used to develop the algorithm, its limitations, and/or its implementation in other fire models. Section six, Subroutine Variables, relates the variables used in the output, input, and calculations sections to the associated FORTRAN variables. The seventh section, labeled Prepared by, 
lists the author(s) of the algorithm/subroutine write-up. Finally, section eight, Computer Subroutine, presents the FORTRAN 77 computer subroutine which implements the algorithm.

\section{I..4. THE VARIABLE CROSS-REFERENCING SCHEME}

A variable cross-referencing scheme has been developed to assist users in selecting algorithms (subroutines) from the catalog. The cross-reference enables catalog users to determine which routines are available to calculate desired values. The user may then refer to the appropriate routines to determine the required input information. If any of the input data are listed as a "Calculated Value", the user may refer back to the variable crossreference to determine whether or not algorithm/subroutine write-ups are available to calculate these additional values.

The variable cross-referencing scheme consists of five parts. Each part is separated into its own column. The first column of the cross-reference contains an identification number. Each variable is assigned a reference number. Whenever a variable is mentioned in the catalog, its associated reference number is also listed. Appendix A lists the variables in the catalog organized according to increasing reference number. The numbers are assigned in no particular order. As the Catalog grows and updates are issued, new variables and associated identification numbers will be added to the list. Eventually, some variables and their identification numbers will be eliminated. Their use in the Catalog will be updated to reflect any changes. (Any 
variables missing from the list should be brought to the attention of the author.)

The second column contains a word definition. A common definition (in words) has been developed for each physical/chemical quantity referenced in the catalog. While there is an attempt to make unambiguous the common definition of a particular physical quantity, its meaning is clarified further from the context of the write-ups of individual algorithms which make use of the variable. The adoption of a method of variable cross-referencing based on common word definitions of physical/chemical quantities and associated identification numbers avoids the need to define specific subroutine variable names and/or nomenclature. However, uniformity in subroutine and equation variable naming is desirable and will be maintained whenever possible.

The third part of the variable cross-reference is a column listing of the nomenclature used in the algorithm write-ups. A list of the mathematical equation symbols used to represent physical/chemical quantities is provided for each common definition. There will be one or more entries in this column for each definition. In some of the algorithm/subroutine write-ups, the mathematical symbol for a given quantity is preceded by the mathematical summation sign $(\Sigma)$. This indicates that the particular quantity is the sum of that quantity for all objects, plumes, walls, or whatever. Its meaning should be clear from the algorithm/subroutine write-up.

The FORTRAN subroutine variable names used to represent physical/chemical quantities are listed in the fourth column of the variable cross-reference. 
There will be one or more entries for each physical/chemical quantity. The listed FORTRAN variable may be used to represent the individual quantity, the summation of that quantity for all sources, or both. The user should check the individual algorithm/subroutine write-ups to determine the exact meaning.

The last column in the variable cross-reference lists the names of the algorithm/subroutine write-ups which calculate the specified physical/chemical quantity. Algorithm/subroutine names will be listed in all capital letters. In some cases, more than one routine will be available to calculate a particular quantity. The user should examine the algorithm write-ups to determine which routines are appropriate for the particular scenario being modeled. The words "Input Data", in a combination of upper and lower case letters, are used to indicate physical/chemical quantities which must be obtained by the user from other sources. For the most part, these values are determined by the situation being modeled, e.g. room dimensions, object location, type of fire, etc. In a few cases, the values are ones which cannot be calculated given the present state of the art of fire science. Another possible entry in this column is a dash (-). The dash is used to indicate quantities whose values are determined by the overall integrated fire model. These quantities include current simulation time, current time step size, and similar type of values. The final possible entry in this column is an asterisk $(*)$. It is used to designate physical/chemical quantities for which one or more algorithms or subroutines are available, but they have not been written up in a form appropriate for inclusion in the Catalog. Eventually, this category will disappear. 
The cross-reference listing is contained in Appendix A of this report. The variables are arranged according to increasing identification number. Appendix B lists the algorithm/subroutine names organized alphabetically for each section heading. In addition, the inputs and output(s) are identified for each algorithm/subroutine. The variable identification numbers are used to identify the inputs and output(s).

Finally, the use of the variable cross-reference will be illustrated with an example. Suppose a catalog user wants a method for calculating the rate of addition of mass to the hot layer from a plume (V.97). The number in parenthesis refers to the variable identification number. The user would first refer to the cross-reference. In the cross-reference, the entry for variable number 97 lists a common definition of "Rate at which the plume over an object adds mass to the hot layer". The cross-reference refers the user to an algorithm/subroutine write-up labeled TMSPLM. This routine calculates the rate at which the plume over an object adds mass to the hot layer. Examining the Appendix $B$ and the algorithm write-up, the user finds that this routine requires ten input items. Six of these inputs are classified as Input Data (density of ambient air (V.17), specific heat of ambient air (V.112), ambient temperature of air (V.120), the plume entrainment coefficient (V.71), pi (V.146), and the acceleration of gravity (V.144)). The other four values are labeled as "Calculated Values". These values are the height of the plume (V.37), the radius of the fire (V.85), the negative of the rate of chemical energy released from the burning object (V.88), and the negative of the mass pyrolysis rate of the object (V.61). 
The Catalog user would refer back to the variable cross-reference and determine whether or not routines to calculate the required "Calculated Value" inputs were currently available in the Catalog. If routines were available, the user would examine those routines to determine whether or not they would be appropriate for the model being developed. If one or more of the routines were appropriate, the user would then determine what additional input data would be required by the additional routines. If additional "Calculated Value"s were required, the user would again examine the cross-reference to determine the available routines and examine the algorithm/subroutine write-ups to determine their appropriateness and required inputs. This process would be repeated until all of the required input data could either be calculated or determined by the user (from reference sources or whatever).

\section{I.5. AN EXAMPLE OF USING THE CATALOG}

Suppose a fire researcher wishes to improve the modeling capabilities of the ASET (Available Safe Egress Time) computer code [7,8]. A likely improvement would involve use of a more fundamental means of estimating heat transfer to the compartment ceiling. This improvement would require an algorithm for calculating the transient heat conduction through the depth of the ceiling material. Such an algorithm and its associated subroutine can be found in the section on Conduction Heat Transfer in the Catalog. In that section, there is an algorithm named TMPWO1 "Heat Conduction in a Slab" (V.122). It may be used to calculate transient heat conduction in a solid where surfaces are exposed to radiative and convective heating. 
In the write-up of TMPWO1, there is a listing of the required inputs. Many of these deal with characteristics of the wall or ceiling material and may be obtained from published data on thermophysical properties of materials. Another input, the depth of the hot layer (V.20), is already calculated by equations in the ASET model. Inputs describing the convective flux (V.'11) and radiative fluxes ( $V .79$ and $V .81$ ) being received by the material are also required. The modeler might derive these by using the simple assumptions already used in the ASET model. (In the ASET model the total rate of heat transfer to bounding surfaces of the compartment is represented as a constant fraction of the instantaneous fire heat release rate.) The alternative would be to compute these inputs using algorithms and subroutines referenced elsewhere in the catalog and to incorporate these subroutines into the ASET mode1.

The final input required by TMPWOI is the absorption coefficient of the hot layer in the room (V.2). The Catalog contains an algorithm for calculating this value. It is labeled ABSRB2 (see section 4 of this report). It assumes the absorptivity is a constant fraction of the mass concentration of the soot in the hot layer. If this routine is selected, another input is required. This input represents the mass concentration of soot in the hot layer $(V .44)$ as a function of time. In this case, a simple way to represent this value would be to use the product of combustion calculation capability of the ASET model. The soot concentration could be modeled as either a constant fraction of the heat release rate or as input data from fire tests. 
Using these two subroutines, TMPWOI and ABSRB2, it would be possible to incorporate heating of a slab (ceiling, floor, or wall) into the ASET model. This would be the first step in developing an improved method of calculating the fraction of heat lost to the bounding surfaces of the room from elementary principles. The modeler would have to find a way to control the calling of these subroutines, but the subroutines themselves would not have to be developed again.

\section{I.6. REFERENCES}

[1] Tanaka, T., "A Model of Multiroom Fire Spread," NBSIR 83-2718, National Bureau of Standards, 1983.

[2] Zukoski, E.E. and Kubota, T., "Two-layer Modeling of Smoke Movement in Building Fires," Fire and Materials, 4 (1) (1980) 17 - 27.

[3] Zukoski, E.E. and Kubota, T., "A Computer Model for Fluid Dynamic Aspects of a Transient Fire in a Two Room Structure," C.I.T. Report prepared for the U.S. National Bureau of Standards, 1978.

[4] Quintiere, J., Steckler, K., and McCaffrey, B., "A Model to Predict the Conditions in a Room Subject to Crib Fires," presented at the First Specialists Meeting of the Combustion Institute, Bordeaux, Talence, France, published by the U.S. National Bureau of Standards, 1981.

[5] Steckler, K., "A Calculation of Wall Fire Spread in an Enclosure," NBSIR 83-2765, U.S. National Bureau of Standards, 1983.

[6] Cooper, L.Y., "A Concept for Estimating Available Safe Egress Time in Fires," Fire Safety Journal, 5 (1983) 135 - 144.

[7] Cooper, L.Y., "A Mathematical Model for Estimating Available Safe Egress Time in Fires," Fire and Materials, 6 (3/4) (1982) 135 - 144.

[8] Cooper, L.Y. and Stroup, D.W., "ASET - A Computer Program for Calculating Available Safe Egress Time," Fire Safety Journal, 9 (1985) 29.

[9] Babrauskas, V., "COMPF2 - A Program for Calculating Post-Flashover Fire Temperatures," NBS TN991, U.S. National Bureau of Standards, 1979.

[10] Mitler, H.E. and Emmons, H.W., "Documentation for CFC V, the Fifth Harvard 
Fire Code," U.S. National Bureau of Standards, Washington, D.C., NBS - GCR-81-344, October 1981.

[11] Pape, R., Waterman, T.E. and Eichler, T.V., "Development of a Fire in a Room from Ignition to Full Room Involvement - RFIRES," IITRI Report NBS-GCR-81-301 for U.S. National Bureau of Standards, 1981.

[12] Jones, W.W., "A Model for the Transport of Fire, Smoke, and Toxic Gases (FAST)," U.S. National Bureau of Standards report NBSIR 84-2934 (1984).

[13] Siu, N.O., "COMPBRN - A Computer Code for Modeling Compartment Fires," University of California at Los Angeles report UCLA-ENG-8257 (1982) and U.S. Nuclear Regulatory Commission Report NUREG/CR-3239 (1983).

[14] MacArthur, C.D., "Dayton Aircraft Cabin Fire Model - Version 3: Vo1. 1 Physical Description," University of Dayton Research Institute, May, 1981.

[15] Yang, K.T. and Liu, V.K., "UNDSAFE - II: A Computer Code for Buoyant Turbulent Flow in an Enclosure with Thermal Radiation, "University of Notre Dame report TR-79002-78-3, July 1978. 
1. ALGORITHMS RELATED TO THE BURNING OBJECT

1-I 


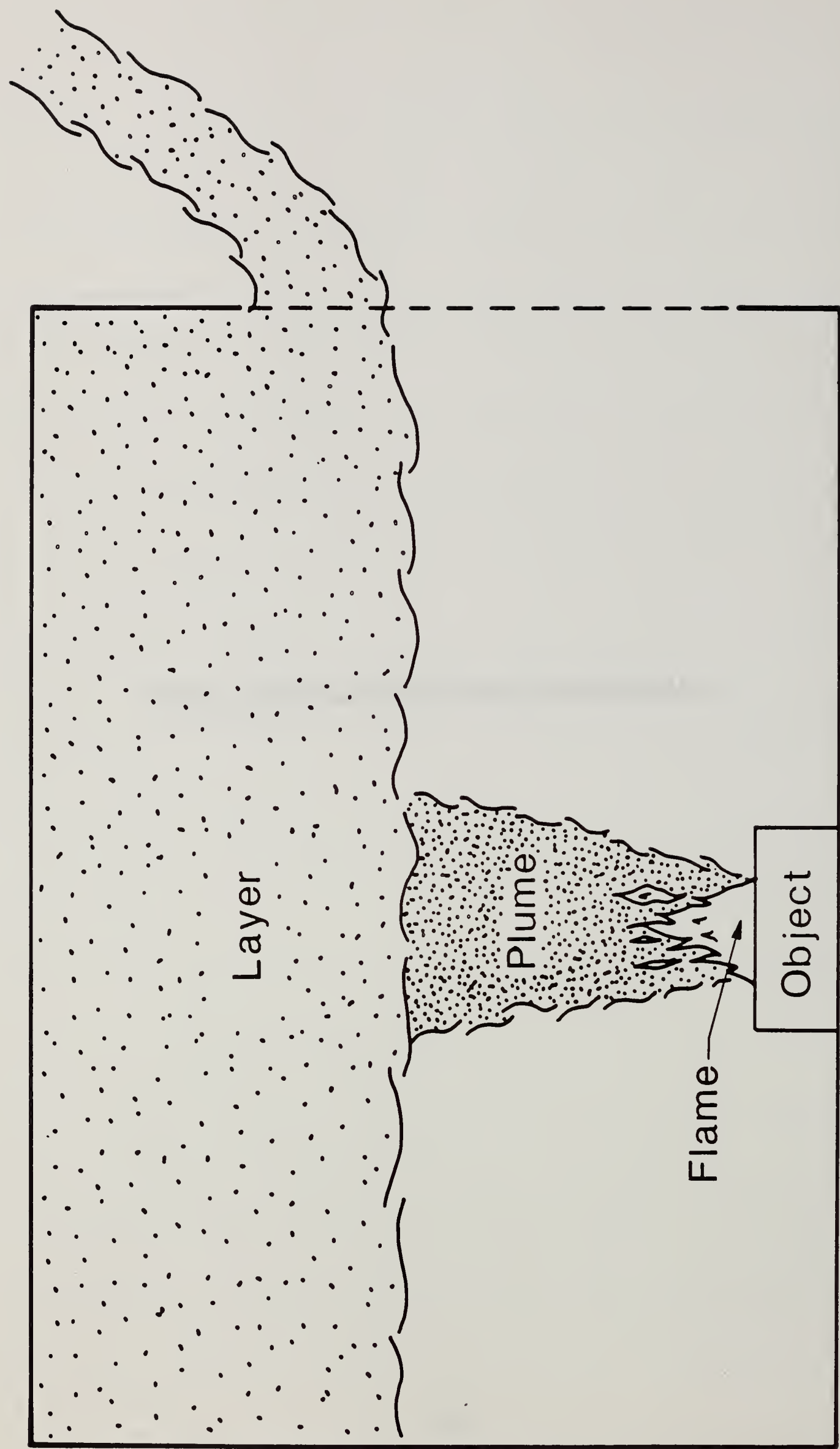

Dar 


\section{ANGLE - Semiapex Angle of Flame Cone}

\section{Description}

This routine calculates the semiapex angle of a cone representing the inhomogeneous, fluctuating, turbulent, flame over a burning object, figure 11. A description of the flame geometry is essential for flame radiation calculations. As an approximation, the flame may be modeled as a right circular cone, figure 1-2, of hot grey gas. The cone has a height equal to the height of the flame above the burning object, and its radius is equal to the radius of the fire on the burning object. The size varies with time as indicated by changing values of the semiapex angle.

\section{$\underline{\text { Output }}$}

$\psi$

Semiapex angle of the cone modeling the flame over a burning object. [degrees] (V.109)

\section{Input}

$\mathrm{R}$

$h_{f}$

\section{$\underline{\text { Calculation }}$}

$$
\psi=\tan ^{-1}\left(\mathrm{R} / \mathrm{h}_{\mathrm{f}}\right)
$$

Radius of the fire on the burning object

(Calculated Value, see Burning Object section).

[m] (V.85)

Height of the flame above the burning object

(Calculated Value, see Burning Object section).

[m] (V.36) 


\section{References}

1. Mitler, H.E., "The Physical Basis of the Harvard Fire Code", Home Fire Technical Report No. 34, Harvard University, October 1978, p. 8.

2. Mitler, H.E., and Emmons, H.W., "Documentation for CFC V, the Fifth Harvard Computer Fire Code", U.S. Department of Commerce, Washington, D.C., NBS-GCR-81-344, October 1981, pp. 84-85, 89.

Subroutine Variables

$$
\begin{aligned}
& \mathrm{PSI1}=\psi \\
& \mathrm{ZRFZZ}=\mathrm{R} \\
& \mathrm{ZHFZZ}=\mathrm{h}_{\mathrm{f}}
\end{aligned}
$$

\section{Prepared by}

David W. Stroup 


\section{Computer Subroutine}

SUBROUTINE ANGLE (ZRFZZ,ZHFZZ,PSII)

C

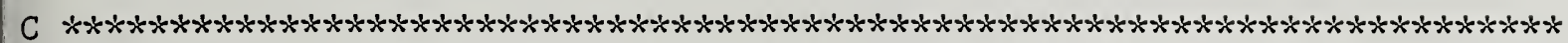

$\mathrm{C}$

IMPLICIT DOUBLE PRECISION ( $\mathrm{A}-\mathrm{H}, \mathrm{O}-\mathrm{Z}$ )

C

C SUbRoUtine to CALCULATE THE SEMIAPEX ANGLE OF A FLAME CONE.

C

C INPUT VARIABLES:

C ZRFZZ - RADIUS OF FIRE

C ZHFZZ - - HEIGHT OF FLAME

$\mathrm{C}$

C OUTPUT VARIABLE:

C PSII - FLAME CONE ANGLE

C

PSI1 = DATAN2 (ZRFZZ, ZHFZZ)

RETURN

END 


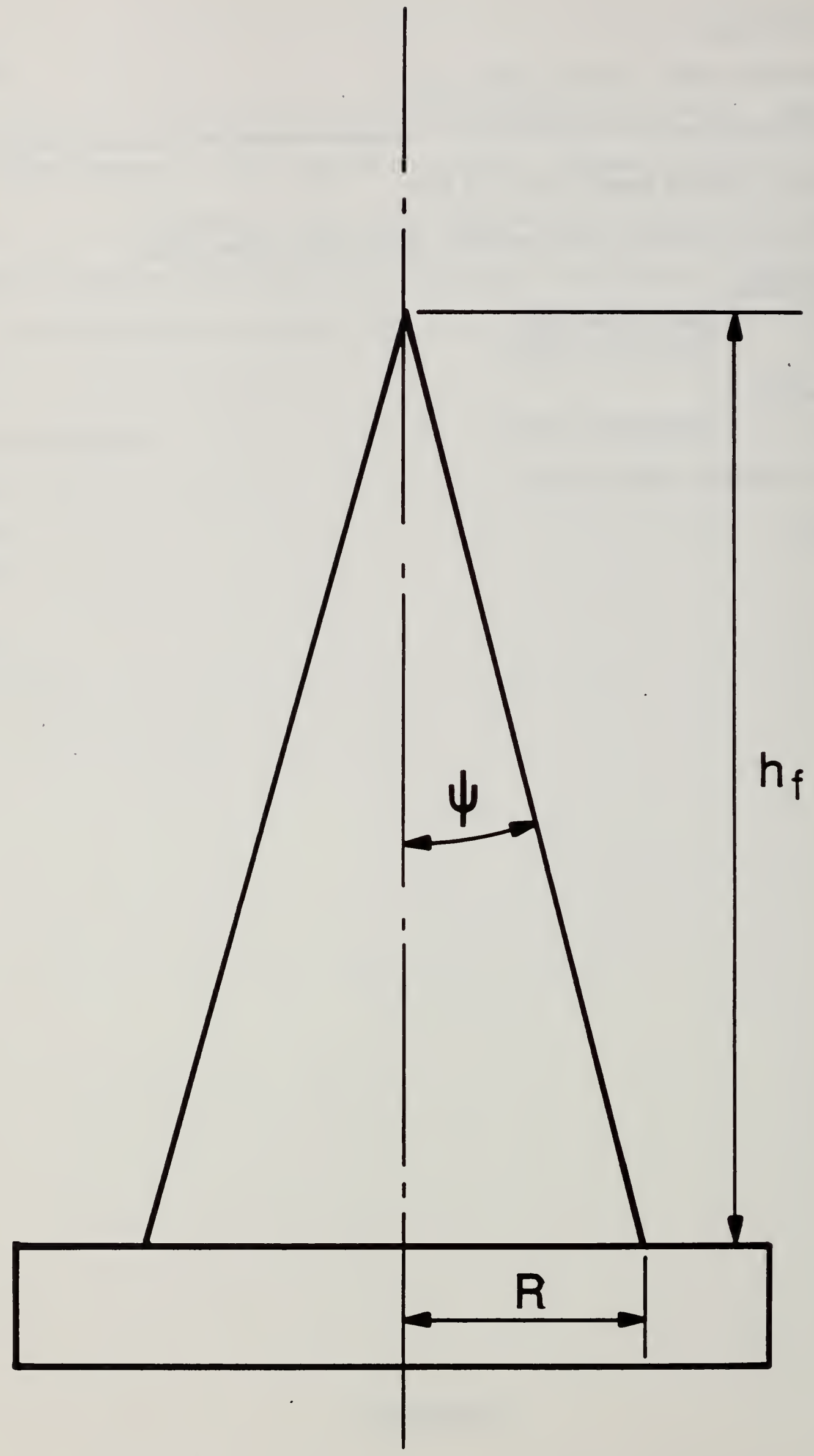

Figure 1-2. Diagram of the flame cone model 


\section{BURN - Mass Rate of Burning of the Fuel from an Object}

\section{Description}

This routine calculates the mass rate of burning of the fuel released from a pyrolyzing object. If the mass pyrolysis rate, $\dot{\mathrm{m}}_{f}$, is known, the object's heat release rate, $\dot{Q}$, may be obtained from

$$
\dot{\mathrm{Q}}=x\left|\dot{\mathrm{m}}_{\mathrm{f}}\right| \mathrm{H}_{\mathrm{c}}
$$

where $\chi$ is the fraction of energy released in open-air burning, $\dot{m}_{f}$ is mass pyrolysis rate of the object (defined to be negative), and $H_{c}$ is the heat of combustion per kilogram as obtained for complete combustion in a bomb calorimeter. A simple (though incorrect) interpretation of the above equation is that only the fraction $\chi$ of the pyrolyzed vapor burns and burns completely. The object's mass burning rate is

$$
\dot{\mathrm{m}}_{\mathrm{b}}=\chi\left|\dot{\mathrm{m}}_{\mathrm{f}}\right|
$$

As long as sufficient oxygen is available, all of the fuel will burn limited only by the combustion efficiency of the chemical reaction.

When oxygen starvation occurs, the burning rate will decrease. The maximum amount of fuel vapor which can burn in the presences of a known amount of air (oxygen) is

$$
\dot{\mathrm{m}}_{\mathrm{b}}=\dot{\mathrm{m}}_{\mathrm{a}} / \gamma
$$

where $\dot{\mathrm{m}}_{\mathrm{a}}$ is the amount of air entrained in the part of the plume below the hot layer and $\gamma$ is the air/fuel mass ratio in a free burn of the object. This routine assumes no entrainment occurs above the layer interface. The quantity of air entrained, $\dot{\mathrm{m}}_{\mathrm{a}}$, into the plume is equal to the sum of the total mass 
flow out the top of the plume, $\dot{m}_{p}$, and the mass pyrolysis rate of the fuel, $\dot{m}_{f}$ (this quantity is negative). At any given time, the burning rate is chosen to be the smaller of either the combustion efficiency value or the oxygen starvation value.

\section{Output}

$\dot{\mathrm{m}}_{\mathrm{b}}$

Mass rate of burning of the fuel from an object.

$$
[\mathrm{kg} / \mathrm{s}](\mathrm{V} .55)
$$

\section{Input}

$x$

$\gamma$

.

$\dot{\mathrm{m}}_{f}$

$\dot{\mathrm{m}}_{\mathrm{p}}$

\section{Calculation}

$\dot{\mathrm{m}}_{\mathrm{b}}=\min \left[-\chi \dot{\mathrm{m}}_{f},\left(\dot{\mathrm{m}}_{\mathrm{p}}+\dot{\mathrm{m}}_{\mathrm{f}}\right) / \gamma\right]$
Fraction of combustion energy released in the flame of the object (Input Data). (V.26)

Air/fuel mass ratio in a free burn of the object (Input Data). (V.3)

(Negative of the) mass pyrolysis rate of the object (Calculated Value, see Burning Object section). [ kg/s] (V.61)

Rate at which the plume over the burning object adds mass to the hot layer (Calculated Value, see Burning Object section). [ $\mathrm{kg} / \mathrm{s}]$ (V.97)

Burning rate, limited by combustion efficiency, $\chi$, or by oxygen starvation. 


\section{$\underline{\text { References }}$}

1. Mitler, H.E., "The Physical Basis of the Harvard Fire Code", Home Fire Technical Report No. 34, Harvard University, October 1978, p. 8.

2. Mitler, H.E., and Emmons, H.W., "Documentation for CFC V, the fifth Harvard Computer Fire Code", U.S. Department of Commerce, Washington, D.C., NBS-GCR-81-344, October 1981, p. 89 .

\section{Subroutine Variables}

TMOZB $=\dot{\mathrm{m}}_{\mathrm{b}}$
CHI $=\chi$
XGAMMA $=\gamma$
TMOZZ $=\dot{\mathrm{m}}_{\mathrm{f}}$
TMPZZ $=\dot{\mathrm{m}}_{\mathrm{p}}$

\section{Prepared by}

David W. Stroup 


\section{Computer Subroutine}

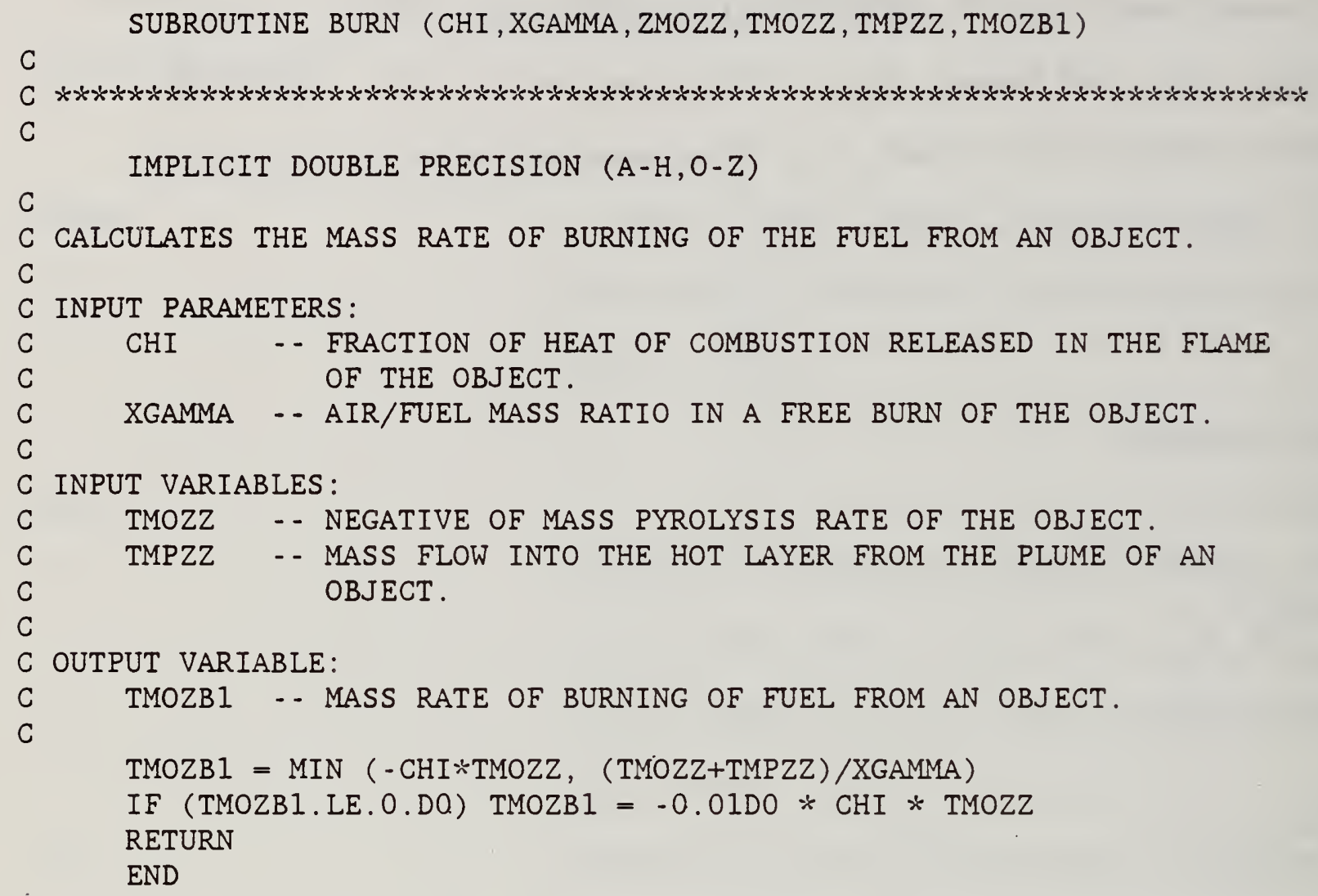




\section{CHEM - Energy Release Rate from a Burning Object}

\section{Description}

This routine calculates the rate at which energy is released from a burning object. In general, an object's heat release rate, $\dot{Q}$, may be obtained from

$$
\dot{\mathrm{Q}}=\chi \dot{\mathrm{m}} \mathrm{H}_{\mathrm{c}}
$$

where $\chi$ is the fraction of energy released in open-air burning, $\dot{m}$ is mass pyrolysis rate of the object, and $H_{c}$ is the heat of combustion per kilogram ar obtained for complete combustion in a bomb calorimeter. A simple (though incorrect) interpretation of the above equation is that only the fraction $x$ of the pyrolyzed vapor burns and burns completely. The energy release is

$$
\begin{gathered}
\dot{\mathrm{Q}}=\dot{\mathrm{m}}_{\mathrm{b}} \mathrm{H}_{\mathrm{c}} \\
\dot{\mathrm{m}}_{\mathrm{b}}=\chi\left|\dot{\mathrm{m}}_{\mathrm{f}}\right|
\end{gathered}
$$

where

In this routine, the heat of combustion, $\mathrm{H}_{c}$, is replaced with an effective heat of combustion. This accounts for the energy required to raise the temperature of the object's pyrolysis gases from ambient to pyrolysis temperature. If the layer interface is above the object's top surface, the net power output by combustion is calculated using the effective heat of combustion and returned as a negative value. If the layer is below the top surface of the object, combustion is assumed to have stopped and a zero value is returned for the heat release rate. 
$\dot{\mathrm{E}}_{\mathrm{f}}$

Input

$c_{p}$

$\mathrm{H}_{c}$

$T_{\mathrm{a}}$

$T_{p}$

$\dot{\mathrm{m}}_{\mathrm{b}}$

$h_{p}$

\section{Calculations}

$H_{c}^{\prime}=H_{c}-c_{p}\left(T_{p}-T_{a}\right)$

$\dot{\mathrm{E}}_{\mathrm{f}}= \begin{cases}0, & \mathrm{~h}_{\mathrm{p}}<0 \\ -\dot{\mathrm{m}}_{\mathrm{b}} * \mathrm{H}_{\mathrm{c}}^{\prime}, & \mathrm{h}_{\mathrm{p}} \geq 0\end{cases}$
(Negative of the) chemical energy released from

a burning object. [W] (V.88)

Specific heat of ambient air (Input

Data). [J/kg-K] (V.112)

Heat of combustion of the material making up the object (Input Data). [J/kg] (V.30)

Ambient temperature of the room containing the object (Input Data). [K] (V.120)

Temperature at which the object begins to

pyrolyzes (Input Data). [K] (V.119)

Mass rate of burning of the fuel from the object (Calculated Value, see Burning Object

section). [ kg/sec] (V.55)

Height of the plume over an object, distance between the object's hot surface and the layer interface (Calculated Value, see Burning Object section). [m] (V.37)

Effective heat of combustion.

Negative of power output by combustion. 


\section{References}

1. Mitler, H.E., "The Physical Basis of the Harvard Fire Codes," Home Fire Project Technical Report No. 34, Harvard University, October 1978.

\section{Subroutine Variables}

$$
\begin{array}{ll}
T E O Z Z & =\dot{\mathrm{E}}_{f} \\
\mathrm{CP} & =\mathrm{c}_{\mathrm{p}} \\
\mathrm{QF} & =\mathrm{H}_{c} \\
\mathrm{ZKAZZ} & =\mathrm{T}_{\mathrm{a}} \\
\mathrm{ZCOPY} & =\mathrm{T}_{\mathrm{p}} \\
\mathrm{TMOZB} & =\dot{\mathrm{m}}_{\mathrm{b}} \\
\mathrm{ZHPZZ} & =\mathrm{h}_{\mathrm{p}}
\end{array}
$$

\section{Prepared by}

David W. Stroup 


\section{Computer Subroutine}

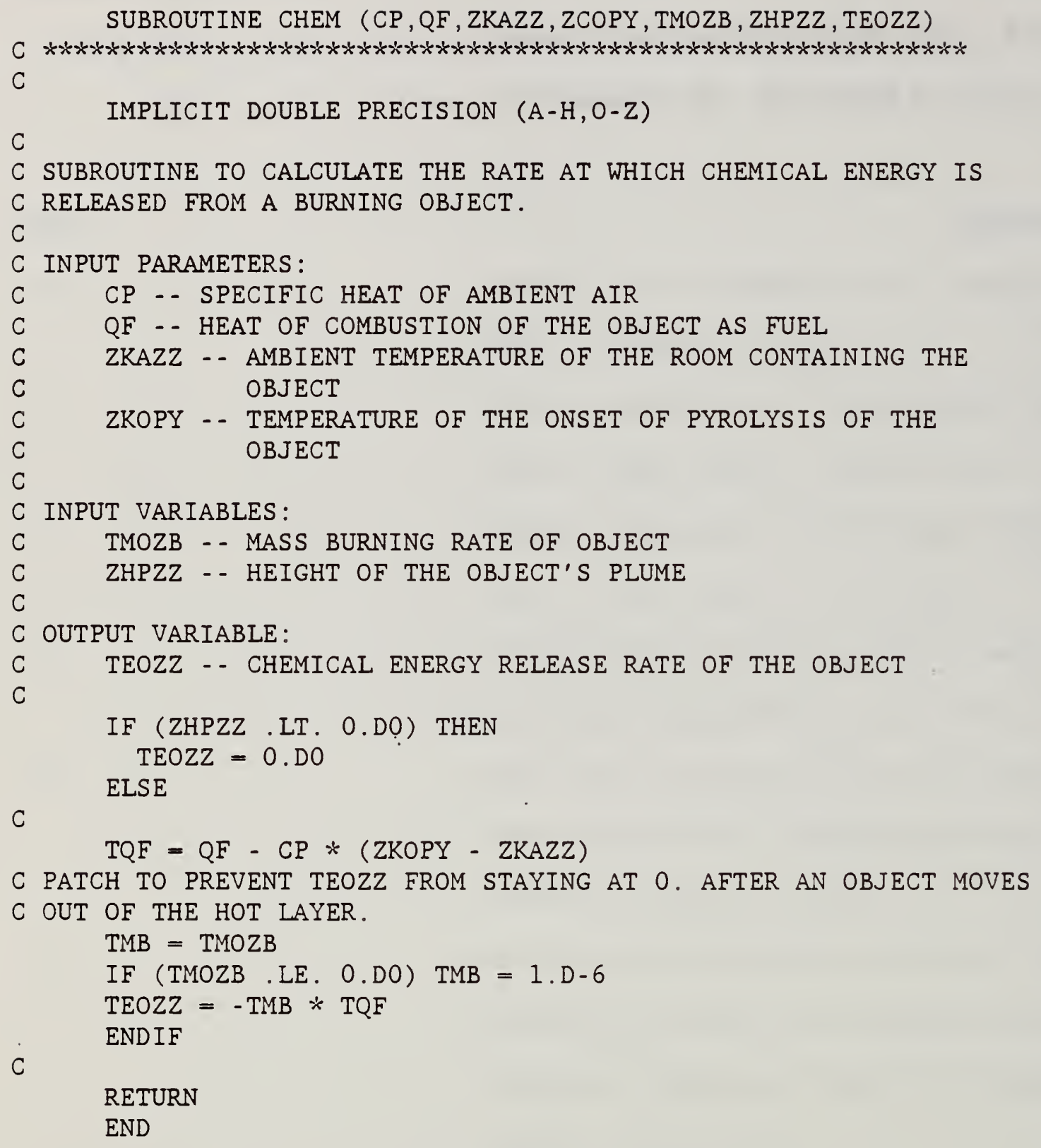


DXDPRD - Rate at which a Burning Object Produces Carbon Dioxide

\section{Description}

This routine calculates the rate at which a burning object produces carbon dioxide. The production rate of a specific gas by a burning object depends on the chemical composition of the material being burned. The rate of production of carbon dioxide by a given burning material is equal to the mass pyrolysis rate of the object multiplied by the mass fraction of the (combustible part of the) object evolved as carbon dioxide, when it burns in open air. The mass fraction must be obtained from fire tests of the specific material (see Tewarsen, A., "Heat Release Rates from Burning Plastics", J. Fire and Flammability 8 (1977) for example).

\section{Output}

$\dot{\mathrm{m}}_{\mathrm{CO} 2}$

Mass rate of evolution of carbon dioxide from the object. [kg/s] (V.56)

Input

$\mathrm{f}_{\mathrm{C} O 2}^{\prime}$

Mass fraction of the (combustible part of the) object evolved as carbon dioxide, when it burns in the open (Input Data). (V.46)

$\dot{\mathrm{m}}_{f}$ (Negative of the) mass pyrolysis rate of the object (Calculated Value, see Burning Object section). [ $\mathrm{kg} / \mathrm{s}](\mathrm{V} .61)$ 
Calculations

$$
\dot{\mathrm{m}}_{\mathrm{CO} 2}=-\mathrm{f}_{\mathrm{CO} 2}^{\prime} \dot{\mathrm{m}}_{\mathrm{f}}
$$

\section{References}

1. Mitler, H.E. and Emmons, H.W., "Documentation for CFC V, the Fifth Harvard Fire Code," U.S. Department of Commerce, Washington, D.C., NBS-GCR-81-344, October 1981, pp. 128 - 131.

Subroutine Variables

$$
\begin{aligned}
& \text { TMOD }=\dot{\mathrm{m}}_{\mathrm{CO} 2} \\
& \text { FCO2 }=\mathrm{f}_{\mathrm{CO} 2}^{\prime} \\
& \text { TMOZZ }=\dot{\mathrm{m}}_{\mathrm{f}}
\end{aligned}
$$

Prepared by

David W. Stroup 


\section{Computer Subroutine}

SUBROUTINE DXDPRD (FCO2, TMOZZ, TMOD)

C

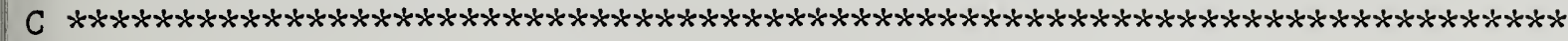
C

C SUBROUTINE TO CALCULATE THE RATE AT WHICH THE FIRE OF AN OBJECT

C PRODUCES CARBON DIOXIDE.

C

C INPUT PARAMETERS:

C FCO2 - - MASS FRACTION OF CARBON DIOXIDE IN THE GASES

C EVOLVED FROM THE BURNING OBJECT.

C

C INPUT VARIABLES:

TMOZZ - NEGATIVE OF THE MASS PYROLYSIS RATE OF THE OBJECT. OUTPUT VARIABLE:

TMOD - - MASS RATE OF EVOLUTION OF CARBON DIOXIDE FROM THE OBJECT .

IMPLICIT DOUBLE PRECISION (A-H,O-Z)

TMOD $=-\mathrm{FCO} 2 * \mathrm{TMOZZ}$

RETURN

END 
1 - DXDPRD - 4 
FLUX - Net Heat Flux Absorbed by the Surface of an Object.

\section{Description}

This subroutine calculates the radiation heat flux absorbed by the surface of a burning target object. The radiation fluxes from all sources (layer, walls, fire plume(s)) must be known. The sum of these fluxes is modified to account for reradiation from the burning target object, the current size of the object's fire plume, and the location of the hot layer interface. The object is represented as a cylinder. The net radiative heat flux incident on a burning object is equal to the sum of the incident radiative heat fluxes from all sources minus an amount which is reradiated away by the object. This net heat flux is the maximum which an object may receive.

When the object is immersed or nearly immersed in the hot layer or when the object is nearly burned out, the net heat flux which it receives must be decreased. When the layer submerges the burning item, it is assumed that the object continues to pyrolyze as before with no flame. If the layer were to rise, the flame would reappear. (Warning: If care is not taken in implementing this routine, it may lead to numerical instabilities in a model.) The immersed surface stays at its previous temperature and pyrolyzes due to the radiative flux it receives from the layer, and from the ceiling and walls $\left(\phi_{+}\right)$. Convective heating or cooling by the layer, and reradiation from the surface are ignored. Finally, when the object is nearly burned out, an effective flux, $\phi_{\text {eff }}$, which allows the object to burn up smoothly, is used. 


\section{Input}

$\mathrm{H}_{\mathrm{v}}$

Heat of vaporization (or pyrolysis) of the object (Input Value). [J/kg] (V.31)

$\kappa$ Absorption coefficient of the flame gases above the burning object (Input Value). $\left[\mathrm{m}^{-1}\right]$ (V.1) Radiative heat flux from the hot layer to the surface of the target object (Calculated Value, see Radiation Heat Transfer section). [W/ $\left./ \mathrm{m}^{2}\right]$ ( $\mathrm{V} .77)$

$\sum \dot{\mathrm{q}} \dot{\mathrm{P}}_{\mathrm{O}}^{\prime \prime}$

$\sum \dot{q}$ wैo

(Sum of the) radiative heat flux(es) from the plume(s) over all burning objects to the surface of the target object (Calculated Value, see Radiation Heat Transfer section). [W/m $]$ (Sum of the) radiative heat flux(es) from the hot walls and ceiling to the target object (Calculated Value, see Radiation Heat Transfer section). $\left[\mathrm{W} / \mathrm{m}^{2}\right](\mathrm{V} .78)$

$m_{f}$ Remaining mass of target object (Calculated Value, see Burning Object section). [kg] (V.108)

Radius of the fire on the target object (Calculate Value, see Burning Object section). $[\mathrm{m}](\mathrm{V} .85)$ 


\section{Calculations}

$\dot{\mathrm{q}}_{\mathrm{f}}^{\prime \prime}=\dot{\mathrm{q}}_{\mathrm{L} O}^{\prime \prime}+\Sigma \dot{\mathrm{q}}_{\mathrm{PO}}^{\prime \prime}+\Sigma \dot{\mathrm{q}}_{\text {WO }}^{\prime \prime}$

$\dot{q}_{r \Sigma}^{\prime \prime}=\min [13200,21700 \kappa R]$

$\phi_{n e t}=\dot{q}_{f}^{\prime \prime}-\dot{q}_{r r}^{\prime \prime}$

$\phi_{+}=\dot{q}_{\mathrm{L} 0}^{\prime \prime}+\Sigma \dot{q}_{\text {HO }}^{\prime \prime}$

$\phi_{e f f}=m_{f} H_{v} / 2 \pi R^{2}$

$\phi_{\max }=\max \left(\phi_{\mathrm{net}}, \phi_{+}\right)$

$\phi=\min \left(\phi_{\max }, \phi_{e f f}\right)$
Radiative flux impinging on target object from all hot sources.

Effective reradiated flux.

Net flux incident on object when flame height not significantly reduced.

Minimum flux incident on fuel surface, when not near burnout.

Effective flux seen by (fictitious) entire surface $R^{2}$, when fuel is nearly exhausted.

Flux incident on surface of target object.

\section{$\underline{\text { References }}$}

1. Mitler, H.E., "The Physical Basis of the Harvard Fire Codes," Home Fire Project Technical Report No. 34, Harvard University, October 1978. 
2. Mitler, H.E., and Emmons, H.W., "Documentation for CFC V, the Fifth Harvard Computer Fire Code", U.S. Department of Commerce, Washington, D.C., NBS-GCR-81-344, October 1981, pp. 84-85.

\section{Subroutine Variables}

$$
\begin{aligned}
& \text { PHI }=\phi \\
& \text { QVAP }=\mathrm{H}_{v} \\
& \text { ZUFZZ }=\kappa \\
& \text { FQLOR }=\dot{\mathrm{q}}_{\mathrm{L} O}^{\prime \prime} \\
& \text { FQPOR }=\Sigma \dot{\mathrm{q}}_{\text {POO }}^{\prime \prime} \\
& \text { FQWOR }=\Sigma \dot{\mathrm{q}}_{\text {WO }}^{\prime \prime} \\
& \text { ZMOZZ }=\mathrm{m}_{\mathrm{f}} \\
& \text { ZRFZZ }=\mathrm{R} \\
& \mathrm{PI}=\pi
\end{aligned}
$$

\section{Prepared by}

David W. Stroup 


\section{Computer Subroutine}

SUBROUTINE FLUX (QVAP, ZUFZZ, FQLOR, FQPOR, FQWOR, ZMOZZ, ZRFZZ, PHI1)

C

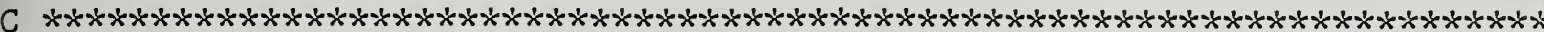

IMPLICIT DOUBLE PRECISION (A-H,O-Z)

SUBROUTINE TO CALCULATE THE FLUX INCIDENT ON THE SURFACE OF A

BURNING TARGET OBJECT.

INPUT PARAMETERS :

QVAP - HEAT OF VAPORIZATION OF THE TARGET OBJECT.

ZUFZZ - - ABSORPTIVITY OF THE OBJECT.

INPUT VARIABLES :

FQLOR - - RADIATIVE FLUX FROM THE HOT LAYER TO THE SURFACE OF THE OBJECT.

FQPOR - S SUM OF THE RADIATIVE FLUXES FROM THE PLUMES OVER ALL BURNING OBJECTS TO THE SURFACE OF THE TARGET OBJECT.

FQWOR - - RADIATIVE FLUX FROM THE WALLS TO THE TARGET OBJECT.

ZMOZZ - - MASS OF THE TARGET OBJECT.

ZRFZZ - RADIUS OF THE FIRE ON THE TARGET OBJECT.

OUTPUT VARIABLE:

PHI1 - FLUX INCIDENT ON THE SURFACE OF THE TARGET OBJECT.

PARAMETER $(P I=3.1415927 D 0)$

C FIND RADIATIVE FLUX IMPINGING ON TARGET OBJECT FROM ALL HOT SOURCES. $F Q O O=F Q P O R+F Q L O R+F Q W O R$

$C$

C EFFECTIVE RERADIATIVE FLUX.

$F Q R R=M I N(13200 . D 0,21700 . D 0 * Z R F Z Z \div Z U F Z Z)$

C

C NET FLUX INCIDENT ON TARGET WHEN FLAME HEIGHT NOT SIGNIFICANTLY

C REDUCED.

$F Q N E T=F Q O O-F Q R R$

$c$

C MINIMUM FLUX INCIDENT ON TARGET WHEN NOT NEAR BURNOUT.

FQPLUS $=$ FQLOR + FQWOR

C

FQMAX $=$ MAX $(F Q N E T, F Q P L U S)$

C EFFECTIVE FLUX SEEN BY (FICTITIOUS) ENTIRE SURFACE WHEN FUEL IS

C NEARLY EXHAUSTED.

IF (ZRFZZ.GT.0.1DO) THEN

$F Q E F F=Z M O Z Z * Q V A P /(2 . D O * P I * Z R F Z Z * * 2)$

ELSE

ENDIF

$F Q E F F=F Q M A X$

1-FLUX- 5 
C

C FLUX INCIDENT ON SURFACE OF TARGET.

C PHII = MIN (FQMAX, FQEFF)

RETURN

END 


\section{HEIGHT - Height of Flame above a Burning Object}

\section{Description}

This routine calculates the height of the flame above a burning object. The flame produced by a burning object is represented as a right circular cone composed of hot grey gas. The tangent of the semiapex angle of this cone, at any given time, is equal to the fire radius (radius of the cone base) divided by the flame height (height of the cone), figure 1-3. It is possible to relate the time varying tangent of the semiapex angle and the mass burning rate.

When the object burns in the presences of sufficient oxygen, its energy release rate is limited only by its mass loss rate and combustion efficiency, $x$. This is interpreted to mean that the "mass burning rate" of the fuel produced by an object is equal to the rate of change of the object's mass multiplied by the combustion efficiency.

$$
\dot{\mathrm{m}}_{\mathrm{b}}=\chi \dot{\mathrm{m}}_{\mathrm{f}}
$$

The semi-apex angle of the flame produced by the burning object remains at some known initial value as long as the object is burning with sufficient oxygen. When the fire on the object becomes oxygen starved, the burning rate and flame volume must be reduced.

\section{Output}

$h_{f}$

Height of the flame over the burning object. [m] (V.36) 
Input

$x$

$\tan \left(\psi_{0}\right)$

$\dot{\mathrm{m}}_{\mathrm{b}}$

$\dot{m}_{f}$

$\mathrm{R}$

\section{Calculation}

$h_{f}=\frac{R \dot{m}_{b}}{\tan \left(\psi_{0}\right) \times\left|\dot{m}_{f}\right|}$
Fraction of the theoretical combustion energy released in the flame of the object (Input Data). (V.26)

Tangent of the initial value of the semiapex angle of the flame of the object (Input Data). (V.118)

Mass rate of burning of the fuel from the object (Calculated Value, see Burning Object section). $[\mathrm{kg} / \mathrm{s}](\mathrm{V} .55)$

(Negative of the) mass pyrolysis rate of the object (Calculated Value, see Burning Object section). [ kg/s] (V.61)

Radius of the fire on the burning object (Calculated Value, see Burning Object section).

[m] (V.85)

\section{References}

1. Mitler, H.E., and Emmons, H.W., "Documentation for CFC V, the Fifth Harvard Computer Fire Code", U.S. Department of Commerce, Washington, D.C., NBS-GCR-81-344, October 1981, pp. 84-87. 
Subroutine Variables

$$
\begin{aligned}
\text { ZHFZZ } & =h_{f} \\
\text { CHI } & =x \\
\text { TPSIO } & =\tan \left(\psi_{0}\right) \\
\text { TMOZB } & =\dot{\mathrm{m}}_{\mathrm{b}} \\
\text { TMOZZ } & =\dot{\mathrm{m}}_{f} \\
\text { ZRFZZ } & =\mathrm{R}
\end{aligned}
$$

\section{Prepared by}

David W. Stroup 


\section{Computer Subroutine}

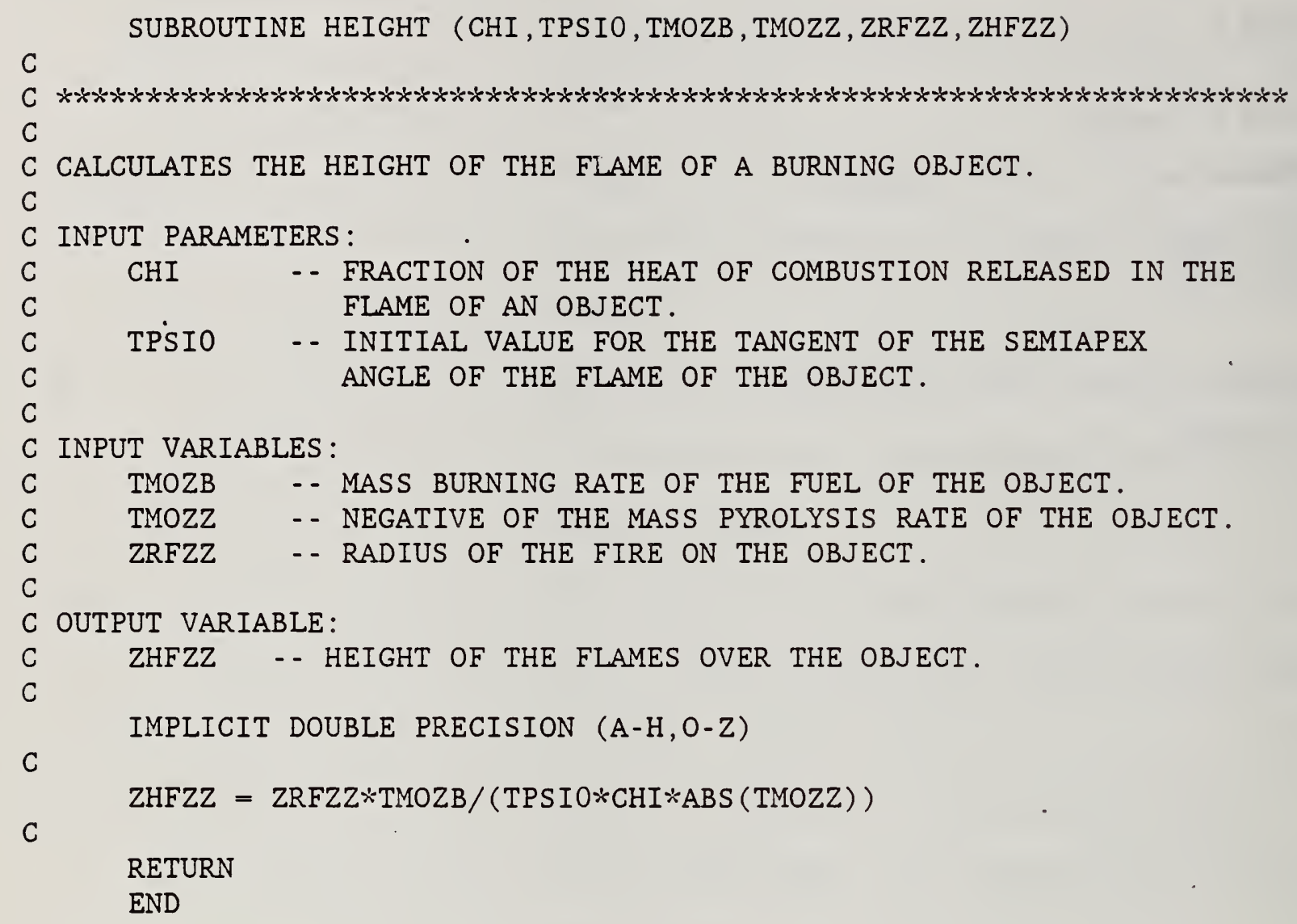




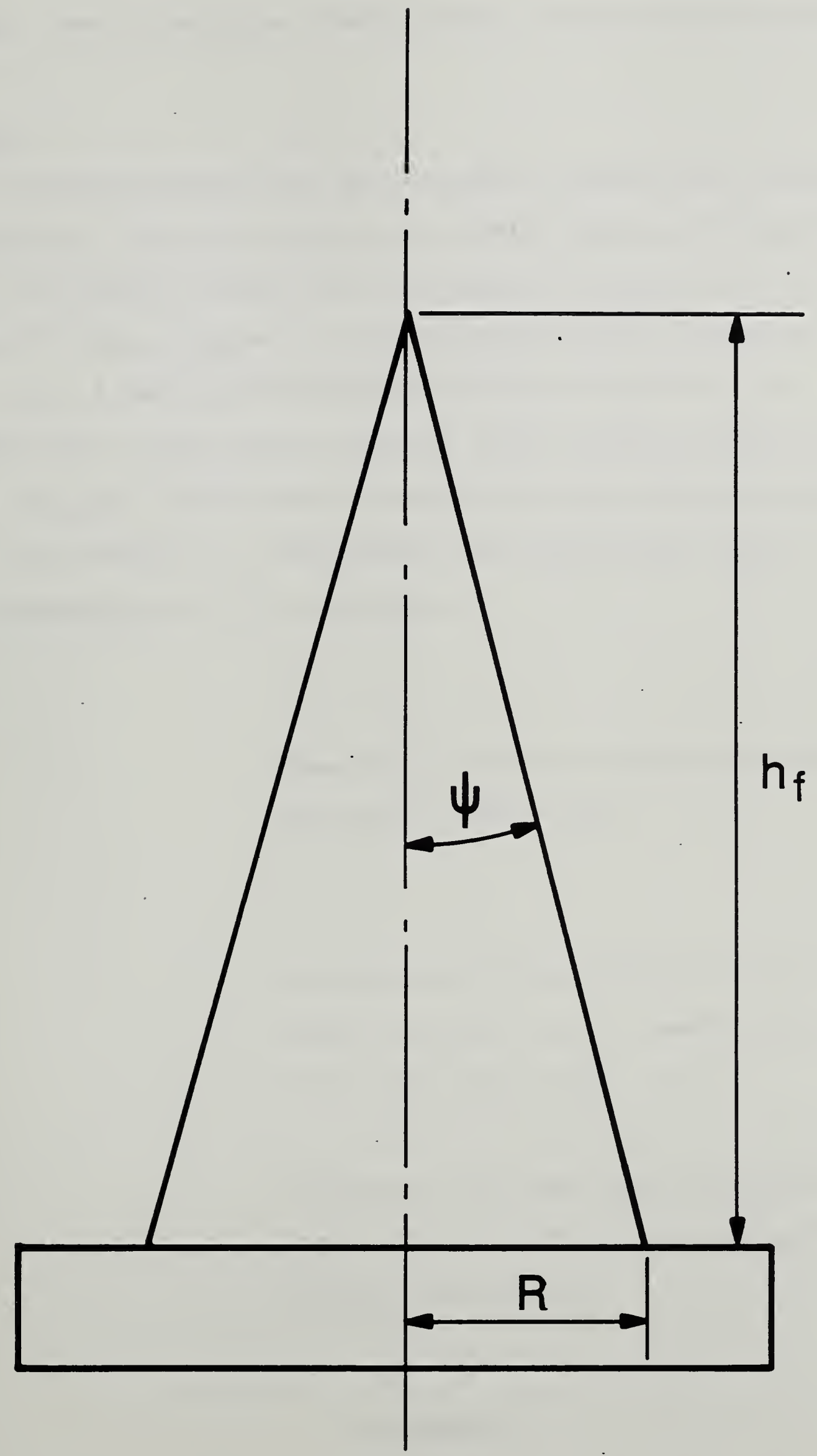

Figure 1-3. Diagram of the flame cone model 
1 - HEIGHT - 6 
MNXPRD - Rate at which the a Burning Object Produces Carbon Monoxide

\section{Description}

This routine calculates the rate at which a burning object produces carbon monoxide. The production rate of a specific gas by a burning object depends on the chemical composition of the material being burned. The rate of production of carbon monoxide by a given burning material is equal to the mass pyrolysis rate of the object multiplied by the mass fraction of the (combustible part of the) object evolved as carbon monoxide, when it burns in open air. The mass fraction must be obtained from fire tests of the specific material (see Tewarsen, A., "Heat Release Rates from Burning Plastics", J. Fire and Flammability 8 (1977) for example).

\section{Output}

$\dot{\mathrm{m}}_{\mathrm{CO}}$

Mass rate of evolution of carbon monoxide from the object. [kg/s] (V.57)

\section{Input}

$f_{C o}^{\prime}$

Mass fraction of the (combustible part of the) object evolved as carbon monoxide, when it burns in the open (Input Data). (V.45)

$\dot{\mathrm{m}}_{\mathrm{f}}$

(Negative of the) mass pyrolysis rate of the object (Calculated Value, see Burning Object section). [ $\mathrm{kg} / \mathrm{s}](\mathrm{V} .61)$ 
Calculations

$$
\dot{m}_{C O}=-f_{C O}^{\prime} \dot{m}_{f}
$$

\section{References}

1. Mitler, H.E. and Emmons, H.W., "Documentation for CFC V, the Fifth Harvard Fire Code," U.S. Department of Commerce, Washington, D.C., NBS-GCR-81-344, October 1981, pp. $128-131$.

Subroutine Variables

$$
\begin{aligned}
& \text { TMOM }=\dot{\mathrm{m}}_{C O} \\
& \text { FCO }=\mathrm{f}_{C O}^{\prime} \\
& \text { TMOZZ }=\dot{\mathrm{m}}_{f}
\end{aligned}
$$

\section{Prepared by}

David W. Stroup 


\section{Computer Subroutine}

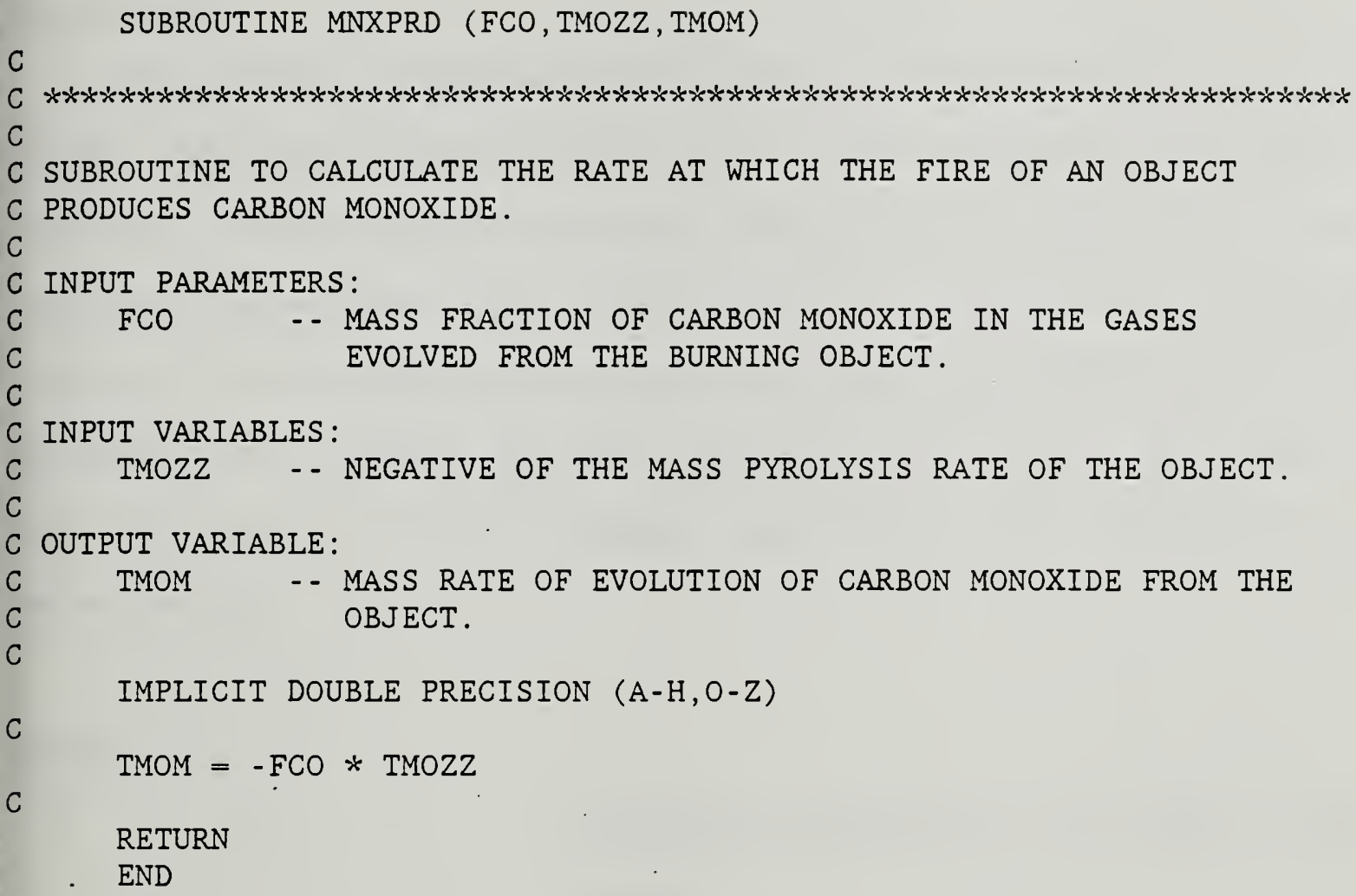


1 - MNXPRD - 4 


\section{PFLUX - Net Heat Flux to a Potentially Pyrolyzing Object}

\section{Description}

This routine calculates the net heat flux to a potentially pyrolyzing object. This net heat flux value is the energy absorbed by the object surface. It may be used to determine if and when the object will ignite. To calculate the net heat flux, a heat balance is formulated for the material surface. The net heat flux is equal to the sum of the total radiation flux incident on the surface, the total convection heat flux to the surface, the heat flux conducted into the material, and the heat flux reradiated by the object surface.

Output

$\phi$

Net heat flux absorbed by an object. $\left[\mathrm{W} / \mathrm{m}^{2}\right]$ $(\mathrm{V} .67)$

Input

$\sum \phi_{\mathrm{SR}}$

(Sum of all) radiation heat flux(es) incident on the object surface (Calculated Value, see

Radiation Heat Transfer section). [W/m $\left.\mathrm{m}^{2}\right]$ (V.82)

$\Sigma \phi_{\mathrm{SC}}$

(Sum of all) convection heat flux(es) incident on the object surface (Calculated Value, see Convection Heat Transfer section). [W/m $\left.\mathrm{m}^{2}\right]$ (V.13)

$\phi_{\text {cond }}$ Heat flux conducted into the object (Calculated Value, see Conduction Heat Transfer section). $\left[\mathrm{W} / \mathrm{m}^{2}\right](\mathrm{V} .28)$ 
$\mathrm{T}_{\mathrm{S}}$

$\sigma$

\section{Calculation}

$$
\phi=\Sigma \phi_{\mathrm{SR}}+\Sigma \phi_{\mathrm{SC}}-\phi_{\mathrm{cond}}-\sigma \mathrm{T}_{\mathrm{S}}^{4}
$$

\section{References}

No references available.

Subroutine Variables

$$
\begin{aligned}
& \text { PHI }=\phi \\
& \text { PHIR }=\Sigma \phi_{\text {SR }} \\
& \text { PHIC }=\Sigma \phi_{\text {SC }} \\
& \text { COND }=\phi_{\text {cond }} \\
& \text { ZKOZZ }=\mathrm{T}_{\mathrm{S}} \\
& \text { SIGMA }=\sigma
\end{aligned}
$$

Prepared by

David W. Stroup
Temperature of the surface of the object

(Calculated Value, see Conduction Heat Transfer section). [K] (V.129)

Stefan - Boltzmann constant (Physical Constant).

$\left[5.67 \times 10^{-8} \mathrm{~W} / \mathrm{m}^{2}-\mathrm{K}^{4}\right](\mathrm{V} .147)$ 


\section{Computer Subroutine}

SUBROUTINE PFLUX (PHIR, PHIC, COND, ZKOZZ, PHI)

C

$\mathrm{C}+$

C SUBROUTINE TO CALCULATE THE NET HEAT FLUX TO A POTENTIALLY

PYROLYZING SURFACE.

INPUT PARAMETER:

SIGMA - - STEFAN - BOLTZMANN CONSTANT

INPUT VARIABLES :

PHIR - - RADIANT FLUX IMPINGING ON THE SURFACE OF THE OBJECT.

PHIC - - CONVECTIVE HEAT FLUX TO SURFACE.

COND - - HEAT CONDUCTION INTO SURFACE.

ZKOZZ -- SURFACE TEMPERATURE OF THE OBJECT.

OUTPUT VARIABLE:

PHI - NET HEAT FLUX TO THE FUEL SURFACE.

IMPLICIT DOUBLE PRECISION (A-H,O-Z)

PARAMETER (SIGMA $=5.67 \mathrm{D}-8)$

PHI $=$ PHIR + PHIC - COND - SIGMA * $(Z \mathrm{KOZZ} * * 4)$

RETURN

END 
1 - PFLUX - 4 


\section{PPYRO - Mass Pyrolysis Rate of a Burning Object}

\section{Description}

This routine calculates the mass pyrolysis rate of a burning object. This routine assumes the fire is circular or can be represented by a circle using an equivalent radius. When not limited by fuel burnout, the total pyrolysis rate is equal to the area of the object covered by the fire multiplied by the pyrolysis rate per unit area. The pyrolysis rate per unit area is equal to the net heat flux to the surface divided by the object's heat of pyrolysis (also called heat of vaporization).

\section{Output}

$\dot{m}_{f}$ (Negative of) mass pyrolysis rate of a burning object. $[\mathrm{kg} / \mathrm{s}](\mathrm{V} .61)$

\section{Input}

$\mathrm{H}_{\mathrm{v}}$

Heat of vaporization (or pyrolysis) of the object (Input Data). [J/kg] (V.31)

$\phi$ Net heat flux absorbed by the object (Calculated Value, see Burning Object section). [W/ $\left.\mathrm{m}^{2}\right]$ (V.67)

$\mathrm{R}$

Radius of the fire on the burning object (Calculated Value, see Burning Object section). [m] (V.85)

Pi (Physical Constant). [3.1415927] (V.146) 


\section{Calculation}

$$
\dot{\mathrm{m}}_{\mathrm{f}}=\frac{-\pi \mathrm{R}^{2} \phi}{\mathrm{H}_{\mathrm{v}}}
$$

\section{References}

1. Mitler, H.E., and Emmons, H.W., "Documentation for CFC V, the Fifth Harvard Computer Fire Code", U.S. Department of Commerce, Washington, D.C., NBS-GCR-81-344, October 1981, pp. 87 .

\section{Subroutine Variables}

$$
\begin{aligned}
& \text { TMOZZ }=\dot{\mathrm{m}}_{\mathrm{f}} \\
& \text { QVAP }=\mathrm{H}_{\mathrm{v}} \\
& \mathrm{PI}=\pi \\
& \mathrm{PHI}=\phi \\
& \mathrm{ZRFZZ}=\mathrm{R}
\end{aligned}
$$

\section{Prepared by}

David W. Stroup 


\section{Computer Subroutine}

SUBROUTINE PPYRO (QVAP, PHI, ZRFZZ, TMOZZ)

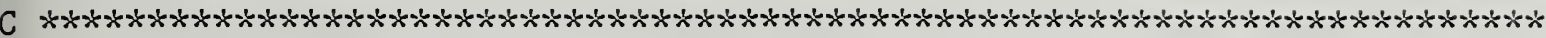
C

SUBROUTINE TO CALCULATE THE MASS PYROLYSIS RATE OF A BURNING OBJECT. INPUT PARAMETER:

QVAP - - HEAT OF VAPORIZATION OF THE OBJECT.

INPUT VARIABLES:

PHI -- NET HEAT FLUX TO THE FUEL SURFACE.

ZRFZZ - - RADIUS OF THE FIRE ON THE OBJECT.

OUTPUT VARIABLE:

TMOZZ - NEGATIVE OF THE MASS PYROLYSIS RATE OF THE OBJECT.

IMPLICIT DOUBLE PRECISION (A-H,O-Z)

PARAMETER $(P I=3.1415927 D 0)$

$\mathrm{TMOZZ}=-\mathrm{PI} * \mathrm{ZRFZZ} * 2 * \mathrm{PHI} / \mathrm{QVAP}$

RETURN

END 
1 - PPYRO - 4 


\section{PULRAD - Radius of a Pool Fire}

\section{Description}

This routine calculates the radius of a pool fire. When the entire (horizontal) surface of a pool of a combustible material is heated to its ignition temperature, $t_{i_{g}}$, ignition will start at a "hot spot" and spread very rapidly over the surface. This rapid spread may introduce numerical instabilities into a fire model. The expression used in this routine provides for a smooth build-up to the maximum radius to improve numerical stability. The radius is assumed to increase asymptotically from a user-specified initial value to its user-specified maximum value. The fire is assumed to reach its maximum size sixty seconds after ignition of the pool. This routine includes limit statements to prevent the calculated fire radius from becoming smaller than the initial object radius or larger than the maximum theoretical object radius.

\section{Output}

$\mathrm{R}$

Radius of the fire on the burning object (pool). [m] (V.85)

Input

$\mathrm{R}_{\mathrm{m}}$

Augmented radius of the (pool) object, -- i.e., maximum equivalent possible radius of the fire (Input Data). [m] (V.8)

$R_{i}$ Initial radius of the fire on the (pool) object (Input Data). [m] (V.39) 
$t_{18}$

$t$
Time of ignition of the object (Calculated Value, see Burning Object section). [s] (V.136) Current simulation time. [s] (V.15)

\section{Calculation}

$$
R= \begin{cases}R_{m}\left[1-\exp \left(-\frac{1}{2}\left(t-t_{i g}\right)\right)\right], & 0<t-t_{i g} \leq 60 \\ R_{m}, & t-t_{i g}>60\end{cases}
$$

Limits:

$$
R= \begin{cases}R_{i}, & R<R_{i} \\ R_{m}, & R>R_{m}\end{cases}
$$

\section{References}

1. Mitler, H.E., and Emmons, H.W., "Documentation for CFC V, the Fifth Harvard Computer Fire Code", U.S. Department of Commerce, Washington, D.C., NBS-GCR-81-344, October 1981, pp. 87-88, 89.

\section{Subroutine Variables}

$$
\begin{aligned}
& Z R F Z Z=R \\
& Z R F Z M=R_{m} \\
& Z R F Z I=R_{i} \\
& Z T I G=t_{i 8} \\
& Z T Z Z Z=t
\end{aligned}
$$

\section{Prepared by}

David W. Stroup 


\section{Computer Subroutine}

SUBROUTINE PULRAD (ZRFZM, ZRFZI, ZTIG, ZTZZZ, ZRFZZ)

C

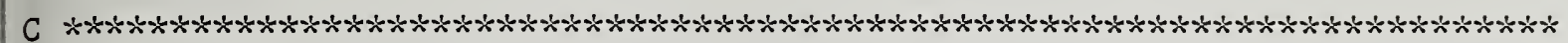

C

C SUBROUTINE TO CALCULATE THE RADIUS OF A POOL FIRE. THE EXPRESSION

$C$ USED IN THIS ROUTINE PROVIDES FOR A SMOOTH BUILD-UP TO THE MAXIMUM

C RADIUS TO IMPROVE STABILITY.

C

C INPUT PARAMETERS:

C ZRFZM -- MAXIMUM BURNING RADIUS OF THE OBJECT.

C ZRFZI - - INITIAL BURNING RADIUS OF THE OBJECT.

C ZTIG - - TIME OF IGNITION OF THE OBJECT.

C ZTZZZ -. SIMULATION TIME.

C

C OUTPUT VARIABLE:

C ZRFZZ -- RADIUS OF THE POOL FIRE.

C

IMPLICIT DOUBLE PRECISION (A-H,O-Z)

c

$Z R F Z Z=Z R F Z M$

IF ((ZTZZZ-ZTIG) .LT. 60.) THEN

IF ((ZTZZZ-ZTIG) .GE. O.) THEN

$Z R F Z Z=Z R F Z M *(1 . D O-D E X P(-(Z T Z Z Z-Z T I G) / 2 . D O))$

ENDIF

ENDIF

C

C LIMITS:

C

IF (ZRFZZ .LT. ZRFZI) THEN $Z R F Z Z=Z R F Z I$

ELSE

IF (ZRFZZ .GT. ZRFZM) ZRFZZ = ZRFZM

ENDIF

RETURN

END 



\section{Description}

This subroutine calculates the mass pyrolysis rate of a burning horizontal fuel slab modified to allow for smooth burn out as the fuel is used up. The pyrolysis rate is taken to be proportional to the net heat flux to the surface and to the (instantaneous) burning area. The net heat flux is the radiation incident from all sources (principally the flame) plus the convective heating from the flame, minus the reradiation. The pyrolysis rate is modified to take into account the smooth cessation of pyrolysis as the fuel nears burnout. This routine includes limits to prevent the mass pyrolysis rate from becoming too large or too small and to set it equal to zero when the fuel is consumed.

\section{Output}

$\dot{\mathrm{m}}_{\mathbf{f}}$

(Negative of the) mass pyrolysis rate of the object (burning slab). [ $\mathrm{kg} / \mathrm{sec}]$ (V.61)

\section{Input}

$\mathrm{H}_{\mathrm{v}}$

Heat of vaporization (or pyrolysis) of the object (Input Data). [J/kg] (V.31)

$R_{m}$ Augmented radius of the object, - i.e., maximum equivalent possible radius of the fire (Input Data). [m] (V.8) 
$\phi$

$\mathrm{m}_{f}$

R

$\pi$

\section{Calculations}

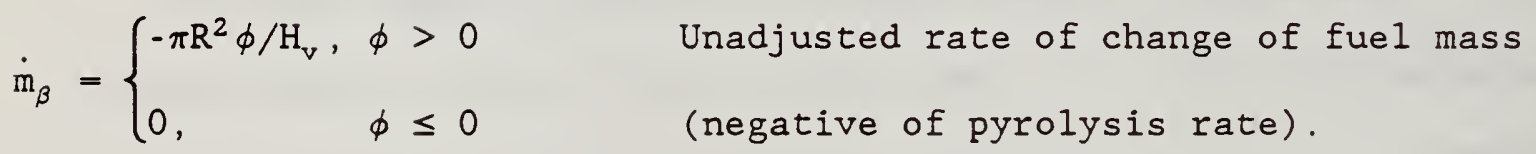

$$
\begin{aligned}
& \mathrm{G}=\mathrm{m}_{\mathrm{f}} /\left(2 \dot{\mathrm{m}}_{\beta}\right) \quad \text { Convenient definition }\left(\text { for } \dot{\mathrm{m}}_{\beta}<0\right. \text { ) }
\end{aligned}
$$

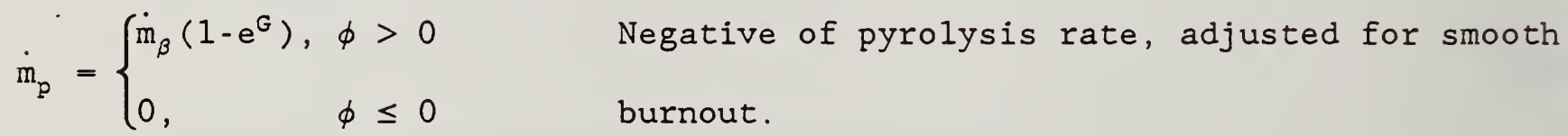

$$
\begin{aligned}
& \text { Limits: } \dot{\mathrm{m}}_{f}=0 \text {, if } \mathrm{m}_{f}=0 \\
& \dot{\mathrm{m}}_{\mathrm{f}}= \begin{cases}-6,000,000 \mathrm{R}_{\mathrm{m}}^{2} / \mathrm{H}_{\mathrm{v}}, & \dot{\mathrm{m}}_{\mathrm{f}}<-6,000,000 \mathrm{R}_{\mathrm{m}}^{2} / \mathrm{H}_{\mathrm{v}} \\
0, & \dot{\mathrm{m}}_{\mathrm{f}}>0\end{cases}
\end{aligned}
$$

\section{$\underline{\text { References }}$}

1. Mitler, H.E., "The Physical Basis for the Harvard Fire Codes," Home Fire Project Technical Report No. 34, Harvard University, October 1978, pp. $59-68$.

2. Mitler, H.E., and Emmons, H.W., "Documentation for CFC V, the Fifth 
Harvard Computer Fire Code", U.S. Department of Commerce, Washington, D.C., NBS-GCR-81-344, October 1981, pp. $83-89$.

\section{Subroutine Variables}

$$
\begin{aligned}
& \text { TMOZZ }=\dot{\mathrm{m}}_{\mathrm{f}} \\
& \text { QVAP }=\mathrm{H}_{\mathrm{v}} \\
& \text { ZRFZM }=\mathrm{R}_{\mathrm{m}} \\
& \text { PHI }=\phi \\
& \mathrm{ZMOZZ}=\mathrm{m}_{\mathrm{f}} \\
& \mathrm{ZRFZZ}=\mathrm{R} \\
& \mathrm{PI}=\pi
\end{aligned}
$$

\section{Prepared by}

David W. Stroup 


\section{Computer subroutine}

SUBROUTINE PYRO (QVAP, ZRFZM, PHI , ZMOZZ, ZRFZZ, TMOZZ)

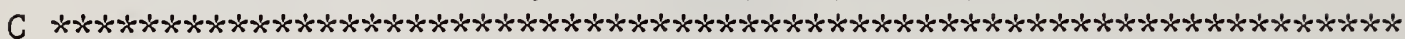

C

IMPLICIT DOUBLE PRECISION ( $\mathrm{A}-\mathrm{H}, \mathrm{O}-\mathrm{Z}$ )

C

C SUBROUTINE TO CALCULATE THE MASS PYROLYSIS RATE OF A BURNING C OBJECT.

C

C INPUT PARAMETERS :

C QVAP - - HEAT OF VAPORIZATION OF THE OBJECT

C ZRFZM - MAXIMUM BURNING RADIUS OF THE OBJECT

C

C INPUT VARIABLES :

C PHI - FLUX IMPINGING ON THE SURFACE OF THE OBJECT

C ZMOZZ - - REMAINING MASS OF THE OBJECT

C ZRFZZ - RADIUS OF THE FIRE ON THE OBJECT

C

C OUTPUT VARIABLE:

C TMOZZ - NEGATIVE OF MASS PYROLYSIS RATE OF THE OBJECT

C

PARAMETER $(P I=3.1415927 D 0)$

C

C

$\mathrm{TMOZZA}=\mathrm{TMOZZ}$

IF (PHI .GT. O.DO) THEN

$\mathrm{TMO}=-\mathrm{PI} * \mathrm{ZRFZZ} * * 2 * \mathrm{PHI} / \mathrm{QVAP}$

C

C THE FOLLOWING LINES PRODUCE A SMOOTH CUT-OFF OF BURNING AT

C FUEL EXHAUSTION.

C

IF (TMO .NE. O.DO) THEN

$G=\mathrm{ZMOZZ} /(2 . \mathrm{DO} * \mathrm{TMO})$

IF (ABS (G) .LT. 30.DO) THEN

$\operatorname{TMOZZ}=\operatorname{TMO} *(1 . \mathrm{DO}-\operatorname{DEXP}(G))$

ELSE

TMOZZ $=$ TMO

ENDIF

ELSE

$\mathrm{TMOZZ}=0 . \mathrm{DO}$

ENDIF

ELSE

$\mathrm{TMOZZ}=0 . \mathrm{DO}$

ENDIF

C

C LIMITS:

IF (TMOZZ . LE. O.DO) THEN

BNDS $=-6$. D $6 *$ ZRFZM $* * 2 /$ QVAP

IF (TMOZZ . LT. BNDS) $\mathrm{TMOZZ}=$ BNDS

1 - PYRO - 4 
ELSE

$\mathrm{TMOZZ}=0 . \mathrm{DO}$

ENDIF

IF (ZMOZZ .LE. O.DO) TMOZZ =0.DO

RETURN

END

1-PYRO - 5 
1 - PYRO - 6 


\section{Description}

This routine calculates the spread rate of a flame on a horizontal fuel slab, ignited at the center of its top surface. The fire radius grows until it reaches a maximum such that the resulting area is the area of the top of the slab plus the sides. This equivalent maximum radius, $R_{m}$, is larger than the radius corresponding to the top surface. The spread rate until $R=0.95 R_{m}$ is given by an expression which yields approximately exponential growth (as observed in experiments). Beyond that point, the spread rate is taken to slow down, as shown under the section "Calculations" below. The fire spread rate equation was developed from data for polyurethane foam obtained by L. Orloff. For additional information, the reader should refer to reference 1 below.

\section{Output}

$\dot{\mathrm{R}}$

Rate of spread rate of a fire on an object

(horizontal fuel slab). [m/sec] (V.107)

\section{Input}

$A_{f}$

Spread rate parameter (Input Data). [m/sec]

(V.115)

$T_{f}$

Temperature of the flaming gases, -. i.e., flame temperature (Input Data). [K] (V.123)

$R_{m}$ Augmented radius of the object, - - i.e., maximum 
equivalent possible radius of the fire (Input

Data). [m] (V.8)

R

Radius of the fire on the object (pool). [m]

(V.85)

$\phi$

Net heat flux absorbed by the object (Calculated

Value, see Burning Object section). [W/ $\left.\mathrm{m}^{2}\right]$

(V.67)

Stefan - Boltzmann constant (Physical

Constant). $\left[5.67 \times 10^{-8} \mathrm{~W} / \mathrm{m}^{2}-\mathrm{K}^{4}\right](\mathrm{V} .147)$

\section{Calculations}

$\mathrm{C}=\phi / \sigma \mathrm{T}_{f}^{4}$

Convenient non-dimensional grouping of terms.

$\dot{R}=\left\{\begin{array}{ll}A_{f} C\left(1+(C / 2)+\left(C^{2} / 3\right)\right), & R \leq 0.95 R_{m} \\ \left(R_{M}-R\right) / 10, & R>0.95 R_{m}\end{array} \quad\right.$ Rate of change of fire radius.

\section{References}

1. Mitler, H.E., "The Physical Basis for the Harvard Fire Codes," Home Fire Project Technical Report No. 34, Harvard University, October 1978, PP. $61-67$.

2. Mitler, H.E., and Emmons, H.W., "Documentation for CFC V, the Fifth Harvard Computer Fire Code", U.S. Department of Commerce, Washington, D.C., NBS-GCR-81-344, October 1981, pp. $83-86$. 
Subroutine Variables

$$
\begin{aligned}
& \text { TRFZZ }=\dot{\mathrm{R}} \\
& \text { AFIRE }=A_{f} \\
& \mathrm{~T}=\mathrm{T}_{f} \\
& \mathrm{ZRFZM}=\mathrm{R}_{\mathrm{m}} \\
& \mathrm{ZRFZZ}=\mathrm{R} \\
& \mathrm{PHI}=\phi \\
& \text { SIGMA }=\sigma
\end{aligned}
$$

\section{Prepared by}

David W. Stroup

1 - SPREAD - 3 


\section{Computer Subroutine}

SUBROUTINE SPREAD (A, T, ZRFZM, PHI , ZRFZZ, TRFZZ)

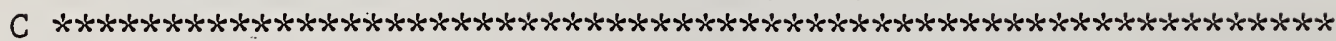

C

IMPLICIT DOUBLE PRECISION (A-H,O-Z)

C

C SUBROUTINE TO CALCULATE THE SPREAD RATE OF THE FIRE ON AN C OBJECT.

C

C INPUT PARAMETERS:

C A - FIRE SPREAD PARAMETER

C T - FLAME TEMPERATURE

C ZRFZM - MAXIMUM BURNING RADIUS OF THE OBJECT

C

C INPUT VARIABLES :

C PHI - - FLUX INCIDENT ON THE SURFACE OF THE OBJECT

C ZRFZZ - R RADIUS OF THE FIRE ON THE OBJECT

C

C OUTPUT VARIABLE:

C TRFZZ - S SPEAD RATE OF THE FIRE ON THE OBJECT

C

C

PARAMETER (SIGMA $=5.67 \mathrm{D}-8)$

C

$\mathrm{ZRFZZA}=\mathrm{ZRFZZ}$

$\mathrm{C}=\mathrm{PHI} /($ SIGMA $* \mathrm{~T} * * 4)$

IF (ZRFZZ . LE. 0.95D0*ZRFZM) THEN

ELSE $T R F Z Z=A * C *(1 . D O+C / 2 . D 0+C * C / 3 . D 0)$ ENDIF

$\mathrm{TRFZZ}=($ ZRFZM $-\mathrm{ZRFZZ}) / 10 . \mathrm{DO}$

C

RETURN

END 


\section{Description}

This routine calculates the rate at which a burning object produces soot. The production rate of a specific gas (or particulate like soot) by a burning object depends on the chemical composition of the material being burned. The rate of production of soot by a given burning material is equal to the mass pyrolysis rate of the object multiplied by the mass fraction of the (combustible part of the) object evolved as soot, when the object burns in open air. The mass fraction must be obtained from fire tests of the specific material (see Tewarsen, A., "Heat Release Rates from Burning Plastics", J. Fire and Flammability 8 (1977) for example).

\section{Output}

$\dot{\mathrm{m}}_{\mathrm{S}}$

Mass rate of evolution of soot from the object. $[\mathrm{kg} / \mathrm{s}](\mathrm{V} .58)$

\section{Input}

$\mathbf{f}_{\mathrm{S}}^{\prime}$

Mass fraction of the (combustible part of the)

object evolved as soot, when the object burns in

the open (Input Data). (V.48)

$\dot{\mathrm{m}}_{\mathrm{f}}$

(Negative of the) mass pyrolysis rate of the object (Calculated Value, see Burning Object section). [ $\mathrm{kg} / \mathrm{s}](\mathrm{V} .61)$ 


\section{Calculations}

$$
\dot{\mathrm{m}}_{\mathrm{S}}=-\mathrm{f}_{\mathrm{s}}^{\prime} \dot{\mathrm{m}}_{\mathrm{f}}
$$

\section{References}

1. Mitler, H.E. and Emmons, H.W., "Documentation for CFC V, the Fifth Harvard Fire Code," U.S. Department of Commerce, Washington, D.C., NBS-GCR-81-344, October 1981, pp. $128-131$.

Subroutine Variables

$$
\begin{array}{ll}
\text { TMOS } & =\dot{\mathrm{m}}_{\mathrm{S}} \\
\text { FS } & =\mathrm{f}_{\mathrm{S}}^{\prime} \\
\text { TMOZZ } & =\dot{\mathrm{m}}_{\mathrm{f}}
\end{array}
$$

\section{Prepared by}

David W. Stroup 
SUBROUTINE SUTPRD (FS, TMOZZ, TMOS)

C

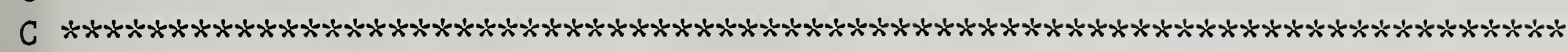
C

C SUBROUTINE TO CALCULATE THE RATE AT WHICH THE FIRE OF AN OBJECT

C PRODUCES SOOT.

C

C INPUT PARAMETERS :

C FS - MASS FRACTION OF SOOT IN THE GASES EVOLVED FROM THE C BURNING OBJECT.

C

C INPUT VARIABLES:

C TMOZZ - - NEGATIVE OF THE MASS PYROLYSIS RATE OF THE OBJECT.

C

C OUTPUT VARIABLE:

C TMOS - - MASS RATE OF EVOLUTION OF SOOT FROM THE OBJECT.

C

IMPLICIT DOUBLE PRECISION (A-H,O-Z)

TMOS $=-$ FS $*$ TMOZZ

RETURN

END 
1 - SUTPRD - 4 


\section{TMGAS - Gas Flow Rate from a Gas Burner}

\section{Description}

This routine computes the gas flow rate at a given time for a gas burner with a variable flow rate. The gas flow rate is assumed to vary linearly with time between fixed input points (time, gas flow rate). The gas flow rate curve is entered by the user as a set of discrete points. The routine does a linear interpolation between the appropriate points to determine the gas flow rate at a specific time. For times of interest prior to the first input time the gas flow rate is assumed to be zero. For times of interest exceeding the last input time, the gas flow rate is assumed to be equal to the flow rate at the last input time. (Note: The computer routine presented in the Computer Subroutine section of this write-up is limited to a maximum of 100 input points. However, the routine may be adjusted to handle any number of points.)

\section{Output}

$\dot{\mathrm{m}}_{\mathrm{f}}$

Input

$t$

$\mathrm{N}_{8}$

$t_{g}^{i} ; i=1,2, \ldots, N_{8}+1$
(Negative of the) mass pyrolysis rate of the object (gas flow rate at time $t$ ). [ $\mathrm{kg} / \mathrm{s}]$ (V.61) rate is desired). [s] (V.15)

Number of segments making up the gas flow rate curve (Input Data). (V.69)

Array containing the times associated with the input gas flow rates, $\dot{\mathrm{m}}_{\mathrm{g}}^{\mathrm{i}}$ (Input Data). [s] (V.7) 


$$
\dot{\mathrm{m}}_{\mathrm{g}}^{\mathrm{i}} ; i=1,2, \ldots, \mathrm{N}_{\mathrm{g}}+1
$$

Array containing the gas flow rates associated with the input times, $t_{g}^{i}$ (Input Data). $[\mathrm{kg} / \mathrm{s}]$ (V.6)

\section{Calculation}

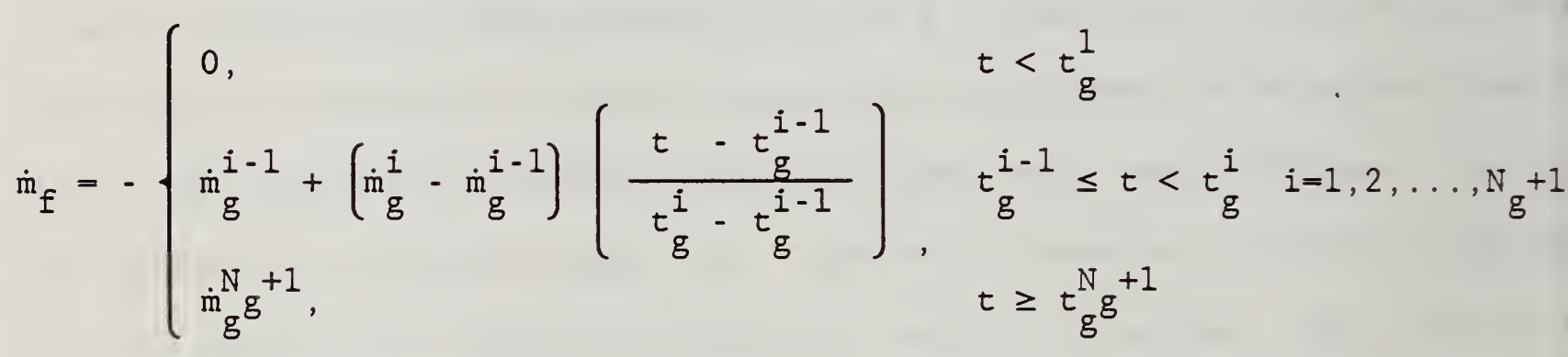

\section{$\underline{\text { References }}$}

No references available.

\section{Subroutine Variables}

$\begin{array}{ll}\operatorname{TMOZZ} & =\dot{\mathrm{m}}_{\mathrm{f}} \\ \operatorname{ZTZZZ} & =t \\ \operatorname{NSEG} & =\mathrm{N}_{8} \\ \operatorname{ZTSEG}(I) & =\mathrm{t}_{8}^{i} \\ \operatorname{TMGSEG}(I) & =\ddot{\mathrm{m}}_{8}^{i}\end{array}$

Note: The value of the index I should range from 1 to NSEG+1 while $i$ ranges from 1 to $\mathrm{N}_{\mathrm{g}}+1$.

\section{Prepared by}

David W. Stroup 


\section{Computer Subroutine}

SUBROUTINE TMGAS (ZTZZZ, NSEG, ZTSEG, TMGSEG, TMOZZ)

C

C SUBROUTINE TO COMPUTE THE GAS FLOW RATE FROM A GAS BURNER. THE GAS

C FLOW RATE VARIES LINEARLY WITH TIME BETWEEN FIXED VALUE PAIRS:

TIME, GAS FLOW RATE.

NOTE: A MAXIMUM OF 100 INPUT DATA POINTS MAY BE SPECIFIED. TO CHANGE THIS NUMBER: ALTER THE VALUE CONTAINED IN VARIABLE MAXSEG.

INPUT PARAMETERS :

NSEG - NUMBER SEGMENTS IN GAS FLOW RATE CURVE.

ZTSEG - ARRAY CONTAINING THE TIMES ASSOCIATED WITH THE GAS FLOW RATES CONTAINED IN ARRAY TMGSEG.

TMGSEG - - ARRAY CONTAINING THE GAS FLOW RATES ASSOCIATED WITH THE TIME CONTAINED IN ARRAY ZTSEG.

INPUT VARIABLES :

ZTZZZ -- CURRENT TIME.

OUTPUT VARIABLE:

TMOZZ -- GAS FLOW RATE AT ZTZZZ.

IMPLICIT DOUBLE PRECISION (A-H,O-Z)

PARAMETER (MAXSEG $=100$ )

DIMENSION ZTSEG (MAXSEG), TMGSEG (MAXSEG)

IF (ZTZZZ ,GE. ZTSEG(1)) THEN

IF $(Z T Z Z Z$.IT. ZTSEG $($ NSEG +1$))$ THEN

DO $10 \quad I=2, N S E G+1$

IF (ZTZZZ .LT. ZTSEG(I)) THEN

$I I=I$

$I I I=I-I$

GO TO 20

ENDIF

CONTINUE

CONTINUE

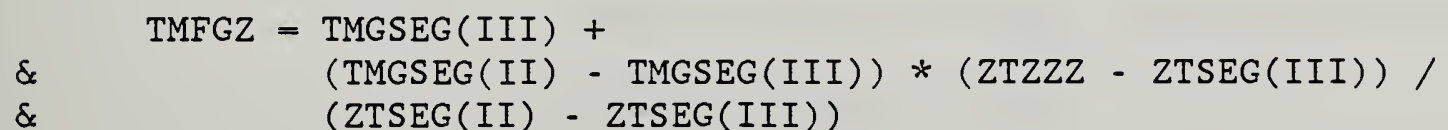

ELSE

TMFGZ = TMGSEG $($ NSEG+1) 


\begin{tabular}{ll} 
& \multicolumn{1}{c}{ ENDIF } \\
C & ELSE \\
C & TMFGZ $=0$. ODO \\
C & ENDIF \\
C & TMOZZ $=-$ TMFGZ \\
& RETURN \\
& END
\end{tabular}

1 - TMGAS - 4 


\section{WTRPRD - Rate at which a Burning Object Produces Water Vapor}

\section{Description}

This routine calculates the rate at which a burning object produces water vapor. The production rate of a specific gas by a burning object depends on the chemical composition of the material being burned. The rate of production of water vapor by a given burning material is equal to the mass pyrolysis rate of the object multiplied by the mass fraction of the (combustible part of the) object evolved as water vapor, when it burns in open air. The mass fraction must be obtained from fire tests of the specific material (see Tewarsen, A., "Heat Release Rates from Burning Plastics", J. Fire and Flammability 8 (1977) for example).

\section{Output}

$\dot{\mathrm{m}}_{\mathrm{H} 2 \mathrm{O}}$

Mass rate of evolution of water vapor from the object. [ $[\mathrm{kg} / \mathrm{s}](\mathrm{V} .59)$

\section{Input}

$f_{\mathrm{H} 20}^{\prime}$

Mass fraction of the (combustible part of the)

object evolved as water vapor, when the object

burns in the open (Input Data). (V.47)

$\dot{\mathrm{m}}_{\mathrm{L}}$

(Negative of the) mass pyrolysis rate of the object (Calculated Value, see Burning Object section). [ $\mathrm{kg} / \mathrm{s}](\mathrm{V} .61)$ 


\section{Calculations}

$$
\dot{\mathrm{m}}_{\mathrm{H} 20}=-\mathrm{f}_{\mathrm{H} 20}^{\prime} \quad \dot{\mathrm{m}}_{\mathrm{L}}
$$

\section{References}

1. Mitler, H.E. and Emmons, H.W., "Documentation for CFC V; the Fifth Harvard Fire Code," U.S. Department of. Commerce, Washington, D.C., NBS-GCR-81-344, October 1981, pp. $128-131$.

\section{Subroutine Variables}

$$
\begin{aligned}
& \text { TMOW }=\dot{\mathrm{m}}_{\mathrm{B} 20} \\
& \text { FH2O }=\mathrm{f}_{\mathrm{H} 20}^{\prime} \\
& \text { TMOZZ }=\dot{\mathrm{m}}_{\mathrm{L}}
\end{aligned}
$$

\section{Prepared by}

David W. Stroup 


\section{Computer Subroutine}

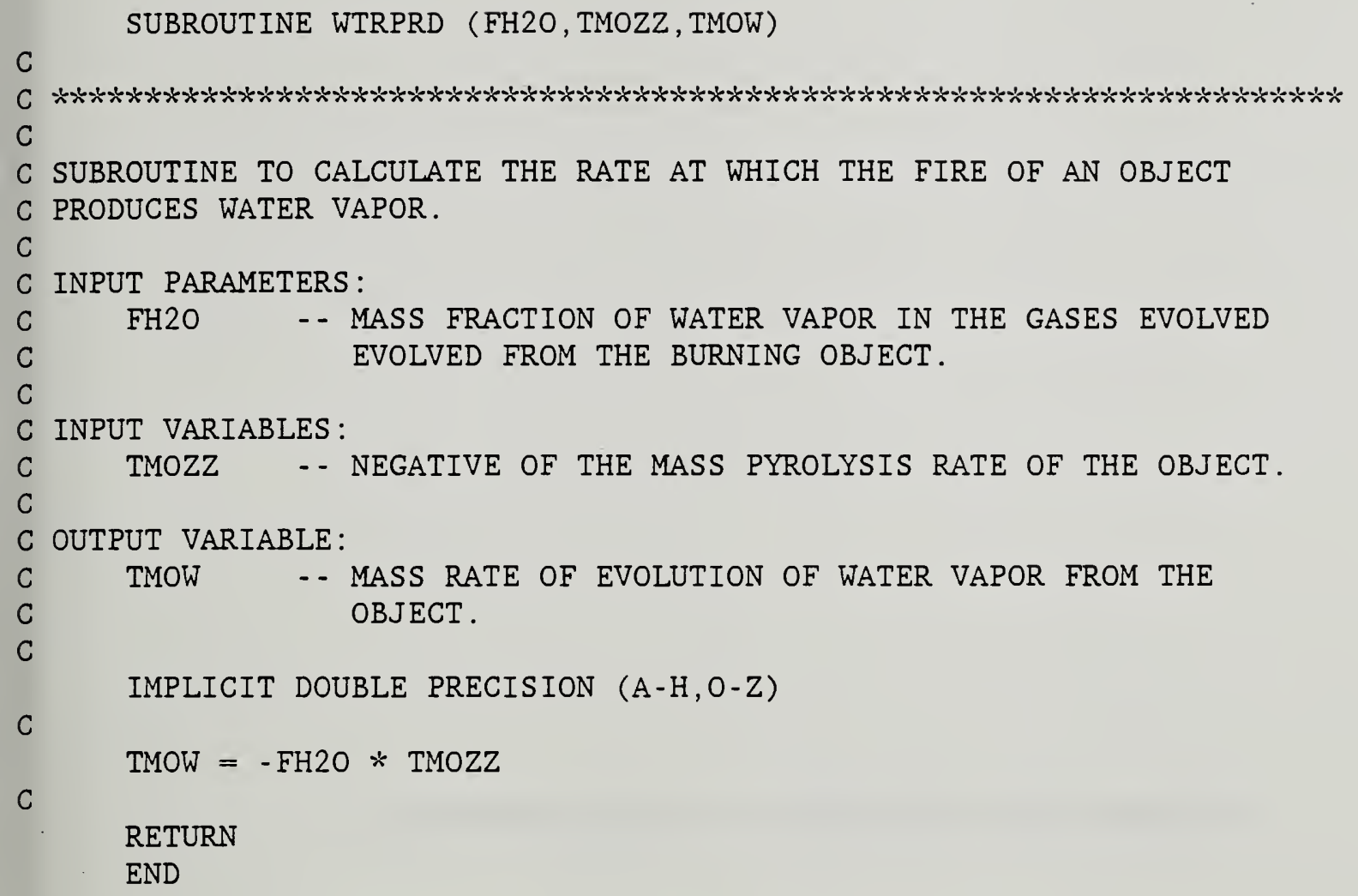


1 -WTRPRD - 4 
2. ALGORITHMS RELATED TO CONDUCTION HEAT TRANSFER

$2-1$ 


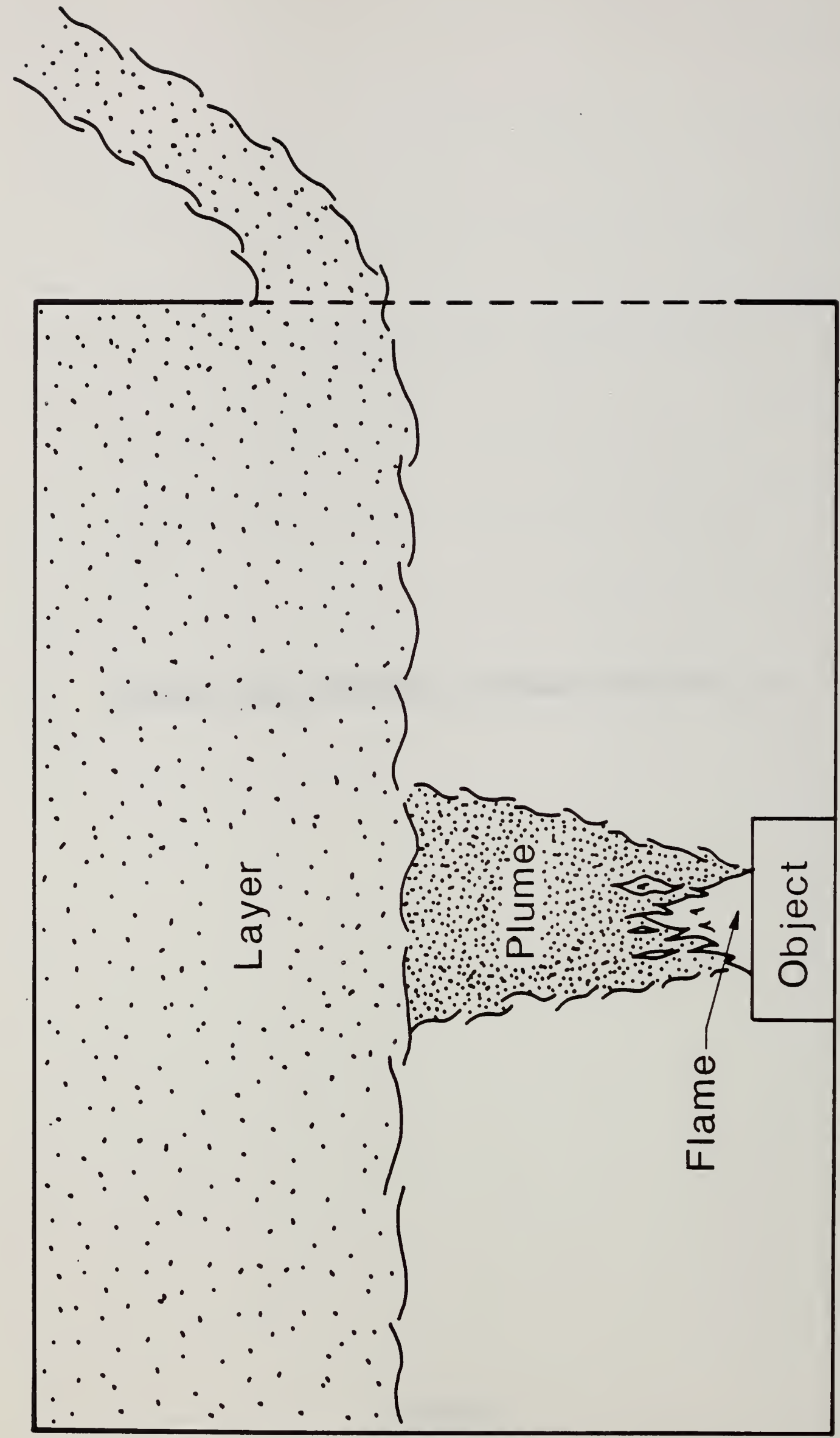




\section{Description}

This algorithm calculates the time dependent temperature profile inside a slab, figure 2-2. A slab of thickness, $T_{W}$, is exposed to radiative and convective heat fluxes on its front and back surfaces. The temperature profile through the slab is calculated numerically by cutting the slab into pieces (parallel to its front surface), and solving the one-dimensional heat diffusion equation explicitly using central differences (see for example Holman, Heat Transfer, pp. 72-98).

This routine assumes that the $s$ lab is exposed to a fire on one side and an ambient temperature environment on the other side. The net heat flux on the fire exposed side of the slab is composed of convection and radiation heat fluxes from the hot layer, radiation heat flux(es) from the flame(s) above the burning object(s), and re-radiation from the slab surface. The unexposed side of the slab is assumed to transfer heat, by convection and radiation, to an ambient temperature environment. The re-radiation (on the exposed side), the radiation (on the unexposed side), and the resulting net heat fluxes are calculated within the routine.

To calculate the slab temperature profile, the slab thermal properties (conductivity, diffusivity, specific heat, and density) and its thickness must be known. It is also necessary to know the convective and radiative fluxes on the exposed side of the slab, and the convection heat flux on the unexposed side. These fluxes may be calculated elsewhere in the user's program or 
appropriate routines may be inserted directly into this subroutine. Of course, the user will have to make sure the necessary input data is available to the routine when needed. This, routine may be used to calculate temperature profiles in walls, ceilings, or floors with appropriately specified convection and radiation heat flux bounciary conditions.

The slab re-radiates energy (received through convection and radiation from the hot layer and flames) through the upper layer to the lower layer. The lower layer is at some temperature, $T_{D}$. In order to calculate the heat flux radiated by the fire exposed slab surface, the present layer height and the absorption coefficient of the hot layer must be specified or calculated in some way. The layer height is usually available from most fire models. Various methods for calculating the absorption coefficient of the hot layer may be found in the Hot Layer section of this catalog. The unexposed side of the slab radiates to an environment at ambient temperature, $T_{a}$. The Stefan-Boltzmann constant must be specified for use in these radiation calculations.

The user must specify the time step to be used in the calculation as well as the maximum number of layers into which the slab may be divided. The method outlined below will automatically calculate the number of layers required for calculation stability. If this exceeds the maximum allowable, the maximum number of layers will be used. This method is numerically stable for $\delta \mathrm{x}>\left(2 \alpha \Delta t_{\mathrm{max}}\right)^{1 / 2}$ and $\Delta t<\Delta t_{\mathrm{max}}$, where $\Delta t_{\mathrm{max}}$ is the maximum time step to be used. The user must exercise care in selecting the maximum value for $\delta \mathrm{x}$. 
If the value is too low, the calculation may be unstable and produce erroneous results.

Finally, the slab temperature profile at the end of the previous time step must be known. Initially, the entire slab is assumed to be at ambient temperature. After a calculation is completed, the new temperature profile must be stored for use in the next time step.

\section{Output}

$\mathrm{T}_{\mathrm{i}}^{\text {new }} ; i=1,2, \ldots, \mathrm{N}$

Temperature of the slab at each node point, i. $[\mathrm{K}](\mathrm{V} .122)$

\section{Input}

$\dot{q}_{L}^{\prime \prime} W$

Convective heat flux from the hot layer inside a room to the adjacent part (interior) of the wall or ceiling (slab) (Calculated Value, see

Convective Heat Transfer section). [W/m $\mathrm{m}^{2}$ (V.11)

$\dot{\mathrm{q}}_{\mathrm{L} W R}^{\prime \prime}$ Radiative heat flux from the hot layer to the adjacent part (interior) of the wall or ceiling (slab) (Calculated Value, see Radiation Heat Transfer section). [W/m $\left.\mathrm{m}^{2}\right]$ (V.81)

$\Sigma \dot{q}_{P W R}^{\prime \prime}$ (Sum of the) radiative heat flux from plume(s) to the adjacent part (interior) of the wall or ceiling (slab) (Calculated Value, see Radiation Heat Transfer section). [W/m $\left.\mathrm{m}^{2}\right]$ (V.79) 


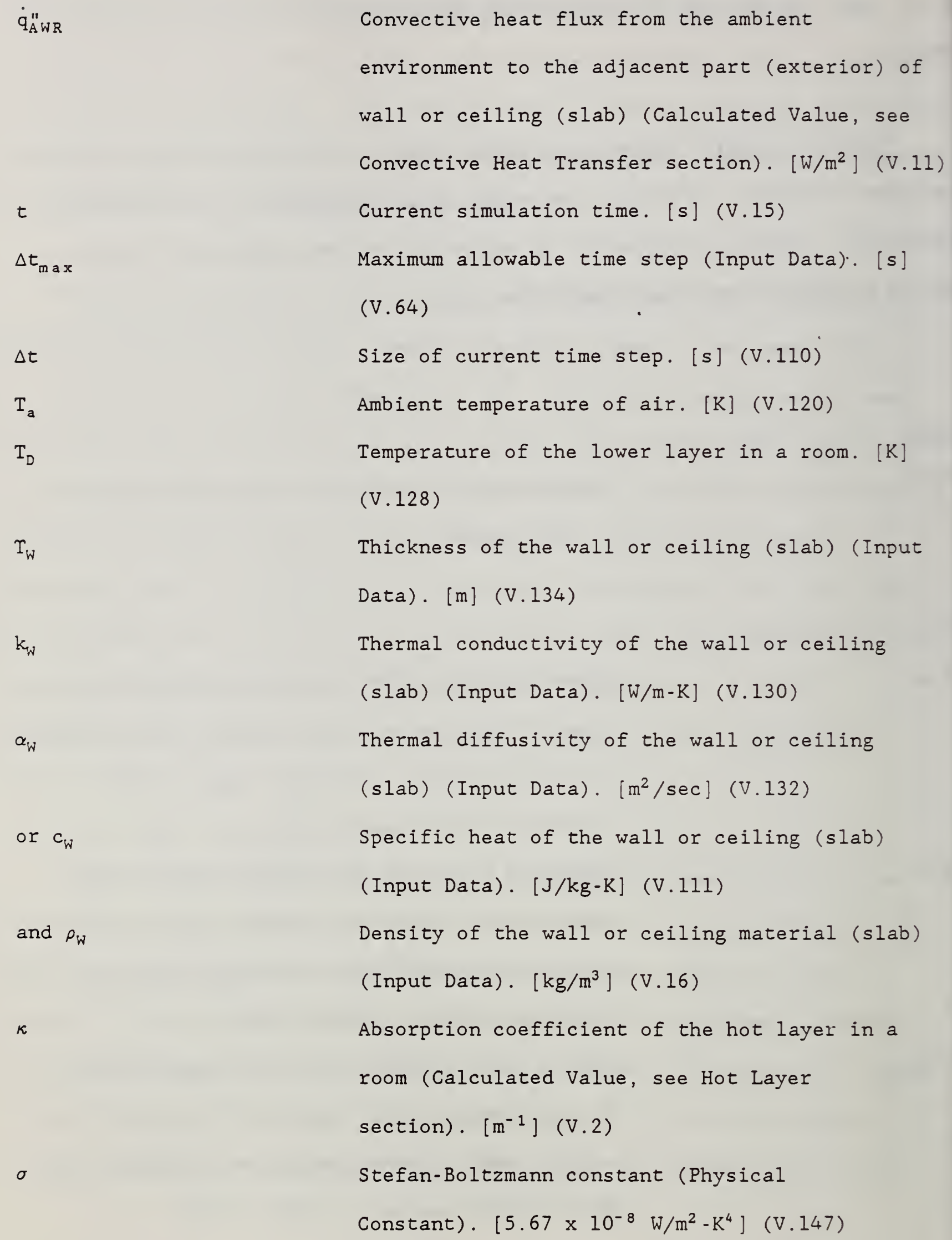




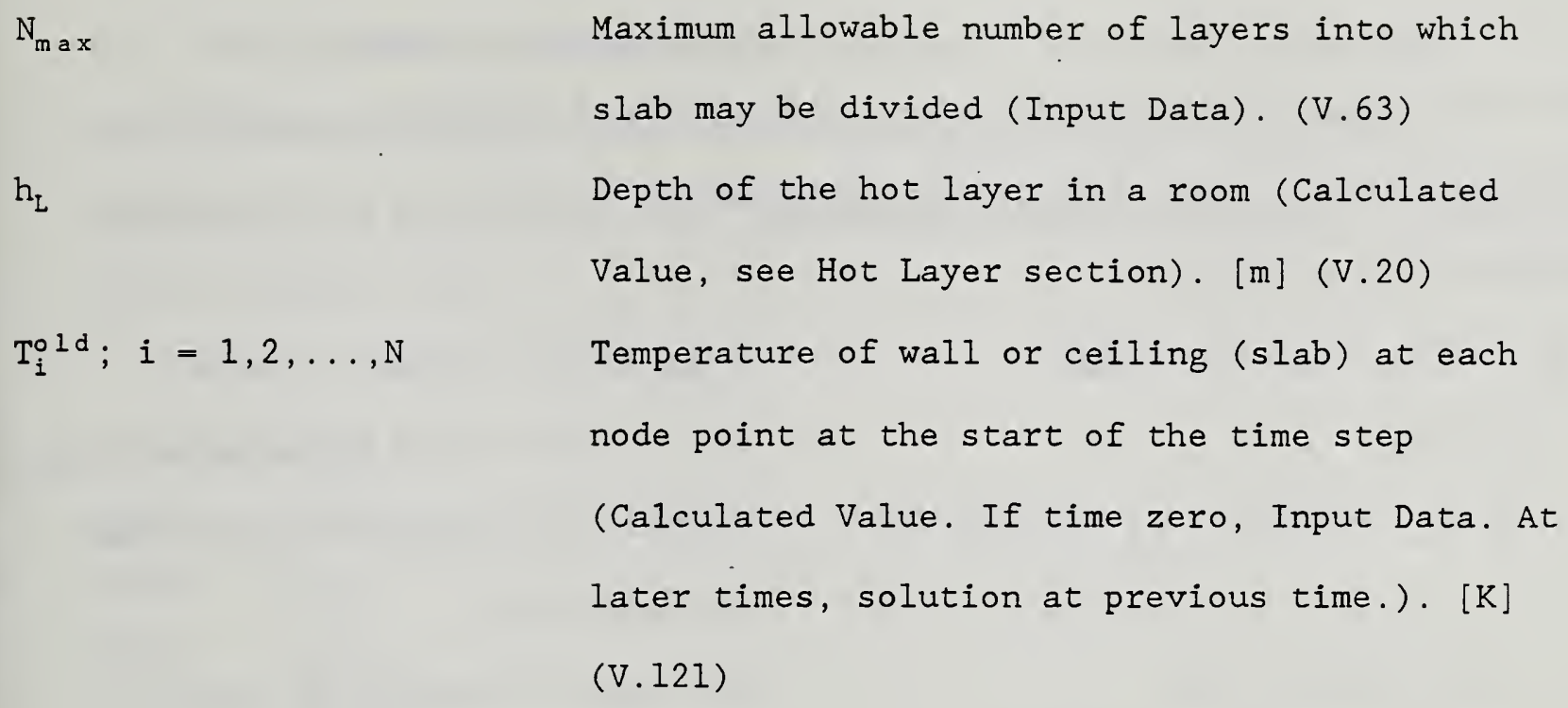

$\mathrm{h}_{\mathrm{L}}$

Depth of the hot layer in a room (Calculated

Value, see Hot Layer section). [m] (V.20)

$\mathrm{T}_{i}^{\circ 1 \mathrm{~d}} ; i=1,2, \ldots, \mathrm{N}$

Temperature of wall or ceiling (slab) at each

node point at the start of the time step

(Calculated Value. If time zero, Input Data. At

later times, solution at previous time.). [K]

(V.121)

\section{Calculations}

The calculations below are executed once, at time $t=0$. The values are returned in the calling argument list for use in future calls to this routine. $\alpha=k_{\mathrm{W}} /\left(\rho_{\mathrm{W}} c_{\mathrm{W}}\right)$ Calculate thermal diffusivity, if necessary.

$\delta \mathrm{x}_{\mathrm{i}}={\sqrt{2 \alpha \Delta \mathrm{t}_{\mathrm{max}}}}$ Smallest permissible time space increment (calculated for the largest time increment to be used). $N=1+\left[\Upsilon_{W} / \delta x_{i}\right]$ $\mathrm{N}$ is the number of points where the temperature is calculated. $\mathrm{n}=1$ on inside surface, $\mathrm{n}=\mathrm{N}$ on outside surface. (take integer part only of term in brackets)

$\delta x= \begin{cases}T_{W} /\left(N_{\text {max }}-1\right), & N>N_{\text {max }} \\ \Upsilon_{W} /(N-1), & 2<N \leq N_{\text {max }} \\ T_{W}, & N \leq 2\end{cases}$ Space increment actually used $a=2 \alpha /(\delta x)^{2}$ Computation parameter. 


$$
\mathrm{b}=\delta \mathrm{x} / \mathrm{k}
$$

Computation parameter.

The calculations below are executed each time this routine is called. The calculation of the temperature distribution at time $t+\Delta t$ given the distribution at time $t$ :

$$
\begin{aligned}
& \dot{q}_{1}^{\prime \prime}=\dot{q}_{L W D}^{\prime \prime}+\dot{q}_{L}^{\prime \prime}+\Sigma \dot{q}_{P N R}^{\prime \prime} \\
& \dot{q}_{N}^{\prime \prime}=\dot{q}_{A}^{\prime \prime} \\
& \phi_{1}=\dot{q}_{1}^{\prime \prime}-\sigma\left(T_{N}^{\circ 1 d}\right)^{4}+\exp \left(-\kappa h_{L}\right) \sigma T_{D}^{4}
\end{aligned}
$$

Heat flux to side 1 (inside).

Heat flux to side $\mathrm{N}$ (outside).

Net flux to inside of wall after re-radiation.

$$
\begin{aligned}
& \phi_{\mathrm{N}}=\dot{\mathrm{q}}_{\mathrm{N}}^{\prime \prime}+\sigma \mathrm{T}_{\mathrm{a}}^{4}-\sigma \mathrm{T}_{\mathrm{N}}^{4} \\
& \mathrm{~T}_{1}^{\mathrm{new}}=\mathrm{T}_{1}^{\circ 1 \mathrm{~d}}(1-\mathrm{a} \Delta \mathrm{t})+\mathrm{a} \Delta \mathrm{t}\left(\mathrm{T}_{2}^{\circ 1 \mathrm{~d}}+\mathrm{b} \phi_{1}\right)
\end{aligned}
$$

Net flux to outside of slab.

Inside surface temperature calculation.

$T_{i}^{n e w}=T_{i}^{o l d}(1-a \Delta t)+(a \Delta t / 2)\left(T_{i-1}^{o l} d+T_{i+1}^{o l}\right)$

Interior node temperature calculation (repeat calculation for each interior node point, $i=$ $2,3, \ldots, N=1)$.

$T_{N}^{n e w}=T_{N}^{\circ 1 d}(1-a \Delta t)+a \Delta t\left(T_{N}^{\circ}-1 d-b \phi_{N}\right)$ Outside surface temperature calculation.

\section{$\underline{\text { References }}$}

1. Mitler, H.E., "The Physical Basis of the Harvard Computer Fire Codes," Harvard University, Home Fire Project Technical Report No. 34, pp. 51 59.

2. Mitler, H.E., and Emmons, H.W., "Documentation for CFC V, the Fifth Harvard Computer Fire Code," U.S. Department of Commerce, Washington, D.C., NBS-GCR-81-344, October 1981, pg. 114. 
3. H.W. Emmons, "Heat Conduction Calculations for Zone Fire Modeling," Harvard University Home Fire Project Technical Report \#44 (1980).

4. Carslaw, H.S., and Jaeger, J.C., Conduction of Heat in Solids, Clarendon Press, Oxford, 1959.

\section{Subroutine Variables}

$$
\begin{aligned}
& \mathrm{ZKW}(I)=\mathrm{T}_{\mathrm{i}}^{\mathrm{new}} ; i=1,2, \ldots, \mathrm{N} \\
& \text { FQLWD }=\dot{\mathrm{q}}_{\mathrm{L} W D}^{\prime \prime} \\
& \text { FQLWR }=\dot{q}_{L W R}^{\prime \prime} \\
& \text { FQPWR }=\Sigma \dot{q}_{P W R}^{\prime \prime} \\
& \text { FQAWD }=\dot{q}_{A}^{\prime \prime} D \\
& \mathrm{ZTZZZ}=t \\
& \text { DT } \quad=\Delta t \\
& \text { DTMAX }=\Delta t_{\text {max }} \\
& \text { ZKAZZ }=T_{a} \\
& Z \mathrm{KDZZ}=\mathrm{T}_{\mathrm{D}} \text {. } \\
& \mathrm{ZNWZZ}=\mathrm{T}_{\mathrm{W}} \\
& Z \mathrm{JWZZ}=k_{\mathrm{W}} \\
& \mathrm{ZGWZZ}=\alpha_{\mathrm{W}} \\
& Z C W Z Z=C_{W} \\
& \text { VMTWZZ }=\rho_{\mathrm{W}} \\
& \text { ZULZZ }=\kappa \\
& \text { SIGMA }=\sigma \\
& \text { MXLYRS }=\mathrm{N}_{\text {max }} \\
& Z \mathrm{HLZZ}=\mathrm{h}_{\mathrm{L}} \\
& \operatorname{ZKWO}(I)=\mathrm{T}_{i}^{\circ} \text { ld } ; i=1,2, \ldots, \mathrm{N}
\end{aligned}
$$

The following variables represent values which are calculated during the first call of this routine:

$\begin{array}{ll}\mathrm{DX} & =\delta \mathrm{x} \\ \mathrm{AW} & =\mathrm{a} \\ \mathrm{BW} & =\mathrm{b} \\ \mathrm{N} & =\mathrm{N}\end{array}$


These values are retained for future use in calls to this routine. The symbols on the right refer to the equations in the Calculations section above.

Prepared by

David W. Stroup 
Computer Subroutine

SUBROUTINE TMPWO1(ZNWZZ, ZJWZZ, ZGWZZ, ZCWZZ, VMWZZ, ZKAZZ, DTMAX, $\&$

$\&$ ZKDZZ , ZKWO, ZHLZZ , ZTZZZ , DT , FQLWD , FQLWR, FQPWR , FQAWD , DX , AW , BW, N , ZKW)

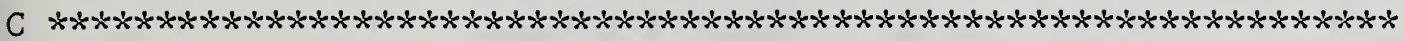

C

IMPLICIT DOUBLE PRECISION ( $\mathrm{A}-\mathrm{H}, \mathrm{O}-\mathrm{Z})$

$\mathrm{C}$

C SUBROUTINE TO CALCULATE THE TEMPERATURE PROFILE WITHIN A SLAB

$C$ USING A DISCRETE GRID. THE SLAB IS HEATED OR COOLED ON EACH

C SIDE BY CONVECTION AND RADIATION AND THE HEAT DIFFUSES

C THROUGH IT BY CONDUCTION.

$\mathrm{C}$

C INPUT PARAMETERS:

C ZNWZZ - S SLAB THICKNESS

C ZJWZZ -. SLAB THERMAL CONDUCTIVITY

C ZGWZZ -- SLAB THERMAL DIFFUSIVITY

C ZCWZZ - SLAB MATERIAL SPECIFIC HEAT

C VMWZZ -- SLAB MATERIAL DENSITY

C

$\mathrm{C}$

ZKAZZ -- AMBIENT AIR TEMPERATURE (EXPOSING EXTERIOR SIDE OF SLAB)

DTMAX -- MAXIMUM ALLOWABLE TIME STEP

INPUT VARIABLES :

ZKDZZ - - LOWER LAYER TEMPERATURE (EXPOSING INTERIOR SIDE OF SLAB)

ZKWO -- PREVIOUS TIME STEP SLAB TEMPERATURE PROFILE

ZHLZZ - - SMOKE LAYER HEIGHT

ZTZZZ - - CURRENT SIMULATION TIME

DT - - CURRENT SIZE OF TIME STEP

FQLWD - - CONVECTIVE HEAT FLUX FROM LAYER TO INTERIOR SIDE OF SLAB

FQLWR -- RADIATIVE HEAT FLUX FROM LAYER TO INTERIOR SIDE OF SLAB

FQPWR - - RADIATIVE HEAT FLUX FROM PLUME(S) TO INTERIOR SIDE OF SLAB

FQAWD - CONVECTIVE HEAT FLUX FROM AMBIENT TO EXTERIOR SIDE OF SLAB

SECONDARY OUTPUT VARIABLES :

DX - - THICKNESS OF PIECES OF SLAB USED IN FINITE DIFFERENCE CALCULATION

AW $\quad-$ CONVENIENT DEFINITION

BW $\quad-$ CONVENIENT DEFINITION

$\mathrm{N}$ - NUMBER OF NODES USED IN FINITE DIFFERENCE CALCULATION

OUTPUT VARIABLE:

C ZKW - TEMPERATURE PROFILE WITHIN SLAB AT NEW TIME 
C

PARAMETER (NON $=20)$

PARAMETER (SIGMA $=5.67 \mathrm{D}-8$ )

C DIMENSION ZKWO(NON), ZKW(NON)

C INITIAL CALCULATIONS

C

IF (ZTZZZ .LE. 0.0$)$ THEN

IF (ZGWZZ .LE. 0.0$)$ ZGWZZ = ZJWZZ / (VMWZZ * ZCWZZ)

$\mathrm{DXM}=\mathrm{DSQRT}(2 . \mathrm{DO} * \mathrm{ZGWZZ} * \mathrm{DT})$

$\mathrm{M}=\operatorname{IDFIX}(\mathrm{ZNWZZ} / \mathrm{DXM})+1$

$N=\operatorname{MINO}(M, 20)$

IF (N .LE. 1) $\mathrm{N}=2$

$\mathrm{DX}=\mathrm{ZNWZZ} /(\operatorname{FLOAT}(\mathrm{N}-1))$

$A W=2 . D O * Z G W Z Z /(D X * D X)$

$\mathrm{BW}=\mathrm{DX} / \mathrm{ZJWZZ}$

ENDIF

C

C WALL TEMPERATURE CALCULATIONS

C

$$
\mathrm{TEMP}=1 . \mathrm{DO}-\mathrm{AW} * \mathrm{DT}
$$

$\mathrm{NM} 1=\mathrm{N}-1$

C CALCULATE INTERIOR NODE TEMPERATURES

DO $10 I=2$, NMI

$\mathrm{ZKW}(I)=\mathrm{ZKWO}(I) * \mathrm{TEMP}+\mathrm{AW} *(\mathrm{DT} / 2 . \mathrm{DO}) \div(\mathrm{ZKWO}(I-I)$

$10 \&$ CONTINUE

C CALCULATE SLAB HEAT FLUXES

$F Q W A=F Q L W D+F Q L W R+F Q P W R$

FQW1 $=$ FQWA - SIGMA $*($ ZKWO $(1) * * 4-$ DEXP $(-$ ZHLZZ $*$

$\&$ ZULZZ) * ZKDZZ $\div * 4)$

FQWB $=$ FQAWD

FQW2 $=$ FQWB + SIGMA $*($ ZKAZZ $* * 4-Z K W O(N) * * 4)$

C CALCULATE INTERIOR NODE TEMPERATURE

$\mathrm{ZKW}(1)=\mathrm{ZKWO}(1) * \mathrm{TEMP}+\mathrm{AW} * \mathrm{DT} *(\mathrm{ZKWO}(2)+\mathrm{BW} * \mathrm{FQW} 1)$

C CALCULATE EXTERIOR NODE TEMPERATURE

$\mathrm{ZKW}(\mathrm{N})=\mathrm{ZKWO}(\mathrm{N}) * \mathrm{TEMP}+\mathrm{AW} * \mathrm{DT} *(\mathrm{ZKWO}(\mathrm{N}-\mathrm{I})+\mathrm{BW} *$

C $\&$ FQW2)

RETURN

END 


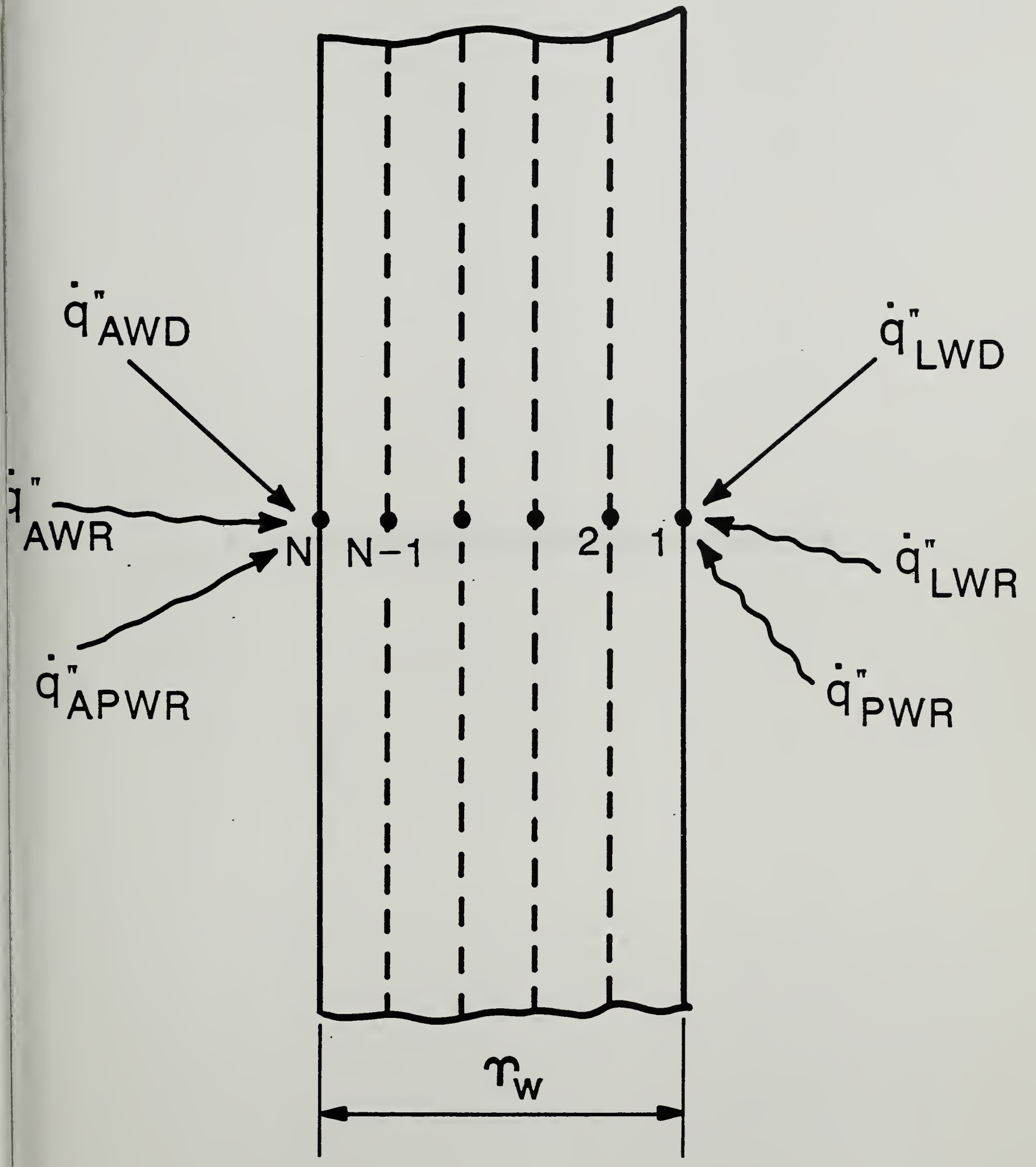

Figure 2-2. Schematic of heat conduction into a slab 
2-TMPW01- 12 
3. ALGORITHMS RELATED TO CONVECTION HEAT TRANSFER

3-1 


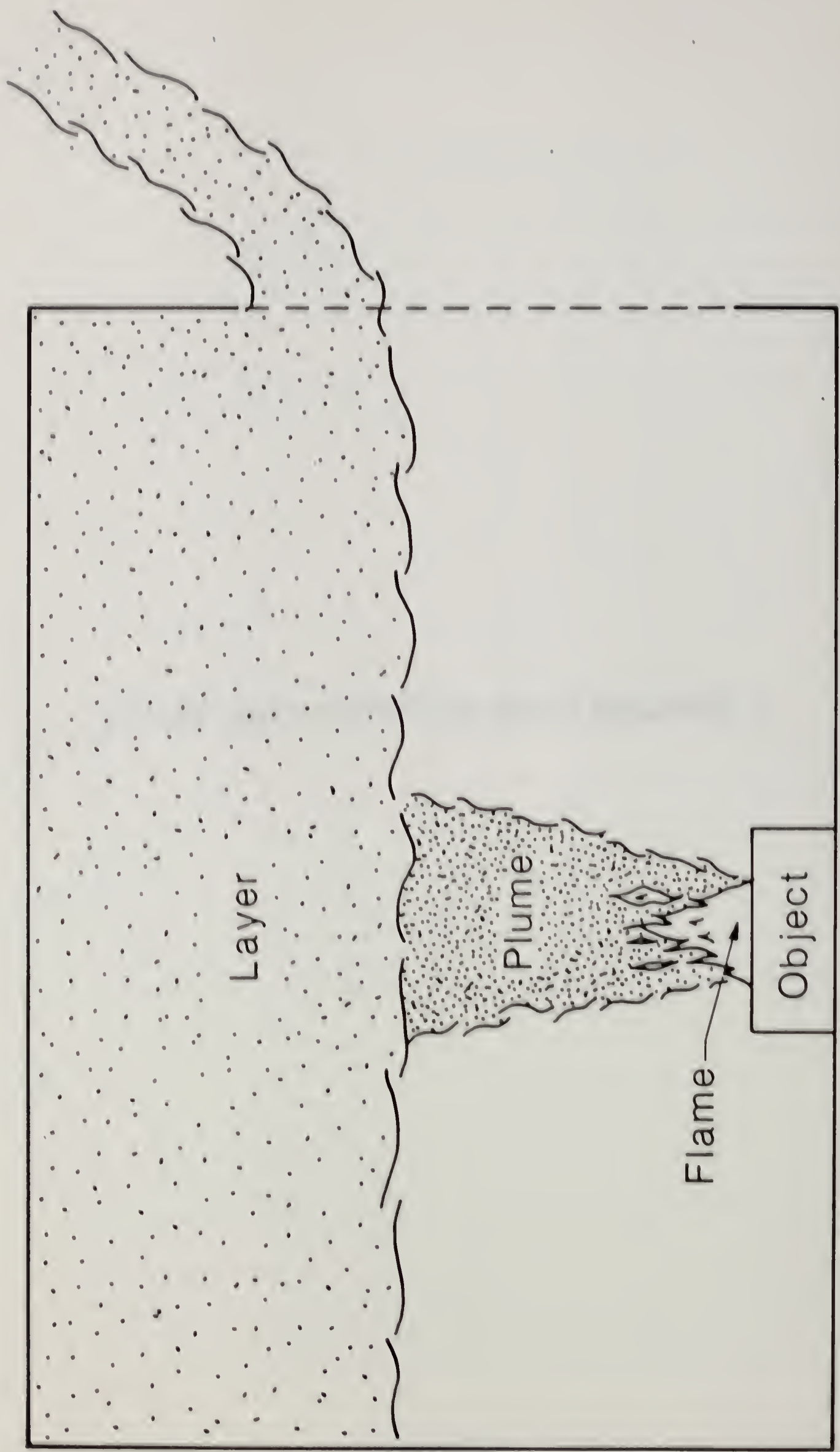

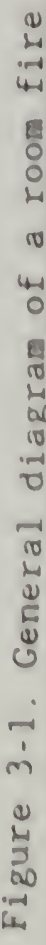




\section{CBLOCK - Convective Heat Flux to the Surface of a Pool}

\section{Description}

This subroutine calculates the convective heat flux from the combustion zone at flame temperature, $T_{f}$, to the surface of a burning pool of combustible liquid at temperature $\mathrm{T}_{\mathbf{s}}$. The convection heat flux is calculated using the equation

$$
\phi_{c \circ n v}=h\left(T_{f}-T_{s}\right) .
$$

This routine requires the user to specify a Prandtl number (V.72). The heat transfer coefficient, $h$, is determined from the Nusselt number (relates convective heat transfer effects to conduction heat transfer effects) for a horizontal heated upward facing plate with free convection. In order to calculate the Nusselt number, the Grashof number (relates buoyancy forces to viscous forces) must be calculated first.

Output

$$
\phi_{\mathrm{conv}}
$$

Convective heat flux to the surface of a pool of liquid. $\left[\mathrm{W} / \mathrm{m}^{2}\right](\mathrm{V} .14)$

\section{Input}

$\dot{\mathrm{m}}_{\mathrm{f}}$

(Negative of the) mass pyrolysis rate of the object (pool) (Calculated Value, see Burning Object section). [ $\mathrm{kg} / \mathrm{s}](\mathrm{V} .61)$

$\mathrm{R}$ Radius of the fire on the hurning object (pool) 
(Calculated Value, see Burning Object section). $[\mathrm{m}](\mathrm{V} .85)$

$T_{s}$

g

$\pi$

$c_{p}$

$T_{f}$

Pr
Temperature of the surface of the object (Input Data). [K] (V.129)

Acceleration of gravity (Input Data). [m/ $\left.\mathrm{s}^{2}\right]$ (V. 144)

Pi (Physical Constant). [3.141592...] (V.146)

Specific heat of ambient air (Input Data). $[\mathrm{J} / \mathrm{kg}-\mathrm{K}](\mathrm{V} .112)$

Temperature of the flaming gases, -- i.e. flame temperature (Input Data). [K] (V.123)

Prandtl number (Input Data). (V.72)

\section{Calculations}

$k=2.72\left(10^{-7}\right)\left(\left(T_{s}-T_{f}\right) / 2\right)^{4 / 5}$

$\nu=7.18\left(10^{-10}\right)\left(\left(\mathrm{T}_{\mathrm{s}}+\mathrm{T}_{\mathrm{f}}\right) / 2\right)^{7 / 4}$

$\mathrm{d}=2 \mathrm{R}$

$\mathrm{Gr}=\operatorname{gd}^{3}\left[\left(\mathrm{~T}_{\mathrm{f}}-\mathrm{T}_{\mathrm{s}}\right) /\left(\nu^{2} \mathrm{~T}_{\mathrm{f}}\right)\right]$

$\mathrm{Nu}=0.012(\mathrm{GrPr})^{1 / 3}$

$z=-\frac{\dot{m}_{f} c_{p}{ }^{4}}{\pi d N u k}$

$\phi_{\text {conv }}=\frac{N u\left[\frac{k}{d}\right]\left(T_{f}-T_{s}\right) z}{\left(e^{z}-1\right)}$
Thermal conductivity of the air layer between flame and pool surface. Kinematic viscosity of the air layer between flame and pool surface. Pool diameter.

Grashof number for flame - surface area. Nusselt number calculation.

Dimensionless blowing factor.

Convective heat flux to the surface of the pool. 


\section{$\underline{\text { References }}$}

1. Holman, J.P., Heat Transfer, McGraw-Hill Book Company, 1981, pp. 265 292.

Subroutine Variables

$$
\begin{aligned}
& \mathrm{PHIC}=\phi_{\mathrm{conv}} \\
& \mathrm{ZRFZZ}=\mathrm{R} \\
& \mathrm{TMOZZ}=\dot{\mathrm{m}}_{\mathrm{f}} \\
& \mathrm{TS}=\mathrm{T}_{\mathrm{s}} \\
& \mathrm{PI}=\pi \\
& \mathrm{G} \quad=\mathrm{g} \\
& \mathrm{CP}=\mathrm{c}_{\mathrm{p}} \\
& \mathrm{TG}=\mathrm{T}_{\mathrm{f}} \\
& \mathrm{PR}=\mathrm{Pr}
\end{aligned}
$$

\section{Prepared by}

David W. Stroup 


\section{Computer Subroutine}

SUBROUTINE CBLOCK (PR, TG, TMOZZ, ZRFZZ, TS, PHIC)

C

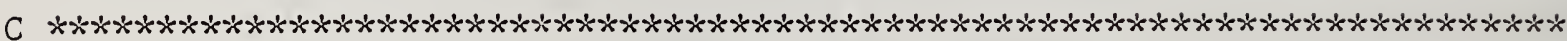

$\mathrm{C}$

C THIS ROUTINE CALCULATES THE CONVECTION HEAT FLUX TO THE SURFACE

C OF A BURNING POOL OF COMBUSTIBLE LIQUID.

C

C INPUT PARAMETERS:

C PR - - PRANDTL NUMBER.

C TG - FLAME TEMPERATURE.

$\mathrm{C}$

C INPUT VARIABLES:

C TMOZZ - MASS PYROLYSIS RATE OF THE POOL.

C ZRFZZ - - RADIUS OF POOL.

C TS - - SURFACE TEMPERATURE OF POOL.

C

C OUTPUT VARIABLE:

C PHIC -- CONVECTIVE HEAT FLUX TO THE POOL SURFACE.

C

C IMPLICIT DOUBLE PRECISION (A-H,O-Z)

C PARAMETER $(P I=3.141592654, G=9.8, C P=1004$.

C CALCULATE TEMPERATURE DEPENDENT THERMAL CONDUCTIVITY AND

C KINEMATIC VISCOSITY OF AIR AT POOL SURFACE. $\mathrm{FK}=2.72 \mathrm{D}-7 *((\mathrm{TS}+\mathrm{TG}) / 2) * *.(4 . / 5$. VISKIN $=7.18 \mathrm{D}-10 *((\mathrm{TS}+\mathrm{TG}) / 2) * *.(7 . / 4$.

C

C CALCULATE POOL DIAMETER.

$D=2 . * Z R F Z Z$

C

C CALCULATE GRASHOF AND NUSSELT NUMBERS.

$\mathrm{GR}=\mathrm{G} * \mathrm{D} * * 3 . *(\mathrm{TG}-\mathrm{TS}) /(\mathrm{VISKIN} * * 2 * \mathrm{TG})$

$\mathrm{NU}=0.012 *(\mathrm{GR} * \mathrm{PR}) * *(1 . / 3$.

C

C CALCULATE THE DIMENSIONLESS BLOWING FACTOR.

IF (-TMOZZ . LT. 1.D -5) TMOZZ = -1.D -5

C

$\mathrm{Z}=-\mathrm{TMOZZ} * \mathrm{CP} * 4 . /(\mathrm{PI} * \mathrm{D} * \mathrm{NU} * \mathrm{FK})$

C CALCULATE THE CONVECTIVE HEAT FLUX TO THE POOL SURFACE.

IF (Z .LT. -30.$)$ THEN

ELSE

PHIC $=N U *(F K / D) *(T G-T S)$

$$
\text { PHIC }=0 \text {. }
$$
ENDIF

IF (Z . LT. 30.) PHIC $=\mathrm{NU} *(F K / D) *(T G-T S) * Z /(D E X P(Z)-1$.

C

RETURN 
END

3-CBLOCK - 5 
3-CBLOCK- 6 


\section{CNVF - Convection Heat Flux from Floor to Lower Layer}

\section{Description}

This routine calculates the convection heat transfer from an elevated temperature floor to the cooler lower layer above it. The floor is heated by radiation from the flames and from the hot layer. The floor in turn will heat the (cool) lower layer of gas above it by convection. This analysis uses the convection heat transfer equation. The flow above the floor may be laminar or turbulent, and the lower layer thermal conductivity and kinematic viscosity may vary with temperature. This routine requires data for the floor temperature, lower layer temperature, and floor dimensions.

\section{$\underline{\text { Output }}$}

$\phi_{£ \text { IO○I }}$ Convective heat flux from the lower layer to the floor. $\left[\mathrm{W} / \mathrm{m}^{2}\right](\mathrm{V} .12)$

Input

$\mathrm{T}_{\mathrm{D}}$

Temperature of the lower layer in the room (Calculated Value, see Hot Layer section). [K]

$T_{\text {floor }}$

Temperature of the floor in the room (Calculated Value, see Radiation Heat Transfer section). [K] $(\mathrm{V} .125)$

Dimension of the room in the $x$-direction (Input Data). [m] (V.2I) 
Ly

$\operatorname{Pr}$

g
Dimension of the room in the $y$-direction (Input Data). [m] (V.22)

PrandtI number (Input Data). (V.72)

Acceleration of gravity (Input Data). (V.144)

\section{Calculations}

$\overline{\mathrm{T}}=\left(\mathrm{T}_{\mathrm{D}}+\mathrm{T}_{\mathrm{f} 100 \mathrm{r}}\right) / 2$

$\nu=13.7\left(10^{-6}\right)\left[\frac{\overline{\mathrm{T}}}{273.16}\right]\left[\frac{392.56}{119.4+\overline{\mathrm{T}}}\right]$

$k=2.829\left(10^{-3}\right)+\left[\frac{0.26262 \overline{\mathrm{T}}}{3080+\overline{\mathrm{T}}}\right]$

$d= \begin{cases}L_{x}, & L_{x}<L_{y} \\ L_{y}, & L_{y}<L_{x}\end{cases}$

$G r=\left(9.8 d^{3} / \nu^{2}\right)\left(\left(T_{f 100 r}-T_{D}\right) / T_{D}\right)$

$\mathrm{Ra}=\operatorname{Pr} \mathrm{Gr}$

$\mathrm{Nu}= \begin{cases}0.1, & \mathrm{Ra}<1 \\ 0.6236 \mathrm{Ra}^{1 / 4}, & 1 \leq \mathrm{Ra}<4\left(10^{7}\right) \\ 0.145 \mathrm{Ra}^{1 / 3}, & \mathrm{Ra} \geq 4\left(10^{7}\right)\end{cases}$

$\overline{\mathrm{h}}=(\mathrm{kNu}) / \mathrm{d}$

$\phi_{f 100 r}=\bar{h}\left(T_{D}-T_{f 100 r}\right)$
Film temperature..

Viscosity of the film (assumed to be air).

Thermal conductivity of the film (air).

Determine the smallest dimension of the floor for use in Grashof number calculation.

Grashof number (relates buoyancy forces to viscosity forces).

Rayleigh number.

Nusselt number (relates convection to conduction).

Convective heat transfer coefficient.

Convective heat flux from the lower layer

to the floor.

$\therefore \cdot C N V F-2$ 


\section{$\underline{\text { References }}$}

1. Holman, J.P., Heat Transfer, McGraw-Hill Book Company, 1981, pp. 265 282.

Subroutine Variables

$$
\begin{aligned}
& \text { FQDFD }=\phi_{\text {floor }} \\
& Z \mathrm{KDZZ}=\mathrm{T}_{\mathrm{L}} \\
& \text { ZKFLO }=T_{f 100 r} \\
& \text { ZLRZX }=L_{X} \\
& \text { ZLRZY }=\mathrm{L}_{\mathrm{Y}} \\
& \mathrm{PR} \quad=\mathrm{Pr} \\
& \mathrm{G} \quad=\mathrm{g}
\end{aligned}
$$

Prepared by

David W. Stroup 


\section{Computer Subroutine}

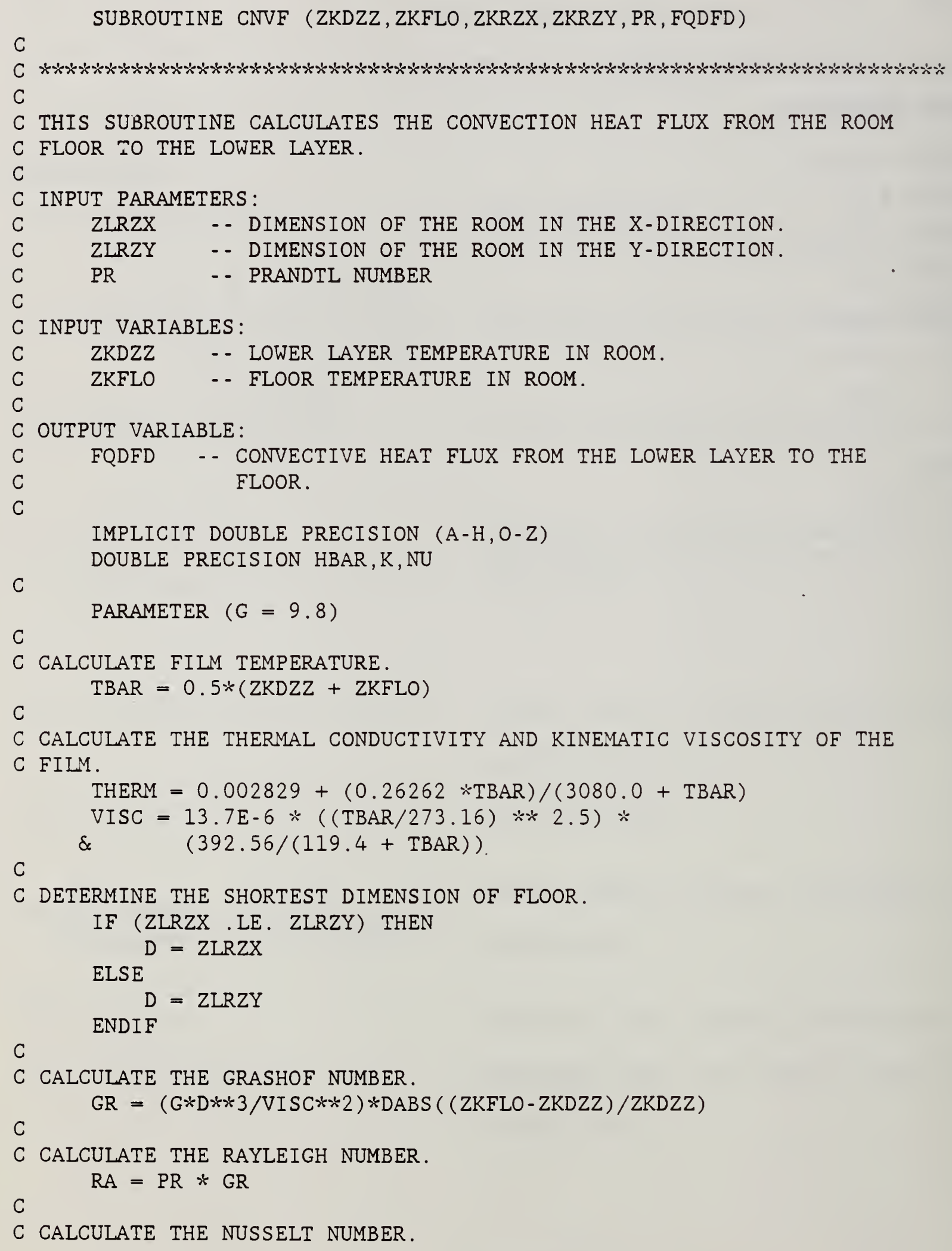


IF (RA . LT. 1.0) THEN

$\mathrm{NU}=0.1$

ELSEIF ((RA.GE. 1.0) .AND. (RA .LT. 4.0D7)) THEN

$\mathrm{NU}=0.6236 * \mathrm{RA} * *(0.25)$

ELSE

$\mathrm{NU}=0.145 * \mathrm{RA} * *(1 . / 3$.

ENDIF

C

C CALCULATE THE HEAT TRANSFER COEFFICIENT.

HBAR $=$ THERM $* N U / D$

C

C CALCULATE THE CONVECTIVE HEAT FLUX FROM THE LOWER LAYER TO THE FLOOR.

$\mathrm{FQDFD}=\mathrm{HBAR} *(\mathrm{ZKDZZ}-\mathrm{ZKFLO})$

RETURN

END 


\section{3-CNVF- 6}




\section{CNVL - Convection Heat Loss from the Hot Layer}

\section{Description}

This subroutine calculates the convective heat loss rate from the hot layer (to the extended ceiling). The hot layer is located in a room surrounded by a uniform ambient environment. The hot layer is assumed to be at a uniform temperature as are the surfaces of the walls and ceiling in contact with the hot layer. The routine also assumes only one "wall" per room, and that side two of the "wall" is in contact with the outside -. i.e., with quiescent ambient air. The decrease in wall area in contact with the hot layer due to vents is also considered in this routine.

Output

$\dot{\mathrm{E}}_{\mathrm{LD}}$

Rate of increase of the energy of the hot layer, by convection, from the walls in a room -generally negative. [W] (V.86)

Input

$\mathrm{L}_{\mathrm{x}}$

Dimension of room in $\mathrm{x}$-direction (Input Data).

[m] (V.21)

Ly

Dimension of room in $\mathrm{y}$-direction (Input Data).

[m] (V.22)

$h_{L}$

Depth of the hot layer in room (Calculated

Value, see Hot Layer section). [m] (V.20)

Net rate of change of the energy of the hot 
layer in a room (Calculated Value, see Hot Layer section). [W] (V.68)

$E_{L}$

$\dot{\mathrm{q}}_{\mathrm{L}}^{\prime \prime} W \mathrm{D}$

$\int_{0}^{t}\left(\dot{\mathrm{q}}_{\mathrm{L} W D}^{\prime \prime}+\dot{\mathrm{q}}_{\mathrm{A} W D}^{\prime \prime}\right) d t$

$\sum A_{V L}$

$\Sigma W_{\mathrm{VL}}$

\section{Calculations}

$A_{W}=2\left(L_{x}+L_{y}\right) h_{L}$

$A=A_{W}+L_{y} L_{x}-\Sigma A_{v L}$
Energy contained in the hot layer in a room

(Calculated Value, see Hot Layer section). [J]

(V.25)

Convective heat flux from the hot layer inside a room to the adjacent part of the wall/ceiling (Calculated Value, see Convection Heat Transfer section). [W/ $\left./ \mathrm{m}^{2}\right](\mathrm{V} .11)$

Total energy stored in a unit area of the hot wall due to convection (Calculated Value, see Convection Heat Transfer section). [W/ $\left.\mathrm{m}_{2}\right]$

(Sum of the) area(s) of the vent(s) covered by the hot layer (Calculated Value, see Vent section). [m] (V.5)

(Sum of the) width(s) of vent(s) which intersect the interface between the hot and cold layers (Calculated Value, see Vent section). [m] (V.141)

Area of heated (vertical) wall.

Area of heated part of wall and ceiling which is not covered by vents.

3-CNVL- 2 


$$
\dot{E}_{L D}= \begin{cases}-A \dot{q}_{L}^{\prime \prime} W D & \dot{E}_{L} E_{L}<0 \\ -A \dot{q}_{L W D}-\frac{1}{2}\left(A_{W}-h_{L} \sum W_{V L}\right)\left[\int_{0}^{t}\left(\dot{q}_{L W D}^{\prime \prime}+\dot{q}_{A W D}^{\prime \prime}\right) d t\right] \dot{E}_{L} / E_{L}, & \dot{E}_{L} E_{L} \geq 0\end{cases}
$$

\section{References}

1. Mitler, H.E., "The Physical Basis of the Harvard Computer Fire Codes," Harvard University, Home Fire Project Technical Report No. 34, October 1978, pp. $49-51$.

2. Mitler, H.E., and Emmons, H.W., "Documentation for CFC V, the Fifth Harvard Computer Fire Code," U.S. Department of Commerce, Washington, D.C., NBS-GCR-81-344, October 1981, pg. 113.

$\underline{\text { Subroutine Variables }}$

$$
\begin{array}{ll}
\text { TELZD } & =\dot{\mathrm{E}}_{\mathrm{L} D} \\
\mathrm{AQ} & =\int_{0}^{t}\left(\dot{\mathrm{q}}_{\mathrm{L} W D}^{\prime \prime}+\dot{\mathrm{q}}_{\mathrm{A} W D}^{\prime \prime}\right) \mathrm{dt} \\
\text { AVLSM } & =\sum A_{V I} \\
\text { WVLS } & =\sum \mathrm{W}_{\mathrm{V} L} \\
\text { ZLRZX } & =\mathrm{L}_{\mathrm{x}} \\
\text { ZLRZY } & =\mathrm{L}_{\mathrm{Y}} \\
\text { ZHLZZ } & =\mathrm{h}_{\mathrm{L}} \\
\text { ZELZZ } & =E_{\mathrm{L}} \\
\text { TELZZ } & =\dot{\mathrm{E}}_{\mathrm{L}} \\
\text { FQLWD } & =\dot{\mathrm{q}}_{\mathrm{L} W D}^{\prime \prime}
\end{array}
$$

Prepared by

David W. Stroup 


\section{Computer Subroutine}

SUBROUTINE CNVL (ZLRZX, ZLRZY, AQ, AVLSM, FQLWD, WVLS , TELZZ, $\&$ ZELZZ, ZHLZZ, TELZD)

$\mathrm{C}$

$\mathrm{C}$

IMPLICIT DOUBLE PRECISION (A-H,O-Z)

C

C FINDS THE RATE OF LOSS OF ENERGY FROM THE HOT LAYER IN

C A ROOM DUE TO CONVECTIVE HEATING OF THE WALLS AND CEILING.

C

C INPUT PARAMETERS:

C ZLRZX - - LENGTH OF THE ROOM ALONG THE X-AXIS.

C ZLRZY -. LENGTH OF THE ROOM ALONG THE Y-AXIS.

C

C INPUT VARIABLES:

C AQ - - CONVECTIVE ENERGY STORED IN A UNIT AREA OF HOT WALL.

C AVLSM - - TOTAL AREA OF THE VENTS COVERED BY THE HOT LAYER.

C FQLWD - - CONVECTIVE HEAT FLUX FROM THE LAYER TO THE ADJACENT

C

WVIS - - TOTAI WIDTH OF VENTS WHICH INTERSECTS THE INTERFACE BETWEEN THE HOT AND COLD LAYERS (I.E. THE AMOUNT BY WHICH THE PERIMETER OF THE WALLS IS DECREASED BY THE VENT HOLES AT THE INTERFACE.)

TELZZ - TIME RATE OF CHANGE OF TOTAL ENERGY OF THE HOT LAYER.

ZELZZ - - TOTAL ENERGY OF THE HOT LAYER.

ZHLZZ - - DEPTH OF THE HOT LAYER.

TELZD - - RATE OF CHANGE OF LAYER ENERGY DUE TO CONVECTIVE HEATING OF THE WALLS.

AWO $=2$. ODO $*($ ZLRZX + ZLRZY $) * Z H L Z Z$

$A=A W O+Z L R Z Y * Z L R Z X-A V L S M$

C

TELZD $=-A *$ FQLWD

IF ( TELZZ * ZELZZ .GT. O.DO ) THEN

ENDIF

TELZD $=$ TELZD $-0.5 \mathrm{D} 0 *($ AWO - WVLS $* Z H L Z Z) * A Q * T E L Z Z$

C

RETURN

END 
CNVW01 - Convective Heat Flux from Hot Layer to Walls and Ceiling

\section{Description}

This routine computes the convective heat transfer rate per unit area from an adjacent hot layer to one side of a wall (or ceiling). The hot lay.er is assumed to have the same temperature throughout and likewise the surface of the walls and/or ceiling are assumed to have a uniform temperature where they are in contact with the hot layer. The standard form of the convection heat transfer equation is used for these calculations. The minimum and maximum heat transfer coefficients for the hot layer gases are assumed to be known. Studies are still being conducted to determine the appropriate values for these coefficients. Reference [2] suggests values of 10 and $50 \mathrm{~W} / \mathrm{m}^{2} \mathrm{~K}$. As the fire grows, the convection currents increase, and the interior heat transfer coefficient should increase. In this routine, the increase is assumed to be linear in the difference between the layer temperature and ambient temperature over a 100 degree rise in temperature.

\section{Output}

$\dot{q}_{\mathrm{L}}^{\prime \prime} \mathrm{WD}$

Convective heat flux from the hot layer in a room to the adjacent part of the wall/ceiling. $\left[\mathrm{W} / \mathrm{m}^{2}\right](\mathrm{V} .11)$

Input

$T_{W}$ Temperature of the surface of the wall and/or ceiling (Calculated Value, see Conduction Heat Transfer section). [K] (V.126) 
$\mathrm{T}_{\mathrm{L}}$

$\mathrm{T}_{\mathrm{a}}$

b

a
Temperature of the hot layer in a room

(Calculated Value, see Hot Layer section). [m]

Temperature of ambient air (Input Data). [K]

Minimum heat transfer coefficient of hot layer gases in the room (Input Data). [W/m $]$ (V.66) Maximum heat transfer coefficient of hot layer gases in the room (Input Data). [W/m²] (V.62)

\section{Calculations}

$$
\begin{array}{ll}
h=\min \left(a,\left[b+(a-b)\left[\left(T_{L}-T_{a}\right) / 100\right]\right]\right. & \text { Inside heat transfer coefficient. } \\
\dot{q}_{L}^{\prime \prime} W D=h\left(T_{L}-T_{W}\right) & \text { Heat flux to inside wall surface. }
\end{array}
$$

\section{References}

1. Mitler, H.E., "The Physical Basis of the Harvard Computer Fire Codes," Harvard University, Home Fire Project Technical Report No. 34, pp. 48 49.

2. Mitler, H.E., and Emmons, H.W., "Documentation for CFC V, the Fifth Harvard Computer Fire Code," U.S. Department of Commerce, Washington, D.C., NBS-GCR-81-344, October 1981, pg. 112.

Subroutine Variables

$$
\begin{aligned}
\text { FQLWD } & =\dot{\mathrm{q}}_{\mathrm{L}}^{\prime \prime}{ }^{\prime} \mathrm{D} \\
\mathrm{ZKWZZ} & =\mathrm{T}_{\mathrm{W}} \\
\mathrm{ZKLZZ} & =\mathrm{T}_{\mathrm{L}} \\
\mathrm{ZKAZZ} & =\mathrm{T}_{\mathrm{a}}
\end{aligned}
$$


$\mathrm{ZOLZZ}=\mathrm{b}$

ZOLZM $=a$

Prepared by

David W. Stroup

3-CNVWO1-3 


\section{Computer Subroutine}

SUBROUTINE CNVWO1 (ZOLZM, ZOLZN, ZKLZZ, ZKAZZ, ZKWZZ, FQLWD)

C

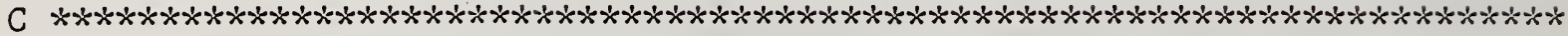

C

C CALCULATES THE CONVECTIVE HEAT TRANSFER FROM THE ADJACENT HOT LAYER

C TO ONE SIDE OF A WALL.

C

C INPUT PARAMETERS:

C ZOLZM - - MAXIMUM HEAT TRANSFER COEFFICIENT.

C ZOLZN - M MNIMUM HEAT TRANSFER COEFFICIENT.

C

C INPUT VARIABLES:

C ZKLZZ - - TEMPERATURE OF THE HOT LAYER.

C ZKAZZ - - TEMPERATURE OF AMBIENT AIR (LOWER, COOL LAYER).

C ZKWZZ - TEMPERATURE OF THE WALL ADJACENT TO THE HOT LAYER.

$\mathrm{C}$

C OUTPUT VARIABLE:

C FQLWD - CONVECTIVE HEAT FLUX TO THE HOT LAYER FROM THE C SURROUNDING WALLS.

C

IMPLICIT DOUBLE PRECISION (A-H,O-Z)

C

C

C HEAT TRANSFER COEFFICIENT.

$\mathrm{H}=$ DMIN1 ( ZOLZM, ZOLZN + (ZOLZM-ZOLZN $) *(Z K L Z Z-Z K A Z Z) / 100 . D 0)$

C

C CALCULATE THE CONVECTIVE HEAT FLUX.

C

FQLWD $=\mathrm{H} *(\mathrm{ZKLZZ}-\mathrm{ZKWZZ})$

RETURN

END 
4. ALGORITHMS RELATED TO THE HOT LAYER

$$
4-1
$$




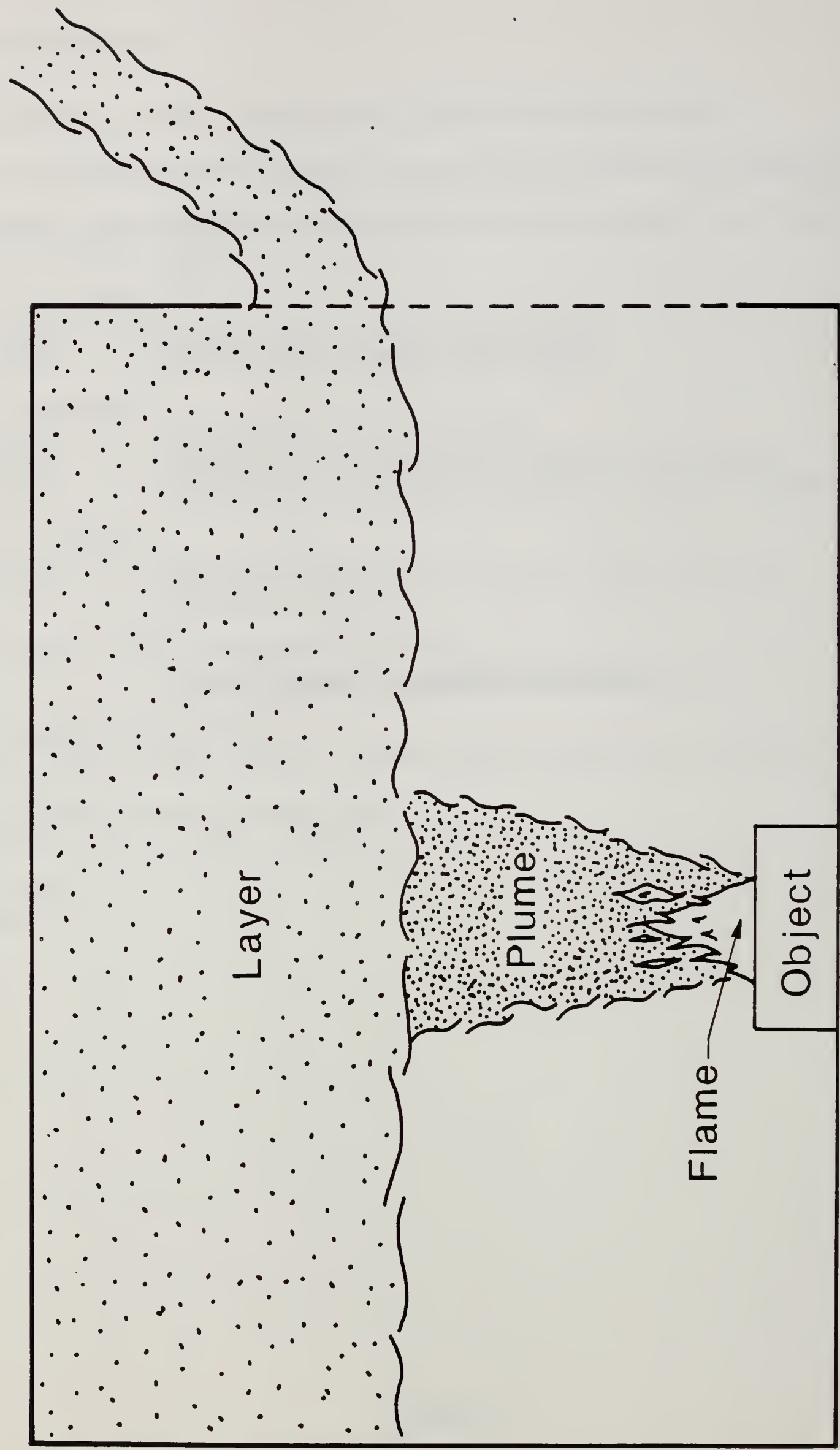




\section{ABSRB2 - Absorption Coefficient of the Hot Layer}

\section{Description}

This routine calculates the infra-red absorptivity of the hot layer. In this routine, the absorption coefficient is assumed to be gray and due mostly to the smoke concentration in the layer. Therefore, it is modeled as being a constant multiple, 265, of the fraction (by mass) of smoke (particulates, mainly $C$, and condensed hydrocarbons) in the hot layer in a room. The proportionality constant used in the equation below was obtained by comparing the infra-red absorptivity as measured in the July 6, 1977 full-scale fire test (channel 126), with the smoke fraction calculated in a standard run of NBS/Harvard 5.

\section{Output}

$\kappa$

Input

$Y_{S}$
Absorption coefficient of the hot layer in a room. $\left[\mathrm{m}^{-1}\right](\mathrm{V} .2)$

Mass fraction of soot (particulates, mainly $C$, and condensed hydrocarbons) in the hot layer in a room (Calculated Value, see Hot Layer section). [grams of soot/grams of hot layer gas] (V.44) 


\section{Calculation}

$\kappa=265 * \mathrm{Y}_{\mathrm{S}}$

\section{References}

1. Mitler, H.E. and Emmons, H.W., "Documentation for CFC V, the Fifth Harvard Fire Code," U.S. Department of Commerce, Washington, D.C., NBS-GCR-81-344, October 1981, pg. 132 .

Subroutine Variables

$$
\begin{aligned}
& \text { ZULZZ }=\kappa \\
& \text { ZYLSZ }=Y_{S}
\end{aligned}
$$

Prepared by

David W. Stroup 


\section{Computer Subroutine}

SUBROUTINE ABSRB2 (ZYLSZ, ZULZZ)

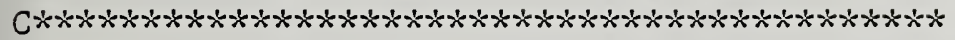

C

IMPLICIT DOUBLE PRECISION (A-H,O-Z)

C

C THIS SUBROUTINE CALCULATES THE INFRA-RED ABSORPTIVITY OF THE

C HOT LAYER. WE ASSUME THE ABSORPTION COEFFICIENT IS IN FACT GRAY,

C AND DUE MOSTLY TO THE SMOKE CONCENTRATION IN THE LAYER. THE

C PROPORTIONALITY CONSTANT USED IN THE EQUATION BELOW WAS

C OBTAINED BY COMPARING THE I.R. ABSORPTIVITY AS MEASURED IN

C THE JULY 6, 1977 FULL-SCALE FIRE TEST (SEE CHANNEL 126), WITH THE

C SMOKE FRACTION CALCULATION CALCULATED BY LAYRO3 IN A

C STANDARD RUN OF HARVARD 5.0 .

C

C INPUT VARIABLES:

C ZYLSZ - MASS FRACTION OF SMOKE IN THE HOT LAYER

C

C OUTPUT VARIABLE:

C

C

ZULZZ - INFRA-RED ABSORPTIVITY OF THE HOT LAYER

$Z U L Z Z=265 . D O * Z Y L S Z$

C LIMITS:

ZULZZ $=$ DMAX1 $(Z U L Z Z, 0.0005 \mathrm{D} 0)$

RETURN

END 
4-ABSRB $2-4$ 


\section{DXDCNC - Mass Fraction of Carbon Dioxide in Hot Layer}

\section{Description}

This routine calculates the mass fraction of carbon dioxide in the hot layer in a room. The mass fraction of carbon dioxide in the hot layer is equal to the ratio of the mass of carbon dioxide in the hot layer to the total mass of the hot layer. The initial mass fraction of carbon dioxide in the hot layer is assumed to be the same as the fraction of carbon dioxide in ambient air, i.e., 500 ppm.

\section{Output}

$\mathrm{Y}_{\mathrm{CO} 2}$ Mass fraction of carbon dioxide $\left(\mathrm{CO}_{2}\right)$ in the hot layer in a room. (V.41)

\section{Input}

$\mathrm{m}_{\mathrm{C} \bigcirc 2}$

Mass of carbon dioxide in the hot layer in the room (Calculated Value, see Hot Layer section). [kg] (V.49)

$m_{L}$ Mass of the hot layer in a room (Calculated Value, see Hot Layer section). [kg] (V.54)

\section{Calculations}

$\mathrm{Y}_{\mathrm{CO} 2}=\left\{\begin{array}{ll}\mathrm{m}_{\mathrm{CO} 2} / \mathrm{m}_{\mathrm{L}}, & \mathrm{m}_{\mathrm{CO} 2} \leq \mathrm{m}_{\mathrm{L}} \& \mathrm{~m}_{\mathrm{L}} \neq 0 \\ 0.0005, & \text { otherwise }\end{array}\right.$ Mass fraction of carbon dioxide. 


\section{$\underline{\text { References }}$}

1. Mitler, H.E. and Emmons, H.W., "Documentation for CFC V, the Fifth Harvard Fire Code," U.S. Department of Commerce, Washington, D.C., NBS-GCR-81-344, October 1981, pp. $128-131$.

\section{$\underline{\text { Subroutine Variables }}$}

$$
\begin{aligned}
& \mathrm{ZYLDZ}=\mathrm{Y}_{\mathrm{CO} 2} \\
& \mathrm{ZMDL}=\mathrm{m}_{\mathrm{CO} 2} \\
& \mathrm{ZMLZZ}=\mathrm{m}_{\mathrm{L}}
\end{aligned}
$$

\section{Prepared by}

David W. Stroup 


\section{Computer Subroutine}

SUBROUTINE DXDCNC (ZMDL, ZMLZZ, ZYLDZ)

C

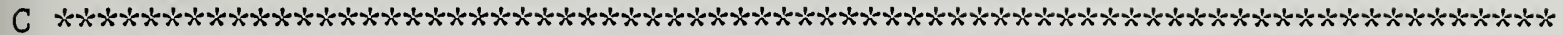
$\mathrm{C}$

C SUBROUTINE TO CALCULATE THE MASS FRACTION OF CARBON DIOXIDE

C IN THE HOT LAYER.

C

C INPUT VARIABLES:

C ZMDL - MASS OF CARBON DIOXIDE IN THE HOT LAYER.

C ZMLZZ - TOTAL MASS OF THE HOT LAYER.

C

C OUTPUT VARIABLE:

C ZYLDZ -. MASS FRACTION OF CARBON DIOXIDE IN THE

C HOT LAYER.

C

IMPLICIT DOUBLE PRECISION ( $\mathrm{A}-\mathrm{H}, \mathrm{O}-\mathrm{Z})$

PARAMETER $($ YCO2 $=5 \cdot D-4)$

IF ((ZMDL .GE. O.DO) .AND. (ZMLZZ .GT. O.DO)) THEN

IF (ZMDL . LE. ZMLZZ) THEN

ELSE

$Z Y L D Z=Z M D L / Z M L Z Z$

ZYLDZ $=$ YCO2

ENDIF

ELSE

$\mathrm{ZYLDZ}=\mathrm{YCO} 2$

ENDIF

C

RETURN

END 
4- DXDCNC - 4 


\section{LAYDPT - Depth of the Hot Layer in a Room}

\section{Description}

This routine calculates the depth of the hot layer in a room containing at least one burning object. The depth of the hot layer may be determined if the internal energy of the layer and the pressure are known. The energy contained in the upper, hot layer is a function of its mass, temperature, and heat capacity (specific heat). In this routine, the heat capacity of the hot layer is assumed to be the same as that of ambient air. Thus

$$
E_{L}=T_{L} c_{p} m_{L}
$$

The hot layer mass is equal to its volume multiplied by its density. Ignoring the small change in molecular weight due to fuel (combusted and uncombusted), the layer density is

$$
\rho=\rho_{\mathrm{a}} \mathrm{T}_{\mathrm{a}} / \mathrm{T}_{\mathrm{L}}
$$

and its mass is (assuming the room is a parallelpiped)

$$
\mathrm{m}=\rho \mathrm{L}_{\mathrm{x}} \mathrm{L}_{\mathrm{y}} \mathrm{h}_{\mathrm{L}}
$$

These three equations may be combined and solved for the depth of the hot layer:

$$
h_{L}=E_{L} /\left(L_{x} L_{y} c_{p} T_{a} \rho_{a}\right)
$$


This is the equation used to determine the depth of the hot layer.

\section{Output}

$\mathrm{h}_{\mathrm{L}}$

Depth of the hot layer in a room. [m] (V.20)

\section{Input}

$c_{p}$

Specific heat of ambient air (Input Data).

$[\mathrm{J} / \mathrm{kg}-\mathrm{K}](\mathrm{V} .112)$

$\rho_{\mathrm{a}}$

Density of ambient air (Input Data). [ $\left.\mathrm{kg} / \mathrm{m}^{3}\right]$

(V.17)

$h_{R}$

Height of the room (Input Data). [m] (V.33)

$\mathrm{T}_{\mathrm{a}}$

Ambient temperature in the room (Input Data).

[K] $(\mathrm{V} .120)$

$\mathrm{L}_{x}$

Dimension of the room in the $\mathrm{x}$-direction (Input Data). [m] (V.21)

Ly

Dimension of the room in the $\mathrm{y}$-direction (Input Data). [m] (V.22)

$E_{L}$

Energy contained in the hot layer in the room

(Calculated Value, see Hot Layer section). [J]

(V. 25)

\section{Calculation}

$h_{L}=E_{L} /\left(\begin{array}{llllll}L_{x} & L_{y} & c_{p} & T_{a} & \rho_{a}\end{array}\right)$ 


\section{$\underline{\text { References }}$}

1. Mitler, H.E., "The Physical Basis of the Harvard Computer Fire Codes," Harvard University, Home Fire Project Technical Report No. 34, pp. 51 18.

2. Mitler, H.E., and Emmons, H.W., "Documentation for CFC V, the Fifth Harvard Computer Fire Code," U.S. Department of Commerce, Washington, D.C., NBS-GCR-81-344, October 1981.

\section{Subroutine Variables}

$$
\begin{aligned}
Z H L Z Z & =h_{L} \\
C P & =c_{p} \\
\text { VMAZZ } & =\rho_{a} \\
Z H R Z Z & =h_{R} \\
Z K A Z Z & =T_{a} \\
Z L R Z X & =L_{x} \\
Z L L Z Y ~ & =L_{y} \\
Z \text { ZELZZ } & =E_{L}
\end{aligned}
$$

\section{Prepared by}

David W. Stroup 


\section{Computer Subroutine}

SUBROUTINE LAYDPT (CP , VMAZZ, ZHRZZ, ZKAZZ, ZLRZX, ZLRZY, ZELZZ, ZHLZZ)

C

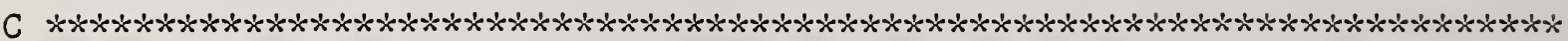

$\mathrm{C}$

C SUBROUTINE TO CALCULATE THE DEPTH OF THE LAYER IN A ROOM.

C

C INPUT PARAMETERS:

C CP - SPECIFIC HEAT OF AMBIENT AIR.

C VMAZZ - D DENSITY OF AMBIENT AIR.

C ZHRZZ - HEIGHT OF THE ROOM.

C ZKAZZ - AMBIENT TEMPERATURE IN THE ROOM.

C ZLRZX - - LENGTH OF THE ROOM ALONG THE X-AXIS.

C ZIRZY -- LENGTH OF THE ROOM ALONG THE Y-AXIS.

C

C INPUT VARIABLES:

C ZELZZ - - TOTAL ENERGY OF THE LAYER.

C

C OUTPUT VARIABLE:

C ZHLZZ - - DEPTH OF THE LAYER.

C

C

IMPLICIT DOUBLE PRECISION (A-H,O-Z)

$Z H L Z Z=Z E L Z Z /(Z L R Z X * Z L R Z Y * C P * Z K A Z Z * V M A Z Z)$

IF (ZHLZZ .GT. ZHRZZ) ZHLZZ $=$ ZHRZZ

C

RETURN

END 


\section{Description}

This routine calculates the mass fraction of carbon monoxide in the hot layer in a room. The mass fraction of carbon monoxide in the hot layer is equal to the ratio of the mass of carbon monoxide in the hot layer to the total mass of the hot layer. The mass fraction of carbon monoxide in the hot layer at the start of the fire is assumed to be zero.

\section{Output}

$Y_{C O}$ Mass fraction of carbon monoxide (CO) in the hot layer in the room. (V.40)

Input

$\mathrm{m}_{\mathrm{CO}}$ Mass of carbon monoxide in the hot layer in the room (Calculated Value, see Hot Layer section). [kg] (V.49)

$\mathrm{m}_{\mathrm{L}}$ Mass of the hot layer in the room (Calculated Value, see Hot Layer section). [kg] (V.54)

\section{Calculations}

$$
\mathrm{Y}_{\mathrm{CO}}=\left\{\begin{array}{ll}
\mathrm{m}_{\mathrm{CO}} / \mathrm{m}_{\mathrm{L}}, & \mathrm{m}_{\mathrm{CO}} \leq \mathrm{m}_{\mathrm{L}} \& \mathrm{~m}_{\mathrm{L}} \neq 0 \\
0.0, & \text { otherwise }
\end{array} \quad\right. \text { Mass fraction of carbon monoxide. }
$$




\section{References}

1. Mitler, H.E. and Emmons, H.W., "Documentation for CFC V, the Fifth Harvard Fire Code," U.S. Department of Commerce, Washington, D.C. , NBS-GCR-81-344, October 1981, pp. $128-131$.

Subroutine Variables

$$
\begin{aligned}
& Z Y L M Z=Y_{C O} \\
& Z M M L=m_{C O} \\
& Z M L Z Z=m_{L}
\end{aligned}
$$

\section{Prepared by}

David W. Stroup 


\section{Computer Subroutine}

SUBROUTINE MNXCNC (ZMML, ZMLZZ, ZYLMZ)

$\mathrm{C}$

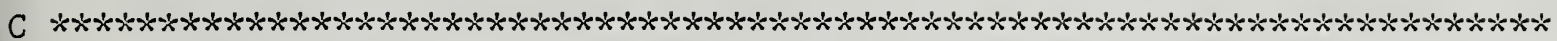

C

C SUBROUTINE TO CALCULATE THE MASS FRACTION OF CARBON MONOXIDE

C IN THE HOT LAYER.

$\mathrm{C}$

INPUT VARIABLES:

C ZMML - MASS OF CARBON MONOXIDE IN THE HOT LAYER.

C ZMLZZ - - TOTAL MASS OF THE HOT LAYER.

$\mathrm{C}$

C OUTPUT VARIABLE:

ZYLMZ - MASS FRACTION OF CARBON MONOXIDE IN THE HOT LAYER.

IMPLICIT DOUBLE PRECISION (A-H,O-Z)

PARAMETER $(Y C O=0 . D O)$

IF ((ZMML .GE. O.DO) .AND. (ZMLZZ .GT. O.DO)) THEN

IF (ZMML . LE. ZMLZZ) THEN $Z Y L M Z=Z M M L / Z M L Z Z$

ELSE

ENDIF

$Z Y L M Z=Y C O$

ELSE

$Z Y L M Z=Y C O$

ENDIF

C

RETURN

END 
4-MNXCNC - 4 


\section{OXYCNC - Mass Fraction of Oxygen in Hot Layer}

\section{Description}

This routine calculates the mass fraction of oxygen in the hot layer in a room. The mass fraction of oxygen in the hot layer is equal to the ratio of the mass of oxygen in the hot layer to the total mass of the hot layer. The initial mass fraction of oxygen in the hot layer is assumed to be the same as the fraction of oxygen in ambient air $(0.2318)$.

\section{Output}

$\mathrm{Y}_{\mathrm{O} 2}$ Mass fraction of oxygen $\left(\mathrm{O}_{2}\right)$ in the hot layer in the room. (V.43)

Input

$\mathrm{m}_{02}$

Mass of oxygen in the hot layer in the room (Calculated Value, see Hot Layer section). [kg] $(\mathrm{V} .52)$

$\mathrm{m}_{\mathrm{Z}}$ Mass of the hot layer in the room (Calculated Value, see Hot Layer section). [kg] (V.54)

\section{Calculations}

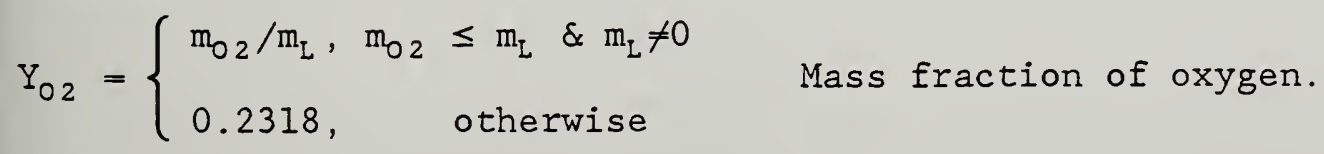




\section{References}

1. Mitler, H.E. and Emmons, H.W., "Documentation for CFC V, the Fifth Harvard Fire Code," U.S. Department of Commerce, Washington, D.C., NBS-GCR-81-344, October 1981, pp. $128-131$.

Subroutine Variables

$$
\begin{aligned}
& \mathrm{ZYLOZ}=\mathrm{Y}_{\mathrm{O} 2} \\
& \mathrm{ZMOL}=\mathrm{m}_{\mathrm{O} 2} \\
& \mathrm{ZMLZZ}=\mathrm{m}_{\mathrm{L}}
\end{aligned}
$$

\section{Prepared by}

David W. Stroup 


\section{Computer Subroutine}

SUBROUTINE OXYCNC (ZMOL, ZMLZZ, ZYLOZ)

C

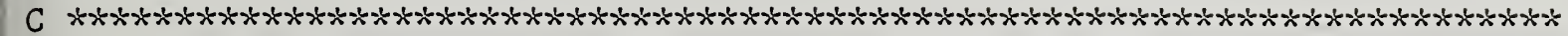
C

C SUBROUTINE TO CALCULATE THE MASS FRACTION OF OXYGEN IN THE C HOT LAYER.

C

C INPUT VARIABLES:

C ZMOL -- MASS OF OXYGEN THE HOT LAYER.

C ZMLZZ - TOTAL MASS OF THE HOT LAYER.

C

C OUTPUT VARIABLE:

C ZYLOZ - - MASS FRACTION OF OXYGEN IN THE HOT LAYER.

$\mathrm{C}$

IMPLICIT DOUBLE PRECISION (A-H,O-Z)

C

PARAMETER $($ YO2 $=.2318 \mathrm{DO})$

IF ((ZMOL .GE. O.DO) .AND. (ZMLZZ .GT. O.DO)) THEN IF (ZMOL . LE. ZMLZZ) THEN

$Z Y L O Z=Z M O L / Z M L Z Z$

ELSE

$\mathrm{ZYLOZ}=\mathrm{YO2}$

ELSE ENDIF

ZYLOZ $=0 . D O$

ENDIF

C

RETURN

END 
4-OXYCNC - 4 


\section{POWL - Rate of Change of the Energy in the Hot Layer}

\section{Description}

The routine calculates the rate of change of the energy contained in the hot layer. The rate of change of the energy in the layer in a room is a function of the rate of convective heat transfer to the hot layer from the walls in the room, rate of radiative heat transfer to the layer from all sources, the total convective energy output of the plumes in the room, and the total convective outflow through the vents in the room from the layer.

\section{Output}

$\dot{\mathrm{E}}_{\mathrm{L}}$ Total rate of change of internal energy of the hot layer in the room. [W] (V.68)

\section{Input}

$\dot{E}_{i D}$

Rate of increase of energy of the hot layer by convection from the walls in the room -generally negative (Calculated Value, see Convection Heat Transfer section). [W] (V.89)

$\dot{\mathrm{E}}_{\mathrm{LR}}$ Rate of change of energy in the hot layer by radiation from all hot sources in the room (Calculated Value, see Radiation Heat Transfer section). [W] (V.86)

$\Sigma \dot{E}_{p}$ (Sum of the) convective enthalpy flows out the top of the plumes in the room into the hot layer (Calculated Value, see Plume section). [W] (V.9) 
$\Sigma \dot{\mathrm{E}}_{\mathrm{v}}$ (Sum of the) convective enthalpy outflow from the hot layer through the vents in the room (Calculated Value, see Vent section). [W] (V.10)

\section{Calculation}

$$
\dot{\mathrm{E}}_{\mathrm{L}}=\cdot \Sigma \dot{\mathrm{E}}_{\mathrm{p}}-\Sigma \dot{\mathrm{E}}_{\mathrm{V}}+\dot{\mathrm{E}}_{\mathrm{LD}}+\dot{\mathrm{E}}_{\mathrm{L} R}
$$

\section{References}

1. Mitler, H.E., "The Physical Basis of the Harvard Computer Fire Codes," Harvard University, Home Fire Project Technical Report No. 34, pg. 17.

2. Mitler, H.E., and Emmons, H.W., "Documentation for CFC V, the Fifth Harvard Computer Fire Code," U.S. Department of Commerce, Washington, D.C., NBS-GCR-81-344, October 1981, pp. 128 - 131.

\section{Subroutine Variables}

$$
\begin{aligned}
\text { TELZZ } & =\dot{\mathrm{E}}_{\mathrm{L}} \\
\text { TELZD } & =\dot{\mathrm{E}}_{\mathrm{LD}} \\
\text { TELZR } & =\dot{\mathrm{Q}} \\
\text { TEPSM } & =\Sigma \dot{\mathrm{E}}_{\mathrm{p}} \\
\text { TEUSM } & =\Sigma \dot{\mathrm{E}}_{\mathrm{V}}
\end{aligned}
$$

\section{Prepared by}

David W. Stroup 


\section{Computer Subroutine}

SUBROUTINE POWL (TELZD, TELZR, TEPSM, TEUSM, TELZZ)

C

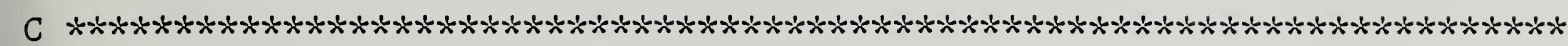

C

C SUBROUTINE TO CALCULATE THE RATE OF CHANGE OF THE ENERGY OF THE HOT

C LAYER.

C

C INPUT VARIABLES :

C TELZD - RATE OF CONVECTIVE HEAT TRANSFER TO THE HOT LAYER

C FROM THE WALLS IN THE SAME ROOM.

C TELZR - RATE OF RADIATIVE HEAT TRANSFER TO THE HOT LAYER

C FROM ALL HOT SOURCES IN THE SAME ROOM.

C TEPSM - TOTAL CONVECTIVE ENERGY OUTPUT OF THE PLUMES IN

C THE ROOM.

C TEUSM - TOTAL CONVECTIVE ENERGY OUTFLOW THROUGH THE VENTS

C IN THE ROOM FROM THE HOT LAYER.

$\mathrm{C}$

C OUTPUT VARIABLE:

C TELZZ - RATE OF INCREASE OF ENERGY OF THE LAYER.

C

IMPLICIT DOUBLE PRECISION (A-H,O-Z)

TELZZ $=$ TEPSM - TEUSM + TELZD + TELZR

RETURN

END 


$$
\text { 4-POWL- } 4
$$




\section{SUTCNC - Mass Fraction of Soot in Hot Layer}

\section{Description}

This routine calculates the mass fraction of soot in the hot layer in a room. The mass fraction of soot in the hot layer is equal to the ratio of the mass of soot in the hot layer to the total mass of the hot layer. The mass fraction of soot in the hot layer at the start of the fire is assumed to be zero.

\section{Output}

$Y_{S}$ Mass fraction of soot in the hot layer in the room. (V.44)

Input

$\mathrm{m}_{\mathrm{S}}$

Mass of soot in the hot layer in the room (Calculated Value, see Hot Layer section). [kg]

$\mathrm{m}_{\mathrm{L}}$ Mass of the hot layer in the room (Calculated Value, see Hot Layer section). [kg] (V.54)

\section{Calculations}

$$
Y_{S}=\left\{\begin{array}{ll}
m_{S} / m_{L}, & m_{S} \leq m_{L} \& m_{L} \neq 0 \\
0.0, & \text { otherwise }
\end{array} \quad\right. \text { Mass fraction of soot. }
$$




\section{$\underline{\text { References }}$}

1. Mitler, H.E. and Emmons, H.W., "Documentation for CFC V, the Fifth Harvard Fire Code," U.S. Department of Commerce, Washington, D.C., NBS-GCR-81-344, October 1981, pp. $128-131$.

Subroutine Variables

$$
\begin{aligned}
& Z Y L S Z=Y_{S} \\
& Z M S L=m_{S} \\
& Z M L Z Z=m_{L}
\end{aligned}
$$

\section{Prepared by}

David W. Stroup 


\section{Computer Subroutine}

SUBROUTINE SUTCNC (ZMSL,ZMLZZ,ZYLSZ)

C

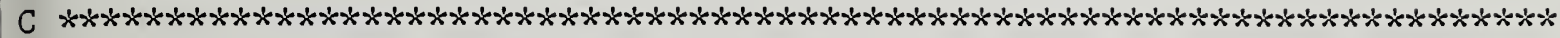
C

C SUBROUTINE TO CALCULATE THE MASS FRACTION OF SOOT IN THE

C HOT LAYER.

C

C INPUT VARIABLES:

C ZMSL -- MASS OF SOOT IN THE HOT LAYER.

C ZMLZZ -- TOTAL MASS OF THE HOT LAYER.

C

C OUTPUT VARIABLE:

C ZYLSZ - MASS FRACTION OF SOOT IN THE HOT LAYER.

C

IMPLICIT DOUBLE PRECISION (A-H,O-Z)

PARAMETER ( $Y S=0 . D 0)$

IF ((ZMSL .GE. O.DO) .AND. (ZMLZZ .GT. O.DO)) THEN IF (ZMSL .LE. ZMLZZ) THEN

$Z Y L S Z=Z M S L / Z M L Z Z$

ELSE

$\mathrm{ZYLSZ}=\mathrm{YS}$

ELSE ENDIF

ZYLSZ $=0 . \mathrm{DO}$

ENDIF

C

RETURN

END 
4-SUTCNC - 4 
TCO2M - Rate of Change of Mass of Carbon Dioxide in the Hot Layer

\section{Description}

This routine calculates the rate of increase of carbon dioxide in the hot layer. The upper layer gains carbon dioxide from entrainment of ambient air into the plume and from production by burning objects. The layer loses carbon dioxide through flow of gases out the vents in the room. A mass balance relating the rates of gain and loss of carbon dioxide in the layer provides the equation necessary for this algorithm.

\section{Output}

$\dot{\mathrm{m}}_{\mathrm{CO} 2}$

Rate of increase of mass of carbon dioxide in the hot layer. [ $\mathrm{kg} / \mathrm{s}](\mathrm{V} .90)$

\section{Input}

$\sum \dot{\mathrm{m}} \stackrel{\mathrm{P}}{\mathrm{P} O \mathrm{od}} \mathrm{d}$

(Sum of the) mass rates of evolution of carbon

dioxide from all objects (Calculated Value, see Burning Object section). [ $\mathrm{kg} / \mathrm{s}]$ (V.56)

$\Sigma \dot{\mathrm{m}}_{\mathrm{f}}$ (Sum of the) (negative of the) mass pyrolysis rates of all objects in the room (Calculated Value, see Burning Object section). [ $\mathrm{kg} / \mathrm{s}]$

$\Sigma \dot{\mathrm{m}}_{\mathrm{p}}$ (Sum of the) rate(s) at which the plume(s) above burning objects in the room add mass to the hot layer (Calculated Value, see Hot Layer section). $[\mathrm{kg} / \mathrm{s}] \quad(\mathrm{V} .97)$ 


\section{Calculation}

$$
\dot{\mathrm{m}}_{\mathrm{CO2}}=0.0005\left(\Sigma \dot{\mathrm{m}}_{\mathrm{p}}+\dot{\mathrm{m}}_{\mathrm{f}}\right)+\Sigma \dot{\mathrm{m}}_{\mathrm{C} 02}^{\mathrm{rod}}-\Sigma \dot{\mathrm{m}}_{\mathrm{CO} 2}^{\mathrm{vent}}
$$

\section{References}

1. Mitler, H.E., "The Physical Basis of the Harvard Computer Fire Codes," Harvard University, Home Fire Project Technical Report No. 34, pp. 16 17.

2. Mitler, H.E., and Emmons, H.W., "Documentation for CFC V, the Fifth Harvard Computer Fire Code," U.S. Department of Commerce, Washington, D.C., NBS-GCR-81-344, October 1981, pp $128-131$.

\section{Subroutine Variables}

$$
\begin{aligned}
& \text { TMDL }=\dot{\mathrm{m}}_{\mathrm{CO2}} \\
& \text { TMODS }=\Sigma \dot{\mathrm{m}}_{\mathrm{CO} 2 \mathrm{~d}}^{\mathrm{p} O \mathrm{~d}} \\
& \text { TMOSM }=\Sigma \dot{\mathrm{m}}_{\mathrm{f}} \\
& \text { TMPSM }=\Sigma \dot{\mathrm{m}}_{\mathrm{p}} \\
& \text { TMDZF }=\Sigma \dot{\mathrm{m}}_{\mathrm{CO2} 2 \mathrm{nt}}^{\mathrm{v}}
\end{aligned}
$$

\section{Prepared by}

David W. Stroup 


\section{Computer Subroutine}

SUBROUTINE TCO2M (TMODS, TMOSM, TMPSM, TMDZF, TMDL)

C

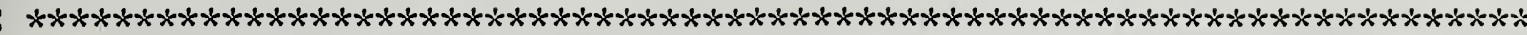

$\mathrm{C}$

C SUBROUTINE TO CALCULATE THE RATE OF CHANGE OF MASS OF CARBON

C DIOXIDE IN THE HOT LAYER.

C

$C$ INPUT PARAMETERS :

C YCO2 - MASS FRACTION OF CARBON DIOXIDE IN AMBIENT AIR.

C

C INPUT VARIABLES :

TMODS -.

RATE AT WHICH THE OBJECTS IN A ROOM PRODUCE CARBON DIOXIDE.

TMOSM - - NEGATIVE OF THE SUM OF THE MASS PYROLYSIS RATES OF ALL OBJECTS IN THE ROOM.

TMPSM - RATE AT WHICH THE PLUMES OVER ALL THE OBJECTS IN THE ROOM ADD MASS TO THE HOT LAYER.

TMDZF - - RATE AT WHICH CARBON DIOXIDE FLOWS OUT OF THE ROOM THROUGH ALL THE VENTS IN THE ROOM.

C OUTPUT VARIABLE:

C TMDL - R RATE OF INCREASE OF MASS OF CARBON DIOXIDE

C IN THE LAYER.

C

IMPLICIT DOUBLE PRECISION (A-H,O-Z)

PARAMETER $($ YCO2 $=5 \cdot D-4)$

TMDL $=$ YCO2 $*($ TMPSM + TMOSM $)+$ TMODS -TMDZF

RETURN

END 
$4-\mathrm{TCO} 2 \mathrm{M}-4$ 


\section{Description.}

This routine calculates the rate of increase of water vapor in the hot layer. The upper layer gains water vapor from the burning of hydrogencontaining fuels, hydrocarbons in particular. The layer loses water vapor through the flow of hot gases out the vents in the room. A mass balance including the rates of gain and loss of water vapor in the layer yields the rate of change.

Output

$\dot{\mathrm{m}}_{\mathrm{B} 20}$

Rate of increase of mass of water vapor in the hot layer. [ kg/s] (V.95)

\section{Input}

$\Sigma \dot{m}$ m $20 d$

(Sum of the) mass rates of evolution of water vapor from all objects (Calculated Value, see Burning Object section). [kg/s] (V.59)

$\sum \dot{\mathrm{m}}_{\mathrm{H} 20}^{\mathrm{v}} \mathrm{n}^{\mathrm{t}}$ (Sum of the) rates at which water vapor flows out through all vents in the room (Calculated Value, see Vents section). [kg/s] (V.102) 


\section{Calculation}

$$
\dot{\mathrm{m}}_{\mathrm{H} 2 \mathrm{O}}=\Sigma \dot{\mathrm{m}}_{\mathrm{H} 2 \mathrm{O} O \mathrm{~d}}^{\mathrm{p}}-\Sigma \dot{\mathrm{m}}_{\mathrm{H} 2 \mathrm{O}}^{\mathrm{vent}}
$$

\section{$\underline{\text { References }}$}

1. Mitler, H.E., "The Physical Basis of the Harvard Computer Fire Codes," Harvard University, Home Fire Project Technical Report No. 34, pp. 16 17.

2. Mitler, H.E., and Emmons, H.W., "Documentation for CFC V, the Fifth Harvard Computer Fire Code," U.S. Department of Commerce, Washington, D.C., NBS-GCR-81-344, October 1981, pp $128-131$.

\section{Subroutine Variables}

$$
\begin{aligned}
\text { TMWL } & =\dot{\mathrm{m}}_{\mathrm{H} 20} \\
\text { TMOWS } & =\Sigma \dot{\mathrm{m}}_{\mathrm{H} 20 \mathrm{~d}}^{\mathrm{r} o \mathrm{~d}} \\
\text { TMWZF } & =\Sigma \dot{\mathrm{m}}_{\mathrm{H} 20}^{\mathrm{v} 2 \mathrm{nt}}
\end{aligned}
$$

\section{Prepared by}

David W. Stroup 
4-TH2OM- 4 
TMNXM - Rate of Change of Mass of Carbon Monoxide in the Hot Layer

\section{Description}

This routine calculates the rate of increase of carbon monoxide in the hot layer. The upper layer gains carbon monoxide from production by burning objects. The layer loses carbon monoxide through the flow of hot gases out the vents in the room. The rate of change is found from a mass balance.

\section{Output}

$\dot{\mathrm{m}}_{\mathrm{CO}}$

Rate of increase of mass of carbon monoxide in the hot layer. $[\mathrm{kg} / \mathrm{s}](\mathrm{V} .91)$

Input

$\Sigma \dot{m} \underset{c}{p}{ }_{0}^{\circ o d}$

(Sum of the) mass rates of evolution of carbon monoxide from all objects (Calculated Value, see Burning Object section). [ $\mathrm{kg} / \mathrm{s}]$ (V.57)

$\Sigma \dot{m}_{\text {vent }}$ (Sum of the) rates at which carbon monoxide flows out through all vents in the room (Calculated Value, see Vents section). [ $\mathrm{kg} / \mathrm{s}]$ (V.99) 


\section{Calculation}

$$
\dot{\mathrm{m}}_{\mathrm{Co}}=\Sigma \dot{\mathrm{m}}_{\mathrm{C} O}^{\mathrm{rod}}-\Sigma \dot{\mathrm{m}}_{\mathrm{Co}}^{\mathrm{vent}}
$$

\section{$\underline{\text { References }}$}

1. Mitler, H.E., "The Physical Basis of the Harvard Computer Fire Codes," Harvard University, Home Fire Project Technical Report No. 34, pp. 16 17.

2. Mitler, H.E., and Emmons, H.W., "Documentation for CFC V, the Fifth Harvard Computer Fire Code," U.S. Department of Commerce, Washington, D.C., NBS-GCR-81-344, October 1981, pp $128-131$.

Subroutine Variables

$$
\begin{aligned}
\text { TMML } & =\dot{\mathrm{m}}_{\mathrm{CO}} \\
\text { TMOMS } & =\sum \dot{\mathrm{m}}_{\mathrm{C}}^{\mathrm{p}} \mathrm{rod} \\
\text { TMMZF } & =\sum \dot{\mathrm{m}}_{\mathrm{C}}^{\mathrm{v}} \mathrm{nt}
\end{aligned}
$$

\section{Prepared by}

David W. Stroup 


\section{Computer Subroutine}

SUBROUTINE TMNXM (TMOMS, TMMZF, TMML)

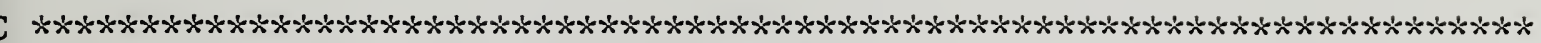
C

C SUBROUTINE TO CALCULATE THE RATE OF INCREASE OF MASS OF CARBON C MONOXIDE IN THE HOT LAYER.

$\mathrm{C}$

C INPUT VARIABLES:

C TMOMS - TOTAL RATE AT WHICH OBJECTS IN THE ROOM PRODUCE

C CARBON MONOXIDE.

C TMMZF - RATE OF MASS OUTFLOW OF CARBON MONOXIDE THROUGH ALL C THE VENTS IN THE ROOM.

$\mathrm{C}$

C OUTPUT VARIABLE:

C TMML $\quad-$ RATE OF INCREASE OF MASS OF CARBON MONOXIDE IN THE C HOT LAYER.

C

IMPLICIT DOUBLE PRECISION (A-H,O-Z)

TMML $=$ TMOMS - TMMZF

RETURN

END 
4- TMNXM - 4 
TMPL - Temperature of the Hot Layer

\section{Description}

This routine calculates the temperature of the hot upper layer in a room with a fire. The energy contained in the upper layer at any given time is a function of the layer mass, the layer temperature, and the specific heat (or heat capacity). If the layer mass and energy content are known, the layer temperature may be calculated. The layer specific heat is assumed to be the same as that of ambient air at $25^{\circ} \mathrm{C}$.

\section{Output}

$\mathrm{T}_{\mathrm{L}}$

Temperature of the hot layer in the room. [K] (V. 127)

\section{Input}

$\mathrm{T}_{\mathrm{a}}$

Temperature of ambient air (Input Data). [K]

$c_{p}$

Specific heat of ambient air (Input Data).

$[\mathrm{J} / \mathrm{kg}-\mathrm{K}](\mathrm{V} .112)$

$E_{L}$

Energy contained in the hot layer in the room (Calculated Value, see Hot Layer section). [J] (V.25)

$\mathrm{m}_{\mathrm{L}}$

Mass of the hot layer in the room (Calculated

Value, see Hot Layer section). [kg] (V.54) 
Calculation

$$
T_{L}= \begin{cases}E_{L} /\left(c_{p} m_{L}\right), & m_{L} \neq 0 \\ T_{a}, & m_{L}=0\end{cases}
$$

\section{References}

1. Mitler, H.E., "The Physical Basis of the Harvard Computer Fire Codes," Harvard University, Home Fire Project Technical Report No. 34, pg. 18.

2. Mitler, H.E., and Emmons, H.W., "Documentation for CFC V, the Fifth Harvard Computer Fire Code," U.S. Department of Commerce, Washington, D.C., NBS-GCR-81-344, October 1981, pp $128-131$.

Subroutine Variables

$$
\begin{aligned}
& \mathrm{ZKLZZ}=T_{\mathrm{L}} \\
& Z \mathrm{KAZZ}=\mathrm{T}_{\mathrm{a}} \\
& \mathrm{CP}=\mathrm{c}_{p} \\
& \mathrm{ZELZZ}=\mathrm{E}_{\mathrm{L}} \\
& \mathrm{ZMLZZ}=\mathrm{m}_{\mathrm{L}}
\end{aligned}
$$

\section{Prepared by}

David W. Stroup 


\section{Computer Subroutine}

SUBROUTINE TMPL (ZKAZZ, CP , ZELZZ, ZMLZZ, ZKLZZ)

C

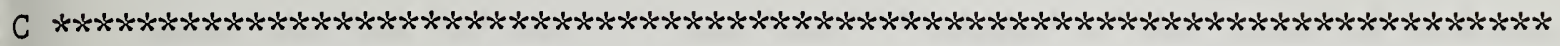
C

C SUBROUTINE TO CALCULATE THE TEMPERATURE OF THE HOT LAYER IN A ROOM.

C

C INPUT PARAMETERS:

C ZKAZZ - - AMBIENT TEMPERATURE IN THE ROOM.

C CP - S SPECIFIC HEAT OF AIR.

C

C INPUT VARIABLES:

C ZELZZ - ENERGY CONTAINED IN THE LAYER.

C ZMLZZ -- MASS OF THE LAYER.

$\mathrm{C}$

C OUTPUT VARIABLE:

C ZKLZZ - T TEMPERATURE OF THE LAYER.

C

IMPLICIT DOUBLE PRECISION (A-H,O-Z)

C

IF (ZMLZZ .EQ. O.DO) THEN

$$
Z K L Z Z=Z K A Z Z
$$

ELSE

$Z \mathrm{KLZZ}=\mathrm{ZELZZ} /(\mathrm{CP} * \mathrm{ZMLZZ})$

ENDIF

C

RETURN

END 
4 - TMPL- 4 


\section{TMSL - Rate of Change of Mass of the Hot Layer}

\section{Description}

This routine calculates the rate of change of the mass of the hot layer. The upper layer gains mass from the plumes above the burning objects in a room while losing mass through flow of hot gases out vents in the room. A mass balance relating the gain and loss of mass in the layer to the rate of change provides the equation necessary for this algorithm.

\section{Output}

$\mathrm{m}_{\mathrm{L}}$

Rate of increase of mass of the hot layer in the room. $[\mathrm{kg} / \mathrm{s}](\mathrm{V} .93)$

Input

$\Sigma \dot{\mathrm{m}}_{\mathrm{p}}$ (Sum of the) rates at which the plumes over the objects in the room add mass to the hot layer (Calculated Value, see Plume section). [ $\mathrm{kg} / \mathrm{s}]$ $(\mathrm{V} .97)$

$\Sigma \dot{\mathrm{m}}_{\mathrm{v}}$ (Sum of the) rates of mass outflow from the hot layer through all the vents in the room (Calculated Value, see Vent section). [kg/s] (V.106) 
Calculation

$$
\dot{\mathrm{m}}_{\mathrm{L}}=\Sigma \dot{\mathrm{m}}_{\mathrm{p}}-\Sigma \dot{\mathrm{m}}_{\mathrm{v}}
$$

\section{References}

1. Mitler, H.E., "The Physical Basis of the Harvard Computer Fire Codes," Harvard University, Home Fire Project Technical Report No. 34 , pp. 16 17.

2. Mitler, H.E., and Emmons, H.W., "Documentation for CFC V, the Fifth Harvard Computer Fire Code," U.S. Department of Commerce, Washington, D.C., NBS-GCR-81-344, October 1981, pp 128 - 131.

\section{Subroutine Variables}

$$
\begin{aligned}
& \text { TMLZZ }=\dot{\mathrm{m}}_{\mathrm{L}} \\
& \text { TMPSM }=\Sigma \dot{\mathrm{m}}_{\mathrm{p}} \\
& \text { TMUSM }=\Sigma \dot{\mathrm{m}}_{\mathrm{v}}
\end{aligned}
$$

\section{Prepared by}

David W. Stroup 


\section{Computer Subroutine}

SUBROUTINE TMSL (TMPSM, TMUSM, TMLZZ)

$\mathrm{C}$

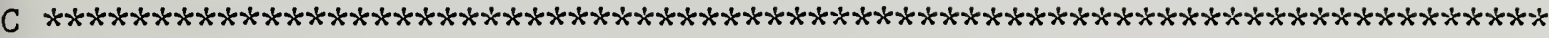

C

C SUBROUTINE TO CALCULATE THE RATE OF CHANGE OF MASS OF THE HOT LAYER.

C

C INPUT VARIABLES:

C TMPSM - - TOTAL MASS OUTFLOW FROM THE PLUMES IN THE ROOM

C INTO THE HOT LAYER.

C TMUSM -- TOTAL MASS OUTFLOW FROM THE HOT LAYER THROUGH ALL

C THE VENTS IN THE ROOM.

C

C OUTPUT VARIABLE:

C TMLZZ - RATE OF CHANGE OF MASS OF THE LAYER.

C

IMPLICIT DOUBLE PRECISION (A-H,O-Z)

TMLZZ $=$ TMPSM - TMUSM

RETURN

END 
4-TMSL- 4 


\section{TOXYM - Rate of Change of Mass of Oxygen in the Hot Layer}

\section{Description}

This routine calculates the rate of increase of oxygen in the hot layer. The upper layer gains oxygen from entrainment of ambient air into the plume, which then "delivers whatever oxygen remains after combustion, to the hot layer. The layer loses oxygen through flow of hot gases out the vents of the room. The rate of change is found via a mass balance.

\section{Output}

$\dot{\mathrm{m}}_{\mathrm{L} O 2}$

Rate of increase of mass of oxygen in the hot layer. [kg/s] (V.94)

Input

$\sum \dot{\mathrm{m}}_{\mathrm{O}}^{\mathrm{u}} \mathrm{s}$ e

(Sum of the) rates at which the objects in the room burn oxygen (Calculated Value, see Hot

Layer section). [ $\mathrm{kg} / \mathrm{s}](\mathrm{V} .103)$

$\Sigma \dot{\mathrm{m}}_{f}$

(Sum of the) (negative of the) mass pyrolysis rates of all objects in the room (Calculated

Value, see Burning Object section). [ $\mathrm{kg} / \mathrm{s}]$

$\Sigma \dot{\mathrm{m}}_{\mathrm{p}}$

(Sum of the) rates at which the plumes over all objects in the room add mass to the hot layer (Calculated Value, see Hot Layer section).

$[\mathrm{kg} / \mathrm{s}](\mathrm{V} .97)$ 


\section{Calculation}

$$
\dot{\mathrm{m}}_{\mathrm{L} 02}=0.2318\left(\Sigma \dot{\mathrm{m}}_{\mathrm{p}}+\Sigma \dot{\mathrm{m}}_{\mathrm{f}}\right)-\Sigma \dot{\mathrm{m}}_{\mathrm{O} 2}^{\mathrm{s}} \mathrm{e}-\Sigma \dot{\mathrm{m}}_{\mathrm{O} 2}^{\mathrm{e}} \mathrm{nt}
$$

\section{References}

1. Mitler, H.E., "The Physical Basis of the Harvard Computer Fire Codes," Harvard University, Home Fire Project Technical Report No. 34, pp. 16 17.

2. Mitler, H.E., and Emmons, H.W., "Documentation for CFC V, the Fifth Harvard Computer Fire Code," U.S. Department of Commerce, Washington, D.C., NBS-GCR-81-344, October 1981, pp $128-131$.

\section{Subroutine Variables}

$$
\begin{aligned}
& \text { TMOL }=\dot{\mathrm{m}}_{\mathrm{L} 02} \\
& \text { BOXYS }=\Sigma \dot{\mathrm{m}}_{2}^{\mathrm{u} s e} \\
& \text { TMOSM }=\Sigma \dot{\mathrm{m}}_{\mathrm{f}} \\
& \text { TMPSM }=\Sigma \dot{\mathrm{m}}_{\mathrm{p}} \\
& \text { TMOZF }=\Sigma \dot{\mathrm{m}}_{\mathrm{O} 2}^{\text {vent }}
\end{aligned}
$$

\section{Prepared by}

David W. Stroup 


\section{Computer Subroutine}

SUBROUT INE TOXYM (BOXYS, TMOSM, TMPSM, TMOZF, TMOL)

$\mathrm{C}$

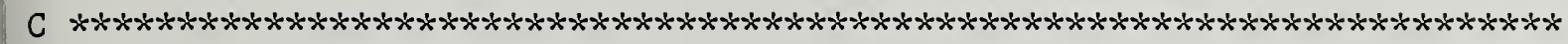
C

C SUBROUTINE TO CALCULATE THE RATE OF CHANGE OF MASS OF OXYGEN IN

C THE HOT LAYER.

C

C INPUT PARAMETERS:

C YO2 -- MASS FRACTION OF OXYGEN IN THE AMBIENT AIR.

C

C INPUT VARIABLES:

C BOXYS - - RATE AT WHICH ALL OBJECTS IN THE ROOM BURN OXYGEN.

C TMOSM - - NEGATIVE OF THE SUM OF THE MASS PYROLYSIS RATES

C OF ALI OBJECTS IN THE ROOM.

C TMPSM -- RATE AT WHICH THE PLUMES OVER ALL THE OBJECTS IN

C THE ROOM ADD MASS TO THE HOT LAYER.

C TMOZF - MASS RATE OF OUTFLOW OF OXYGEN FROM THE HOT LAYER

C

$\mathrm{C}$

C OUTPUT VARIABLE:

C TMOL -. RATE OF INCREASE OF MASS OF OXYGEN IN THE LAYER.

C

IMPLICIT DOUBLE PRECISION (A-H,O-Z)

C

PARAMETER $($ YO2 $=.2318 \mathrm{DO})$

TMOL $=$ YO2 $*($ TMPSM + TMOSM $)-$ BOXYS - TMOZF

RETURN

END 
4-TOXYM - 4 
TSUTM - Rate of Change of Mass of Soot in the Hot Layer

\section{Description}

This routine calculates the rate of increase of soot in the hot layer. The upper layer gains soot from production by burning objects. The layer loses soot through flow of hot gases out the vents in the room. The rate of change is found via a mass balance.

\section{$\underline{\text { Output }}$}

$\dot{\mathrm{m}}_{\mathrm{SOOT}}$

Rate of increase of mass of soot in the hot layer. [ $\mathrm{kg} / \mathrm{s}](\mathrm{V} .92)$

$\underline{\text { Input }}$

$\sum \dot{m}$ S rood

(Sum of the) mass rates of evolution of soot from all objects (Calculated Value, see Burning Object section). [ $\mathrm{kg} / \mathrm{s}](\mathrm{V} .58)$

$\Sigma \dot{m}_{\text {SOOT }}^{\text {vent }}$

(Sum of the) rates at which soot flows out through all the vents in the room (Calculated Value, see Vent section). [ $\mathrm{kg} / \mathrm{s}]$ (V.101)

\section{Calculation}

$\dot{\mathrm{m}}_{\mathrm{SOOT}}=\Sigma \dot{\mathrm{m}}_{\mathrm{SOOT}}^{\mathrm{PrOd}}-\Sigma \dot{\mathrm{m}}_{\mathrm{SOOT}}^{\mathrm{vent}}$ 


\section{References}

1. Mitler, H.E., "The Physical Basis of the Harvard Computer Fire Codes," Harvard University, Home Fire Project Technical Report No. 34, pp. 16 17.

2. Mitler, H.E., and Emmons, H.W., "Documentation for CFC V, the Fifth Harvard Computer Fire Code," U.S. Department of Commerce, Washington, D.C., NBS-GCR-81-344, October 1981, pp $128-131$.

Subroutine Variables

$$
\begin{aligned}
& \text { TMSL }=\dot{\mathrm{m}}_{\mathrm{SOOT}} \\
& \text { TMOSS }=\Sigma \dot{\mathrm{m}}_{\mathrm{SOOT}}^{\text {POOd }} \\
& \text { TMSZF }=\Sigma \dot{\mathrm{m}}_{\mathrm{SOOT}}^{\text {VOnt }}
\end{aligned}
$$

\section{Prepared by}

David W. Stroup 


\section{Computer Subroutine}

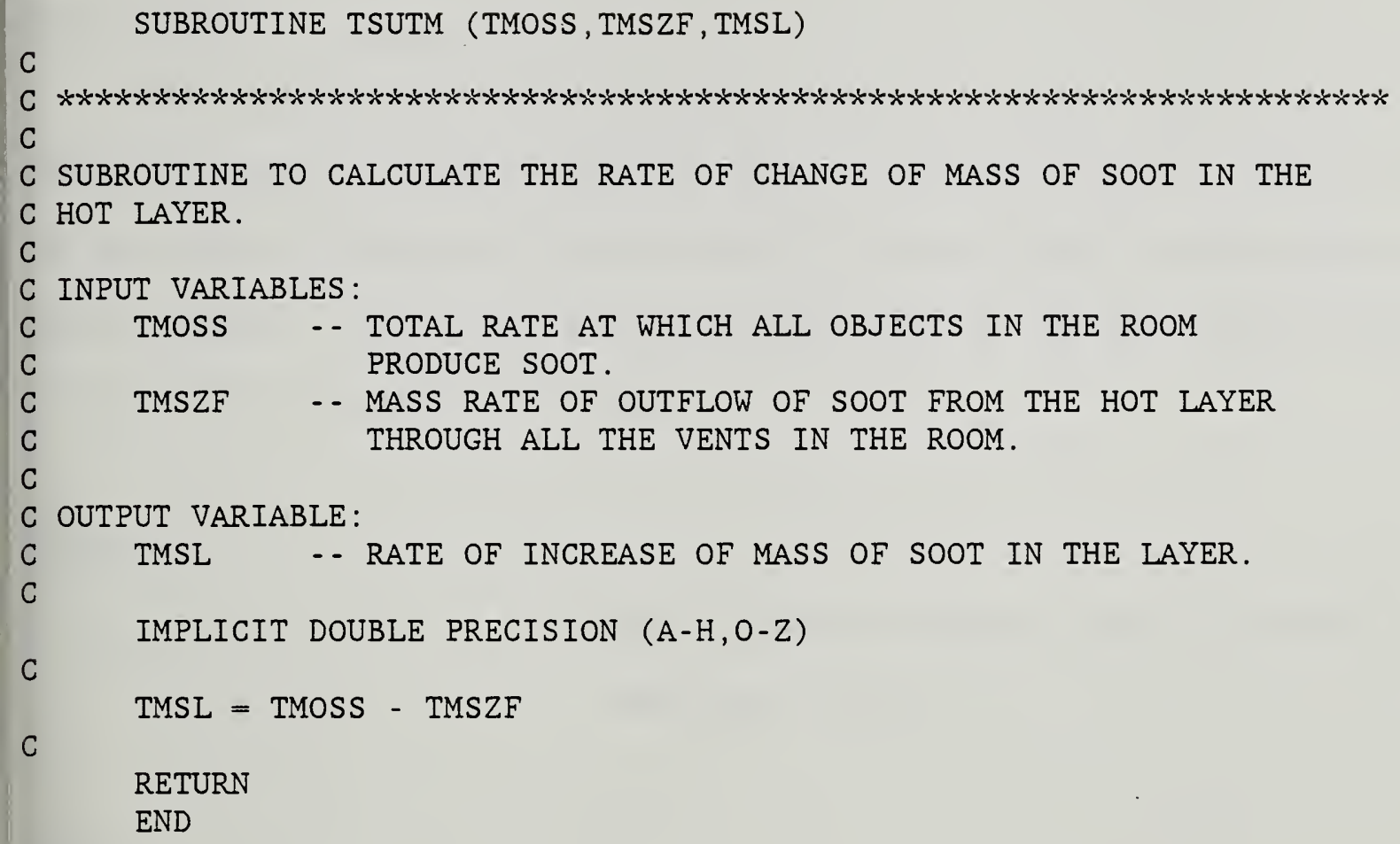

END 
4- TSUTM- 4 


\section{WTRCNC - Mass Fraction of Water Vapor in Hot Layer}

\section{Description}

This routine calculates the mass fraction of water vapor in the hot layer in a room. The mass fraction of water vapor in the hot layer is equal to the ratio of the mass of water vapor in the hot layer to the total mass of the hot layer. The mass fraction of water vapor in the hot layer at the start of the fire is assumed to be zero.

\section{Output}

$\mathrm{Y}_{\mathrm{H} 20}$ Mass fraction of water vapor in the hot layer in the room. (V.42)

Input

$\mathrm{m}_{\mathrm{H} 20}$ Mass of water vapor in the hot layer in the room (Calculated Value, see Hot Layer section). [ $\mathrm{kg}]$

$m_{I}$ Mass of the hot layer in the room (Calculated Value, see Hot Layer section). [kg] (V.54)

\section{Calculations} $\mathrm{Y}_{\mathrm{H} 20}=\left\{\begin{array}{l}\mathrm{m}_{\mathrm{H} 20} / \mathrm{m}_{\mathrm{L}}, \mathrm{m}_{\mathrm{H} 20} \leq \mathrm{m}_{\mathrm{L}} \& \mathrm{~m}_{\mathrm{L}} \neq 0 \\ 0.0, \text { otherwise }\end{array}\right.$ Mass fraction of water vapor. 


\section{References}

1. Mitler, H.E. and Emmons, H.W., "Documentation for CFC V, the Fifth Harvard Fire Code," U.S. Department of Commerce, Washington, D.C., NBS-GCR-81-344, October 1981, pp. $128-131$.

Subroutine Variables

$$
\begin{aligned}
& Z Y L W Z=Y_{\mathrm{H} 20} \\
& Z \text { MWL }=m_{\mathrm{H} 20} \\
& Z M L Z Z=m_{\mathrm{L}}
\end{aligned}
$$

\section{Prepared by}

David W. Stroup 


\section{Computer Subroutine}

SUBROUTINE WTRCNC (ZMWL, ZMLZZ, ZYLWZ)

c

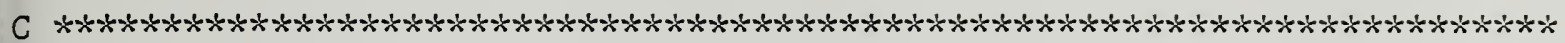
C

C SUBROUTINE TO CALCULATE THE MASS FRACTION OF WATER VAPOR

C IN THE HOT LAYER.

C

C INPUT VARIABLES:

C ZMWL - - MASS OF WATER VAPOR IN THE HOT LAYER.

C ZMLZZ - TOTAL MASS OF THE HOT LAYER.

C

C OUTPUT VARIABLE:

C ZYLWZ - MASS FRACTION OF WATER VAPOR IN THE

C HOT LAYER.

C

IMPLICIT DOUBLE PRECISION (A-H,O-Z)

PARAMETER ( $Y W=0 . D O)$

IF ((ZMWL .GE. O.DO) .AND. (ZMLZZ .GT. O.DO)) THEN

IF (ZMWL . LE. ZMLZZ) THEN

$Z Y L W Z=Z M W L / Z M L Z Z$

ELSE

$Z Y L W Z=Y W$

ENDIF

ELSE

ZYLWZ $=0 . D O$

ENDIF

C

RETURN

END 
4-WTRCNC - 4 
5. ALGORITHMS RELATED TO THE PLUME

$5-1$ 


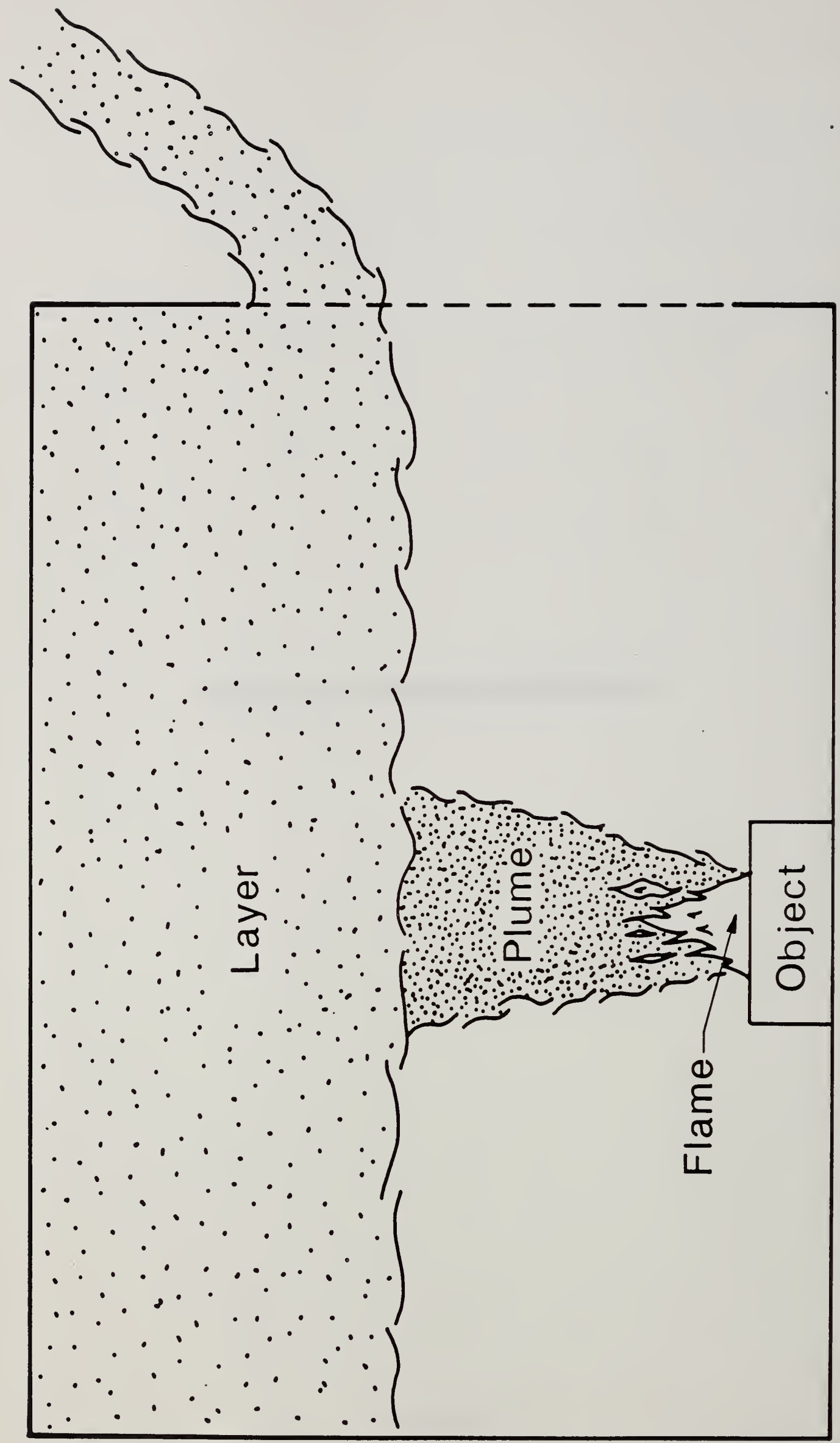




\section{OXYBRN - Mass Rate of Oxygen Burning in the Plume of an Object}

\section{Description}

This routine calculates the mass rate of oxygen burning in the plume of an object. The rate of oxygen consumption by a burning object is a function of the mass rate of burning the object and the amount of oxygen required for combustion. The stoichiometric air/fuel ratio is a measure of the amount of oxygen required for combustion of a certain fuel item. This value can be determined for each fuel item from numerous texts on the chemical reaction of materials. The mass burning rate is calculated by other routines in this catalog.

\section{Output}

$\dot{\mathrm{m}}_{\mathrm{O} 2}$

Mass rate of oxygen burning in the plume of an object. $[\mathrm{kg} / \mathrm{s}](\mathrm{V} .60)$

\section{Input}

$\mathrm{Y}_{\mathrm{O} 2}^{0}$

Mass concentration of oxygen in ambient air

(Input Data). (V.43)

$\gamma_{\mathrm{s}}$

Stoichiometric air/fuel mass ratio for the

object (Input Data). (V.116)

$\dot{\mathrm{m}}_{\mathrm{b}}$

Mass rate of burning of the fuel from the object (Calculated Value, see Burning Object section).

$[\mathrm{kg} / \mathrm{s}](\mathrm{V} .55)$ 
Calculation

$$
\dot{\mathrm{m}}_{\mathrm{O} 2}=\mathrm{Y}_{\mathrm{O} 2}^{0} \gamma_{\mathrm{s}} \quad \dot{\mathrm{m}}_{\mathrm{b}}
$$

\section{$\underline{\text { References }}$}

1. Mitler, H.E., "The Physical Basis of the Harvard Computer Fire Codes," Harvard University, Home Fire Project Technical Report No. 34, pp. 59 67.

2. Mitler, H.E., and Emmons, H.W., "Documentation for CFC V, the Fifth Harvard Computer Fire Code," U.S. Department of Commerce, Washington, D.C., NBS-GCR-81-344, October 1981, pp. $83-91$.

Subroutine Variables

$$
\begin{array}{ll}
\text { BOXY } & =\dot{\mathrm{m}}_{\mathrm{O} 2} \\
\text { XGAMAS } & =\gamma_{\mathrm{s}} \\
\text { YO2 } & =\mathrm{Y}_{\mathrm{O} 2}^{0} \\
\text { TMOZB } & =\dot{\mathrm{m}}_{\mathrm{b}}
\end{array}
$$

\section{Prepared by}

David W. Stroup 
5- OXYBRN - 4 


\section{PLMHT - Height of the Plume over an Object}

\section{Description}

This routine calculates the height of the plume above a burning object. Specifically, the height calculated is the length of the plume as measured from the top of the object to the bottom of the hot layer. The height of the plume may be determined from the room height, the object height, and the smoke layer depth. The height of the object and the height of the room above floor level are input values. The depth of the hot layer is a calculated value.

\section{Output}

$h_{p}$ Height of the plume over an object. [m] (V.37)

\section{Input}

ho Height of the surface of an object above the floor (Input Data). [m] (V.38)

$\mathrm{h}=$ Height of the room (Input Data). [m] (V.33)

$\mathrm{h}_{\mathrm{L}}$ Depth of the hot layer in the room (Calculated Value, see Hot Layer section). [m] (V.20)

\section{Calculation}

$h_{p}=h_{r}-h_{0}-h_{L}$

\section{References}

1. Mitler, H.E., "The Physical Basis of the Harvard Computer Fire Codes," 
Harvard University, Home Fire Project Technical Report No. 34, pp. 10 13.

2. Mitler, H.E., and Emmons, H.W., "Documentation for CFC V, the Fifth Harvard Computer Fire Code," U.S. Department of Commerce, Washington, D.C., NBS-GCR-81-344, October 1981, pp. $136-137$.

\section{Subroutine Variables}

$$
\begin{aligned}
\mathrm{ZHPZZ} & =h_{\mathrm{p}} \\
\mathrm{ZHOZZ} & =h_{\circ} \\
\mathrm{ZHRZZ} & =h_{\mathrm{r}} \\
\mathrm{ZHLZZ} & =h_{\mathrm{L}}
\end{aligned}
$$

\section{Prepared by}

David W. Stroup 


\section{Computer Subroutine}

SUBROUTINE PLMHT (ZHOZZ, ZHRZZ, ZHLZZ, ZHPZZ)

$\mathrm{C}$

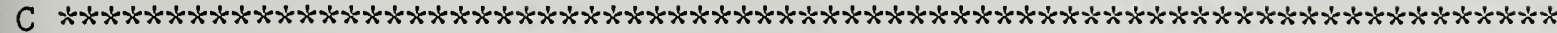
C

C SUBROUTINE TO CALCULATE THE HEIGHT OF THE PLUME OVER AN OBJECT. $\mathrm{C}$

C INPUT PARAMETERS:

C. ZHOZZ -- HEIGHT OF THE OBJECT.

C ZHRZZ - - HEIGHT OF THE ROOM CONTAINING THE OBJECT.

C

C INPUT VARIABLES:

C ZHLZZ -- DEPTH OF THE HOT LAYER IN THE ROOM CONTAINING THE C OBJECT.

C

C OUTPUT VARIABLE:

C ZHPZZ -- HEIGHT OF THE PLUME OVER THE OBJECT.

$\mathrm{C}$

$\mathrm{ZHPZZ}=\mathrm{ZHRZZ}-\mathrm{ZHOZZ}-\mathrm{ZHLZZ}$

RETURN

END 


\section{5-PLMHT - 4}


TENPLM - Rate of Addition of Energy to the Hot Layer from the Plume

\section{Description}

This routine calculates the rate at which the plume over an object adds energy to the hot layer. The rate at which energy is convected into the hot layer is determined from a plume energy balance. The object's flame is included as part of the plume. When an object burns, it produces energy at a rate $\dot{E}_{f}$. Some of this energy is lost by radiation from the flame, $\dot{E}_{P R}$. Another portion of the energy produced by the burning object is used to maintain the object at pyrolysis temperature. Any energy left over from the combustion of the object plus the energy in the air entrained into the plume is carried into the hot layer.

\section{Output}

$\dot{E}_{p}$

Rate at which the plume over a burning object adds energy to the hot layer. [W] (V.96)

\section{Input}

$\mathrm{T}_{\mathrm{a}}$ Ambient temperature in the room containing the plume (Input Data). [K] (V.120)

$T_{p}$ Temperature at which an object begins to pyrolyze (Input Data). [K] (V.119)

$c_{p}$ Specific heat of ambient air (Input Data). $[\mathrm{J} / \mathrm{kg}-\mathrm{K}] \quad(\mathrm{V} .112)$

$\dot{\mathrm{E}}_{£}$ (Negative of the) rate of chemical energy 
released from a burning object (Calculated

Value, see Burning Object section). [W] (V.88)

$\dot{\mathrm{E}}_{\mathrm{PR}}$

Heat loss rate from the flame of the object (Calculated Value, see Radiation Heat Transfer section). [W] (V.29)

$\dot{\mathrm{m}}_{\mathrm{f}}$ (Negative of the) mass pyrolysis rate of the object (Calculated Value, see Burning Object section). [ $\mathrm{kg} / \mathrm{s}](\mathrm{V} .61)$

$\dot{\mathrm{m}}_{\mathrm{p}}$ Rate at which the plume over an object adds mass to the hot layer (Calculated Value, see Plume section). [ $\mathrm{kg} / \mathrm{s}](\mathrm{V} .97)$

\section{Calculation}

$\dot{\mathrm{E}}_{\mathrm{p}}=-\dot{\mathrm{E}}_{\mathrm{f}}+\left(\dot{\mathrm{m}}_{\mathrm{p}}+\dot{\mathrm{m}}_{\mathrm{f}}\right) \mathrm{c}_{\mathrm{p}} \mathrm{T}_{\mathrm{a}}-\dot{\mathrm{E}}_{\mathrm{PR}}-\dot{\mathrm{m}}_{\mathrm{f}} \mathrm{c}_{\mathrm{p}} \mathrm{T}_{\mathrm{p}}$

\section{References}

1. Mitler, H.E., "The Physical Basis of the Harvard Computer Fire Codes," Harvard University, Home Fire Project Technical Report No. 34, pp. 10 13.

2. Mitler, H.E., and Emmons, H.W., "Documentation for CFC V, the Fifth Harvard Computer Fire Code," U.S. Department of Commerce, Washington, D.C., NBS-GCR-81-344, October 1981, pp. $136-137$.

\section{Subroutine Variables}

$$
\begin{aligned}
& \text { TEPZZ }=\dot{\mathrm{E}}_{\mathrm{p}} \\
& \text { ZKAZZ }=\mathrm{T}_{\mathrm{a}} \\
& \text { ZKOPY }=\mathrm{T}_{\mathrm{p}}
\end{aligned}
$$




$$
\begin{aligned}
\text { TEOZZ } & =\dot{\mathrm{E}}_{f} \\
\mathrm{CP} & =\mathrm{c}_{\mathrm{p}} \\
\text { TEPZR } & =\dot{\mathrm{E}}_{\mathrm{PR}} \\
\mathrm{TMOZZ} & =\dot{\mathrm{m}}_{f} \\
\mathrm{TMPZZ} & =\dot{\mathrm{m}}_{\mathrm{p}}
\end{aligned}
$$

\section{Prepared by}

David W. Stroup

5 -TENPLM - 3 
SUBROUTINE TENPLM (ZKAZZ, ZCOPY, TEOZZ, TEPZR, TMOZZ, TMPZZ, TEPZZ)

$\mathrm{C}$

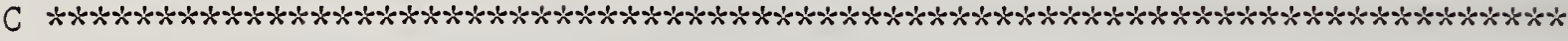

$\mathrm{C}$

C SUBROUTINE TO CALCULATE THE RATE AT WHICH THE PLUME OVER AN OBJECT

C ADDS ENERGY TO THE HOT LAYER.

C

C INPUT PARAMETERS:

C ZKAZZ - A AMBIENT TEMPERATURE IN THE ROOM CONTAINING THE PLUME.

C ZKOPY - P PYROLYSIS TEMPERATURE OF THE OBJECT.

C

C INPUT VARIABLES:

C TEOZZ - - RATE OF CHEMICAL ENERGY PRODUCTION IN THE COMBUSTION C OF THE OBJECT.

C TEPZZ - HEAT LOSS RATE FROM THE FLAME OF THE OBJECT.

C TMOZZ - - NEGATIVE OF MASS PYROLYSIS RATE OF THE OBJECT.

C TMPZZ - - RATE AT WHICH THE PLUME OVER THE OBJECT ADDS MASS

C

C

C OUTPUT VARIABLE:

C TEPZZ - - RATE AT WHICH THE PLUME ADDS ENERGY TO THE HOT C C

C

C LAYER.

IMPLICIT DOUBLE PRECISION ( $\mathrm{A}-\mathrm{H}, \mathrm{O}-\mathrm{Z})$

PARAMETER $(C P=1004 . D 0)$

$\mathrm{TEPZZ}=-\mathrm{TEOZZ}+(\mathrm{TMPZZ}+\mathrm{TMOZZ}) * \mathrm{CP} * \mathrm{ZKAZZ}-\mathrm{TEPZR}$

$\&$

- $\mathrm{TMOZZ} * \mathrm{CP} * \mathrm{ZKOPY}$

RETURN

END 
TMSPLM - Rate of Addition of Mass to the Hot Layer from a Plume

\section{Description}

This routine calculates the rate at which the plume over an object adds mass to the hot layer. The density and velocity profiles are assumed to be Gaussian, and the equations are essentially the same as those found by Morton, Taylor, and Turner (ref. 3 below), for a point source of heat. This formulation assumes an area source of heat of given radius by taking a virtual point source at an appropriate distance below the base of the fire, and subtracting from the resulting mass flux the amount of air which would have been entrained between the vertex and the base of the fire. The plume is assumed to stop at the interface. The entrainment coefficient, $\alpha$, is assumed to be constant. The equations are discussed in detail in reference 1 listed below.

\section{Output}

$\dot{\mathrm{m}}_{\mathrm{p}}$

Rate at which the plume over an object adds mass to the hot layer. [ $\mathrm{kg} / \mathrm{s}](\mathrm{V} .97)$

Input

$\alpha$

Plume entrainment coefficient (Input Data).

$\rho_{\mathrm{a}}$

Density of ambient air in the room containing the plume (Input Data). [kg/s] (V.17)

$\mathrm{T}_{\mathrm{a}}$ Ambient temperature in the room containing the plume (Input Data). [K] (V.120) 
$\dot{\mathrm{E}}_{f}$

$m_{f}$

$h_{p}$

$\mathrm{R}$

$\pi$

g

$c_{p}$

\section{Calculations}

$\mathrm{x}=\mathrm{R} /(1.2 \alpha)$

$h_{p x}=h_{p}+x$

$b_{p}=1.2 \propto h_{p x}$

$C_{p}^{\prime}=-\frac{25 g \dot{E}_{f}}{48 \alpha^{2} \pi c_{p}{ }^{T}{ }_{a}{ }{ }_{a}}$

$\mathrm{U}=\left(\mathrm{C}_{p}^{\prime} / \mathrm{h}_{\mathrm{px}}\right)^{1 / 3}$
(Negative of the) rate of chemical energy released from a burning object (Calculated Value, see Burning Object section). [W] (V.88) (Negative of the) mass pyrolysis rate of the object (Calculated Value, see Burning Object section). [ $\mathrm{kg} / \mathrm{s}](\mathrm{V} .61)$

Height of the plume over the object (Calculated Value, see Plume section). [m] (V.37).

Radius of the fire on the object (Calculated Value, see Burning Object section). [m] (V.85) Pi (Physical Constant). [3.1415927...] (V.146) Acceleration of gravity (Physical Constant). $\left[\mathrm{m} / \mathrm{s}^{2}\right](\mathrm{V} .144)$

Specific heat of ambient air (Input Data). $[\mathrm{J} / \mathrm{kg}-\mathrm{K}] \quad(\mathrm{V} .112)$

Distance of virtual point source below base of fire.

Height of augmented plume -. i.e. distance between virtual point source and layer. Plume radius at layer.

Convenient coefficient.

Axial velocity of plume gases at top of plume. 


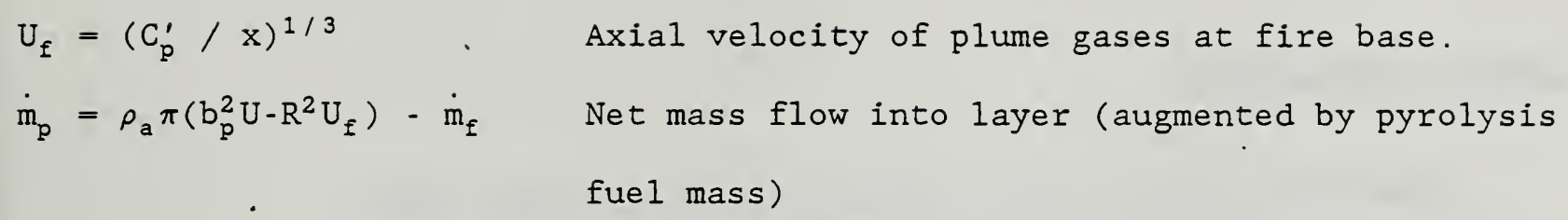

\section{References}

1. Mitler, H.E., "The Physical Basis of the Harvard Computer Fire Codes," Harvard University, Home Fire Project Technical Report No. 34, pp. 10 13.

2. Mitler, H.E., and Emmons, H.W., "Documentation for CFC V, the Fifth Harvard Computer Fire Code," U.S. Department of Commerce, Washington, D.C., NBS-GCR-81-344, October 1981, pp. $136-137$.

3. Morton, B.R., Taylor G.I., and Turner, J.S., "Turbulent Gravitational Convection from Maintained and Instantaneous Sources", Proc. of Royal Soc. (London) $\underline{\mathrm{A} 234}(1956), 1$.

\section{Subroutine Variables}

$$
\begin{aligned}
\text { TMPZZ } & =\dot{m}_{\mathrm{p}} \\
\text { ALPHA } & =\alpha \\
\text { VMAZZ } & =\rho_{a} \\
\text { ZKAZZ } & =T_{a} \\
\text { TEOZZ } & =\dot{E}_{f} \\
\text { TMOZZ } & =\dot{m}_{f} \\
\text { ZHPZZ } & =h_{p} \\
\text { ZRFZZ } & =R \\
\text { PI } & =\pi \\
G & =g \\
C P & =c_{p}
\end{aligned}
$$

\section{Prepared by}

David W. Stroup 


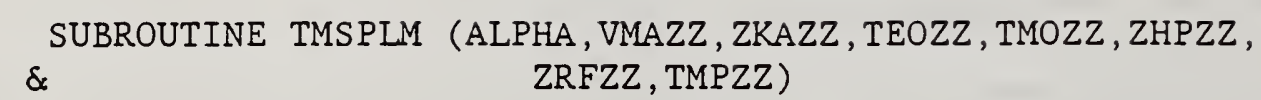

$C$

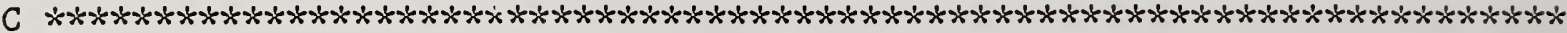

C

C SUBROUTINE TO CALCULATE THE RATE AT WHICH THE PLUME OVER AN OBJECT C ADDS MASS TO THE HOT LAYER.

C

C INPUT PARAMETERS:

C ALPHA - - PLUME ENTRAINMENT COEFFICIENT.

C VMAZZ -- DENSITY OF AMBIENT AIR IN THE ROOM CONTAINING THE

C

C

C

C

C INPUT VARIABLES:

C TEOZZ - NEGATIVE OF THE RATE OF CHEMICAL ENERGY RELEASE IN

C

C THE COMBUSTION OF THE OBJECT.

TMOZZ - NEGATIVE OF MASS PYROLYSIS RATE OF THE OBJECT.

ZHPZZ - - HEIGHT OF THE PLUME OF THE OBJECT.

ZRFZZ - R RADIUS OF THE FIRE ON THE OBJECT.

C

C OUTPUT VARIABLES:

C TMPZZ - RATE AT WHICH THE PLUME OVER THE OBJECT ADDS MASS TO C

C

C THE HOT LAYER.

IMPLICIT DOUBLE PRECISION (A-H,O-Z)

PARAMETER ( $\mathrm{PI}=3.1415927 \mathrm{DO}, \mathrm{G}=9.8 \mathrm{DO}, \mathrm{CP}=1004 . \mathrm{DO})$

IF (ZHPZZ . LT. O.DO) THEN

TMPZZ $=-T M O Z Z$

ELSE

$\mathrm{X}=\mathrm{ZRFZZ} /(1.2 \mathrm{DO} * \mathrm{ALPHA})$

$\mathrm{HPX}=\mathrm{ZHPZZ}+\mathrm{X}$

$\mathrm{BP}=1.2 \mathrm{DO} * \mathrm{ALPHA} * \mathrm{HPX}$

$\mathrm{TMP}=(-25 . \mathrm{DO} * \mathrm{G} * \mathrm{TEOZZ}) /$

$\& \quad(48 . D 0 *$ ALPHA*ALPHA * PI *CP * ZKAZZ * VMAZZ)

C PROVIDE SAFETY AGAINST FLUCTUATIONS:

IF (TMP .LE. O.DO) THEN

TMPZZ $=-T M O Z Z$

ELSE

$U=(\operatorname{TMP} / \operatorname{HPX}) * * *(1 . D 0 / 3 . D 0)$

$\mathrm{UF}=(\operatorname{TMP} / \mathrm{X}) * *(1 . \mathrm{DO} / 3 . \mathrm{DO})$

$\mathrm{TMPZZ}=\mathrm{VMAZZ} * \mathrm{PI} *(\mathrm{BP} * \mathrm{BP} * \mathrm{U}-\mathrm{ZRFZZ} * \mathrm{ZRFZZ} * \mathrm{UF})-\mathrm{TMOZZ}$ ENDIF

ENDIF

RETURN

END 
6. ALGORITHMS RELATED TO RADIATION HEAT TRANSFER

$6-1$ 


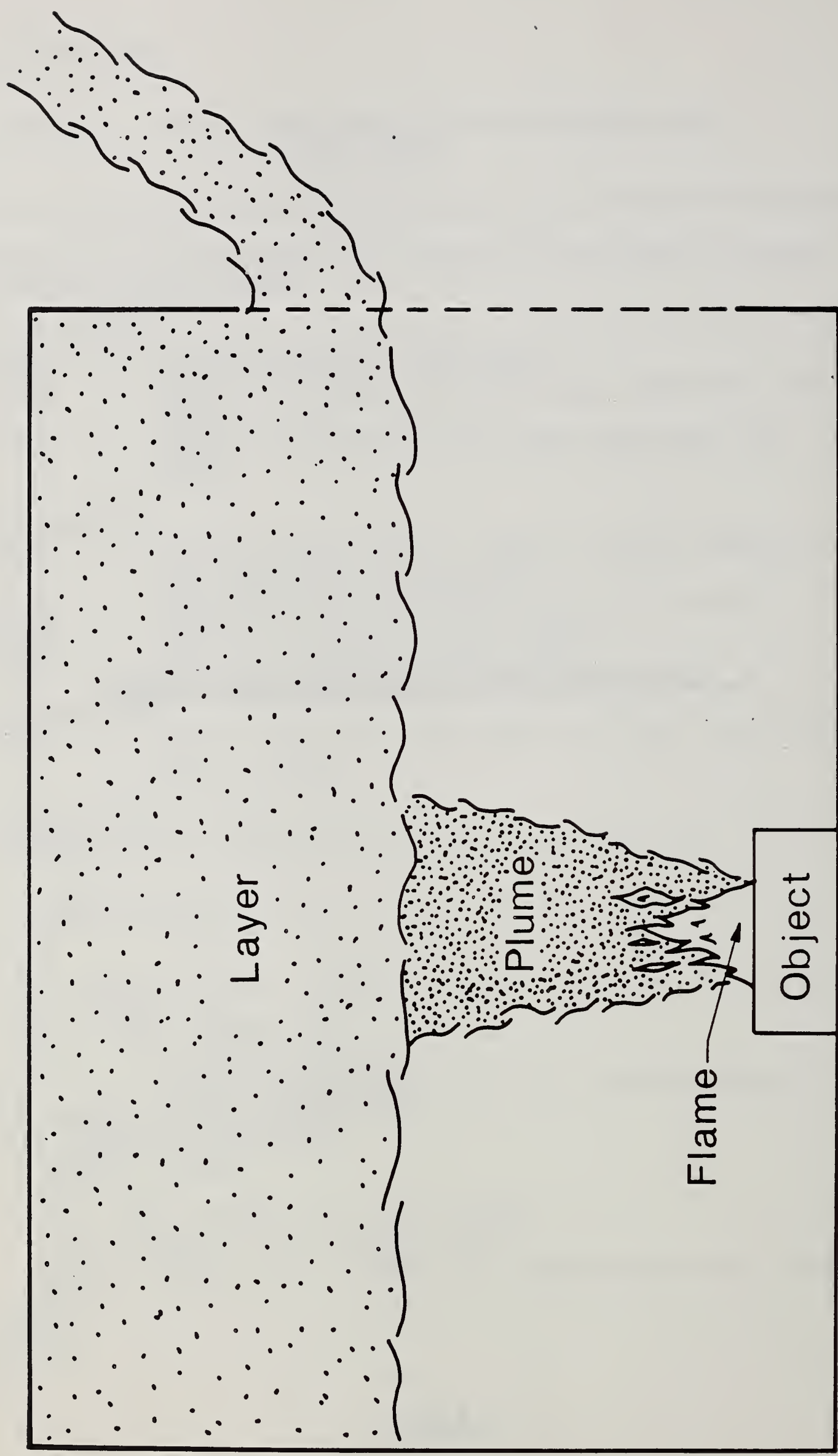

 
7. ALGORITHMS RELATED TO THE VENT

$$
7-1
$$




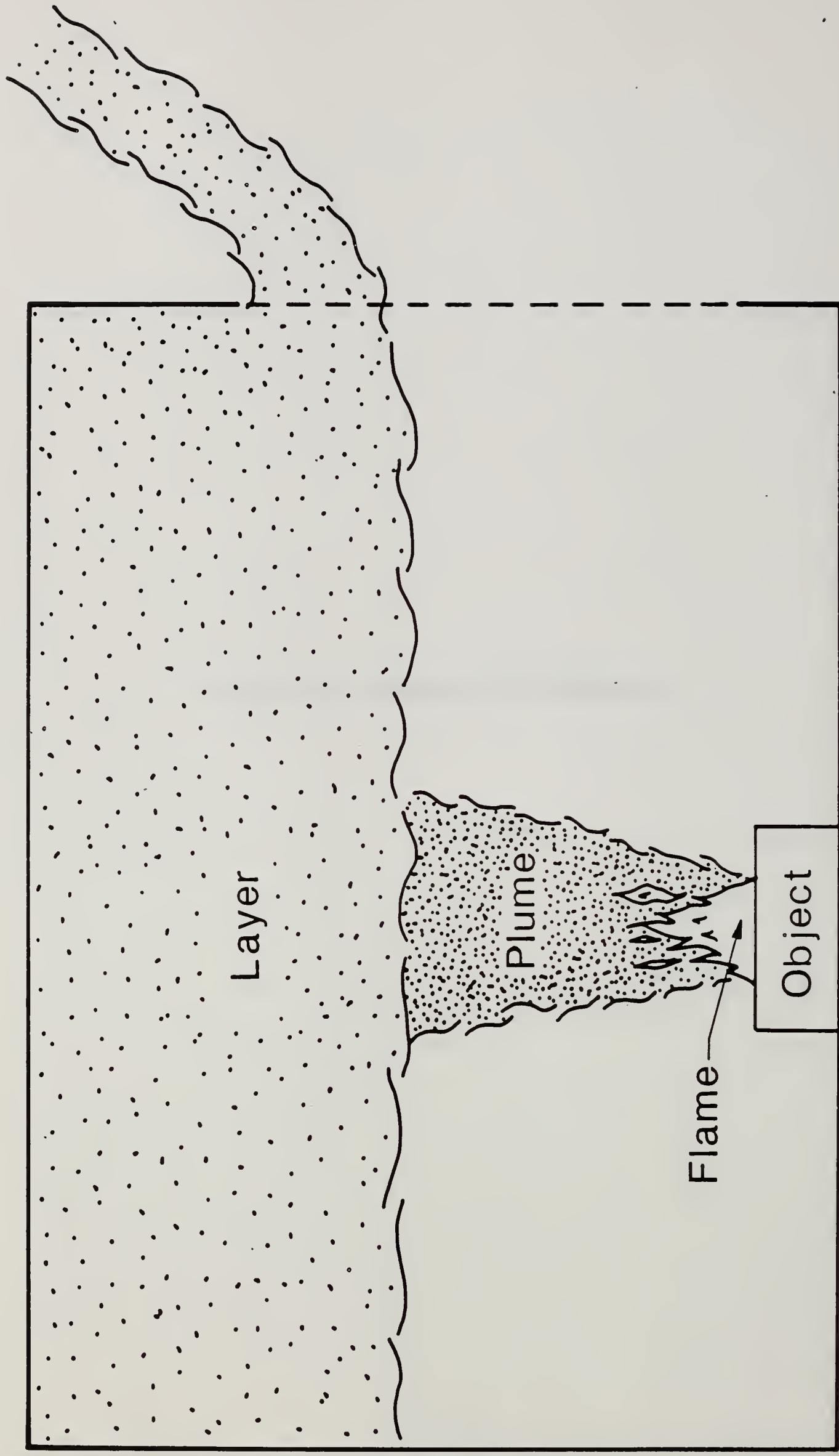


CVWID - Width of the Segment of a Vent which Intersects the Layer

\section{Description}

This algorithm calculates the width of the segment of a given vent which is intersected by the interface between the hot and cold layers. Thus, if the layer interface intersects the vent, the routine returns a value equal to the user-specified width of the vent. If the interface does not intersect the vent, the routine returns a value of zero. When the interface is very close to the top or bottom of the vent, an intermediate width is calculated in order to maintain continuity.

\section{Output}

$\mathrm{W}_{\mathrm{V} \text { L }}$ Width of the vent which intersects the interface between the hot and cold layers. [m] (V.141)

\section{Input}

B

$h_{t}$

$h_{\mathrm{v}}$

$\mathrm{h}_{\mathrm{L}}$

\section{Calculations}

$h_{v}^{\prime}=h_{L}-h_{t}$
Width of the vent (Input Data). [m] (V.140)

Distance of the top of the vent below the ceiling, --i.e. transom height (Input Data). [m]

Height of the vent (Input Data). [m] (V.34)

Depth of the hot layer in the room (Calculated

Value, see Hot Layer section). [m] (V.20) 


$$
W_{v L}= \begin{cases}0.0, & h_{v}^{\prime}<0.0 \\ B h_{v}^{\prime} /\left(.2 h_{v}\right), & 0.0 \leq h_{v}^{\prime}<.2 h_{v} \\ B, & .2 h_{v} \leq h_{v}^{\prime}<.8 h_{v} \\ -B\left(h_{v}^{\prime}-h_{v}\right) /\left(.2 h_{v}\right), & .8 h_{v} \leq h_{v}^{\prime} \leq h_{v} \\ 0.0, & h_{v}^{\prime}>h_{v}\end{cases}
$$

\section{References}

1. Mitler, H.E., "The Physical Basis of the Harvard Computer Fire Codes," Harvard University, Home Fire Project Technical Report No. 34, pg. 51.

2. Mitler, H.E., and Emmons, H.W., "Documentation for CFC V, the Fifth Harvard Computer Fire Code," U.S. Department of Commerce, Washington, D.C., NBS-GCR-81-344, October 1981, pp. $113-114$.

Subroutine Variables

$$
\begin{aligned}
\text { WVL } & =\mathrm{W}_{\mathrm{VL}} \\
\mathrm{ZBVZZ} & =\mathrm{B} \\
\mathrm{ZHTZZ} & =\mathrm{h}_{\mathrm{t}} \\
\mathrm{ZHVZZ} & =\mathrm{h}_{\mathrm{v}} \\
\mathrm{ZHLZZ} & =\mathrm{h}_{\mathrm{L}}
\end{aligned}
$$

\section{Prepared by}

David W. Stroup 


\section{Computer Subroutine}

SUBROUTINE CVWID (ZBVZZ, ZHTZZ, ZHVZZ, ZHLZZ, WVL)

C

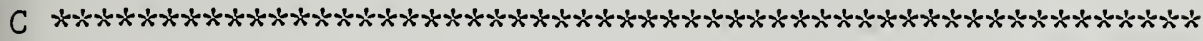

C

IMPLICIT DOUBLE PRECISION (A-H,O-Z)

C

C THIS SUBROUTINE CALCULATES THE WIDTH OF THE SEGMENT OF A GIVEN

C VENT WHICH INTERSECTS THE INTERFACE BETWEEN THE HOT AND COLD

C LAYERS. THUS, IF THE LAYER INTERFACE INTERSECTS THE VENT, THE

C SUBROUTINE RETURNS ZBVZZ, AND IF THE INTERFACE DOES NOT INTERSECT

C THE VENT THE SUBROUTINE RETURNS 0 . WHEN THE INTERFACE IS VERY

C CLOSE TO THE TOP OF THE VENT, THE SUBROUTINE RETURNS AN INTER-

MEDIATE VALUE IN ORDER TO MAINTAIN CONTINUITY.

C

INPUT PARAMETERS:

ZBVZZ -.- WIDTH OF THE VENT.

ZHTZZ -- DISTANCE FROM THE CEILING TO THE TRANSOM OF THE VENT.

ZHVZZ - - HEIGHT OF THE VENT.

\section{INPUT VARIABLES:}

ZHLZZ - - DEPTH OF THE HOT LAYER.

OUTPUT VARIABLE:

WVL - - LENGTH OF THE INTERSECTION OF THE VENT WITH THE INTERFACE.

$\mathrm{HV}=\mathrm{ZHLZZ}-\mathrm{ZHTZZ}$

$\mathrm{TOP}=.2 \mathrm{DO} * \mathrm{ZHVZZ}$

BOTTOM $=.8 \mathrm{DO} * \mathrm{ZHVZZ}$

IF (HV.LT.O.DO .OR. HV.GT.ZHVZZ) THEN

WVL $=0 . D O$

ELSE IF (HV.GE.O.DO .AND. HV.LT.TOP) THEN

$\mathrm{WVL}=\mathrm{ZBVZZ} * \mathrm{HV} / \mathrm{TOP}$

ELSE IF (HV.GE.TOP .AND. HV.LT.BOTTOM) THEN

$\mathrm{WVL}=\mathrm{ZBVZZ}$

ELSE IF (HV.GE.BOTTOM .AND. HV. LE.ZHVZZ) THEN

WVL $=-\mathrm{ZBVZZ} / \mathrm{TOP} *(\mathrm{HV}-\mathrm{ZHVZZ})$

ENDIF

RETURN

END 
7 - CVWID - 4 


\section{VNTCVR - Area of a Vent Covered by the Hot Layer.}

\section{Description}

This algorithm calculates the area of the part of a vent covered by the hot layer. When the layer interface is above the top of the vent, this routine returns a value of zero. When the layer interface is below the vent, it returns a value equal to the total area of the vent. If the layer interface is located somewhere between the top and bottom of the vent, this algorithm calculates how far down the layer extends below the top of the vent, and multiplied by the (user-specified) vent width to obtain the area of the vent covered by the hot layer.

\section{Output}

$A_{V L}$ Area of the vent covered by the hot layer. $\left[\mathrm{m}^{2}\right]$ (V.5)

\section{Input}

B

Width of the vent (Input Data). [m] (V.140)

$h_{t}$ Distance of the top of vent below the ceiling, -

- i.e. transom height (Input Data). [m] (V.23)

$h_{\mathrm{v}}$

Height of the vent (Input Data). [m] (V.34)

$h_{L}$ Depth of the hot layer in the room (Calculated Value, see Hot Layer section). [m] (V.20) 


\section{Calculations}

$$
\begin{aligned}
& h_{v}^{\prime}= \begin{cases}0.0, & h_{L}-h_{t}<0.0 \\
h_{L}-h_{t}, & 0.0 \leq h_{L}-h_{t} \leq h_{v} \\
h_{v}, & h_{L}-h_{t}>h_{v}\end{cases} \\
& A_{v L}=h_{v}^{\prime} B
\end{aligned}
$$

\section{$\underline{\text { References }}$}

1. Mitler, H.E., "The Physical Basis of the Harvard Computer Fire Codes," Harvard University, Home Fire Project Technical Report No. 34, pg. 51.

2. Mitler, H.E., and Emmons, H.W., "Documentation for CFC V, the Fifth Harvard Computer Fire Code," U.S. Department of Commerce, Washington, D.C., NBS-GCR-81-344, October 1981, pp. $113-114$.

\section{Subroutine Variables}

$$
\begin{aligned}
& \text { AVLI }=A_{V I} \\
& Z B V Z Z=B \\
& Z H T Z Z=h_{t} \\
& Z \text { HVZZ }=h_{V} \\
& Z \text { HLZZ }=h_{I}
\end{aligned}
$$

\section{Prepared by}

David W. Stroup 


\section{Computer Subroutine}

SUBROUTINE VNTCVR (ZBVZZ, ZHTZZ, ZHVZZ, ZHLZZ, AVLI)

C

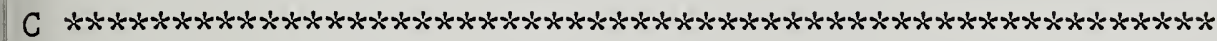

$\mathrm{C}$

IMPLICIT DOUBLE PRECISION (A-H,O-Z)

C

C SUBROUTINE TO CALCULATE THE AREA OF A VENT COVERED BY THE HOT

C LAYER.

INPUT PARAMETERS:

ZBVZZ - - WIDTH OF THE VENT.

ZHTZZ -- DISTANCE FROM THE CEILING TO THE TRANSOM OF THE VENT.

ZHVZZ - - HEIGHT OF THE VENT.

INPUT VARIABLES :

ZHLZZ - - DEPTH OF THE LAYER IN THE ROOM CONTAINING THE VENT. OUTPUT VARIABLE:

AVL1 - - AREA OF THE VENT COVERED BY THE HOT LAYER.

$\mathrm{HV}=\mathrm{ZHLZZ}-\mathrm{ZHTZZ}$

IF ( HV .LT. O.DO) THEN

$\mathrm{HV}=0 . \mathrm{DO}$

ELSE IF (HV .GT. ZHVZZ) THEN

$\mathrm{HV}=\mathrm{ZHVZZ}$

END IF

$\mathrm{AVLI}=\mathrm{HV} * \mathrm{ZBVZZ}$

RETURN

END 
7 - VNTCVR - 4 
8. MISCELLANEOUS ALGORITHMS

$8-1$ 


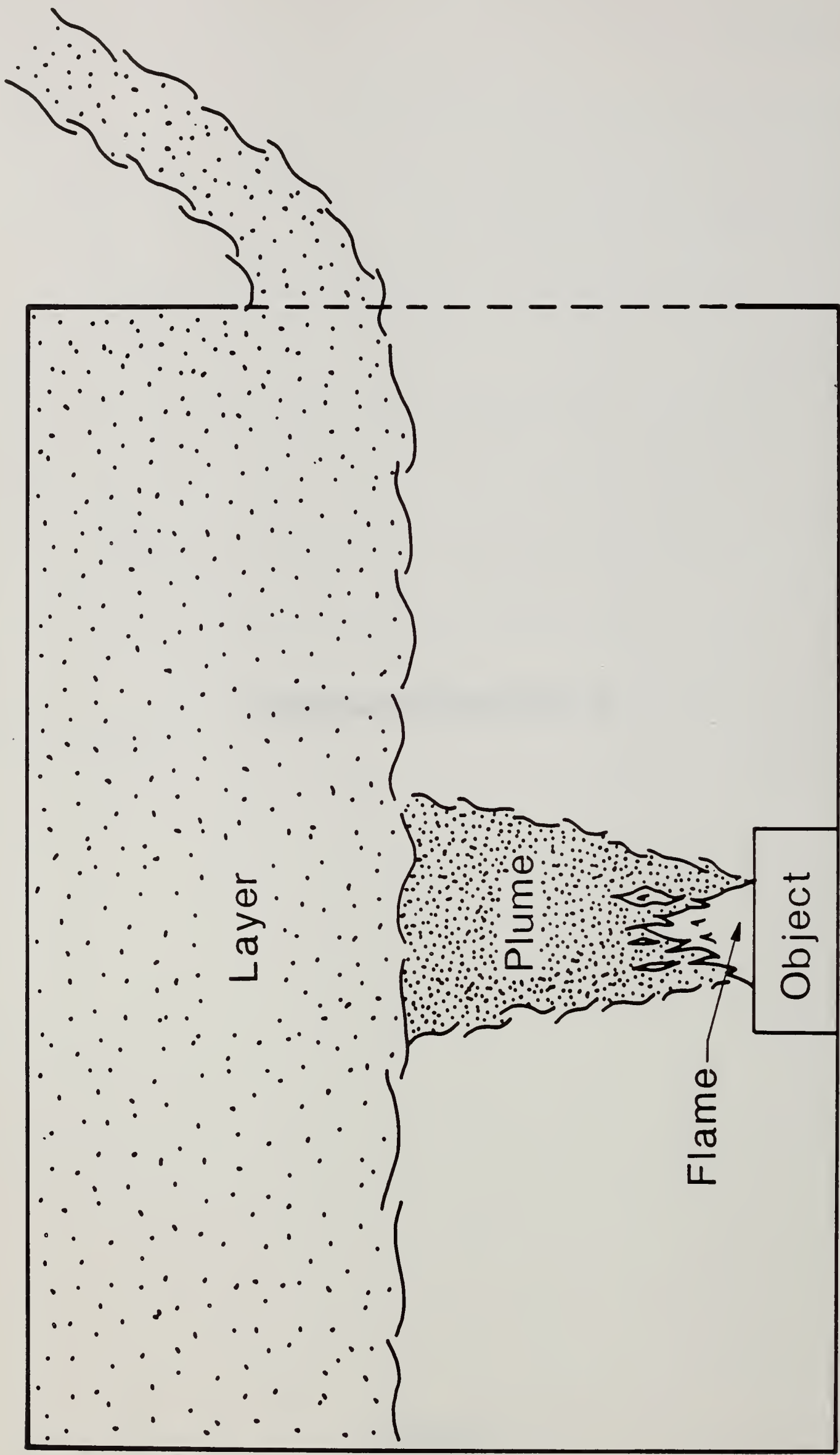


APPENDIX A

VARIABLE CROSS-REFERENCE

$$
\text { A - } 1
$$




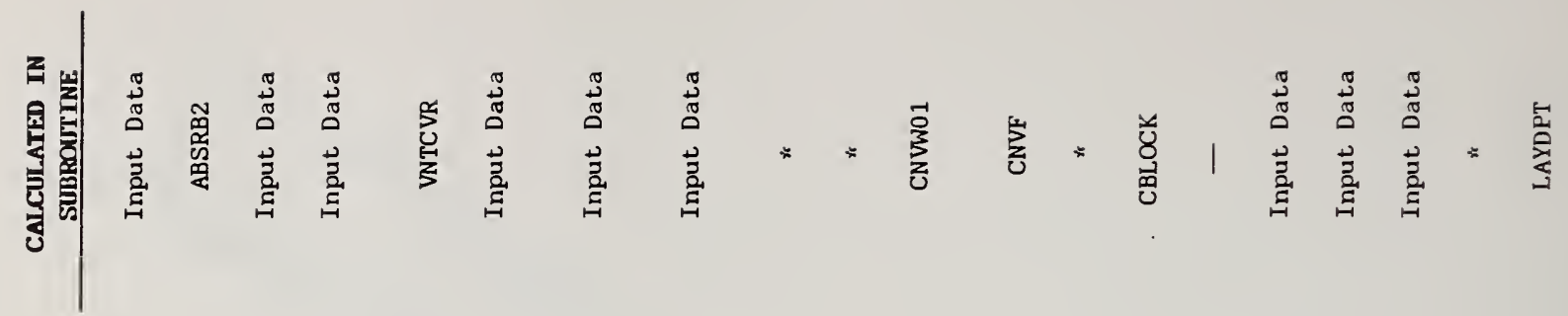

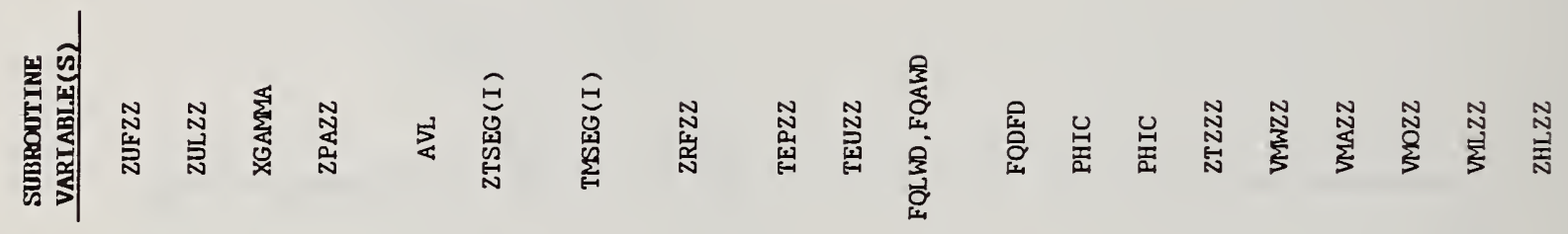
| 
IU⿴囗十)

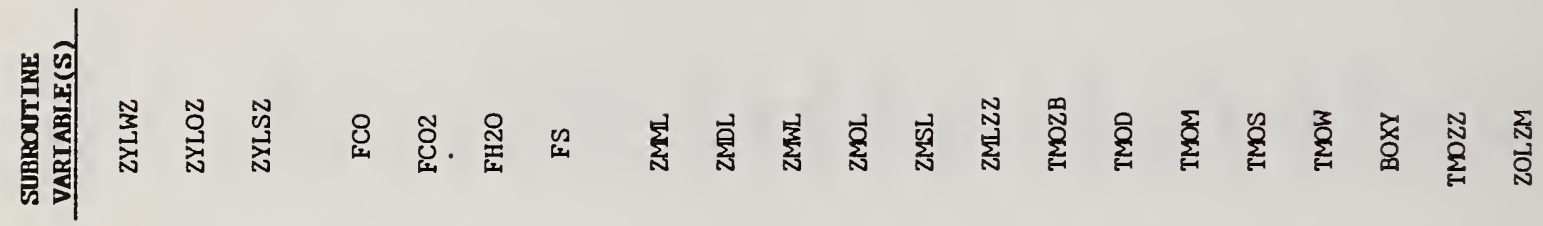

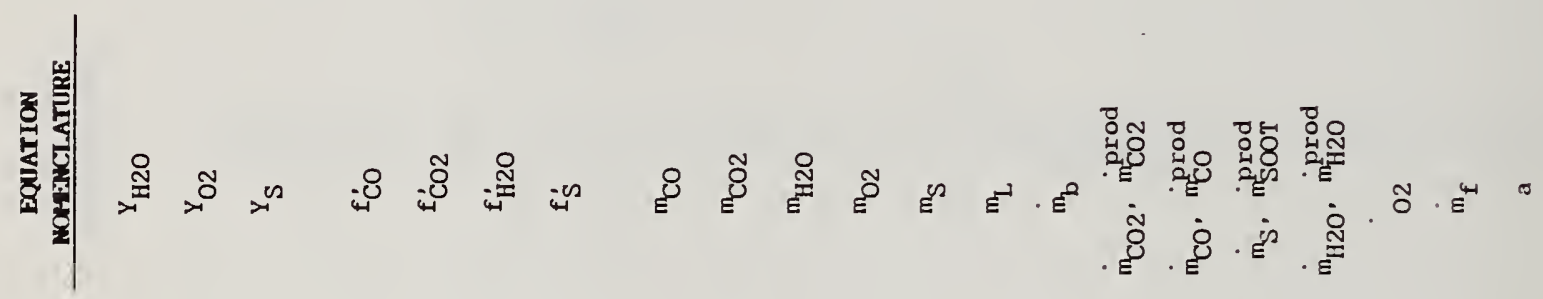

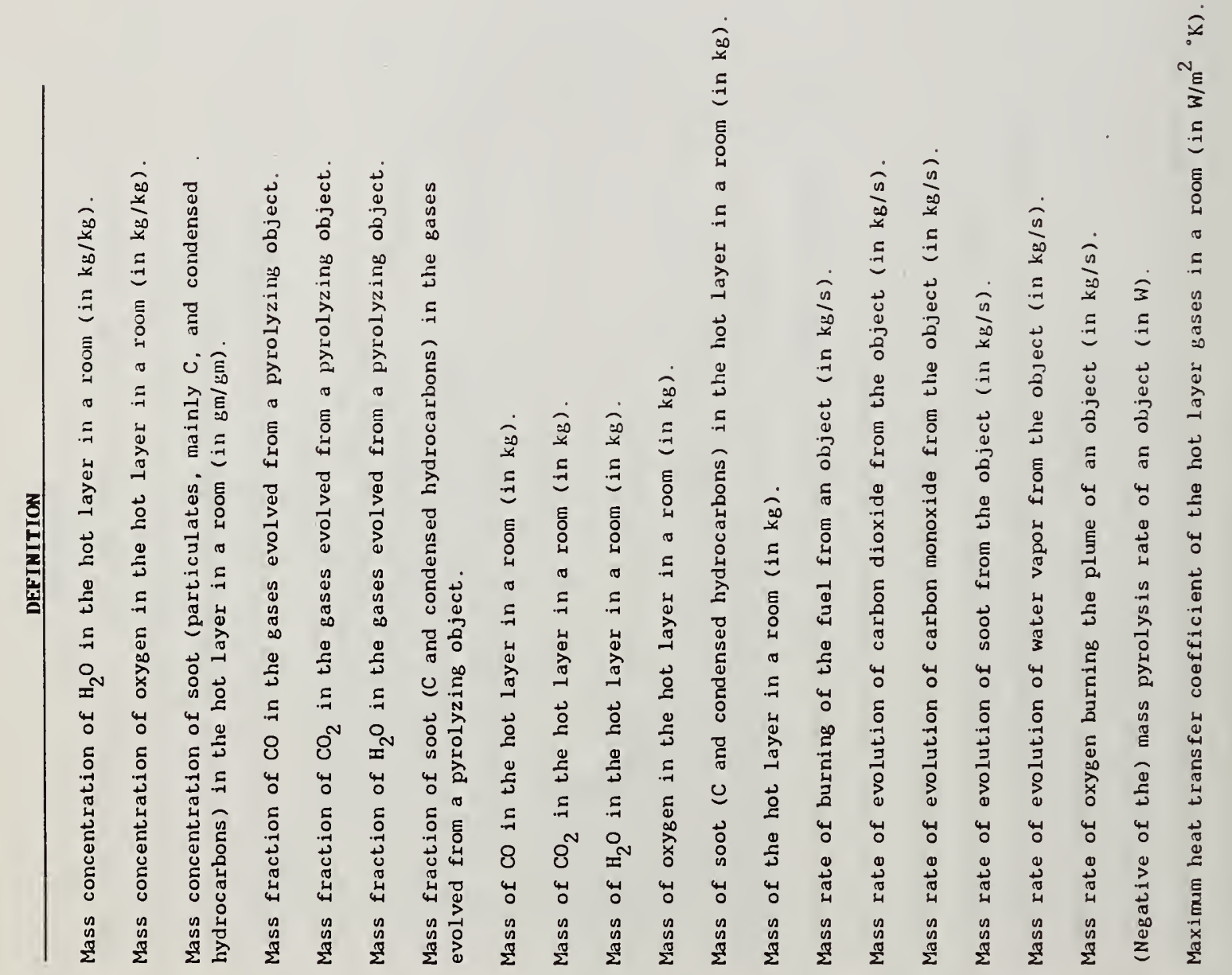

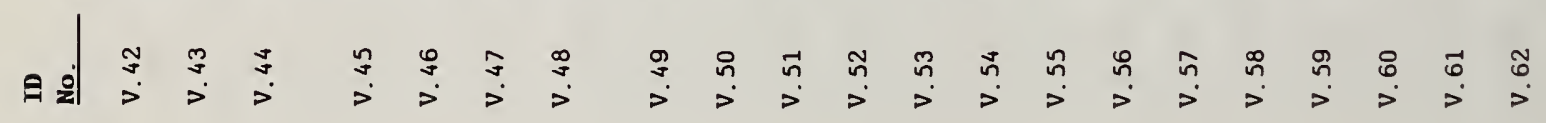


.

$\sum_{\substack{0 \\:}}^{0}$

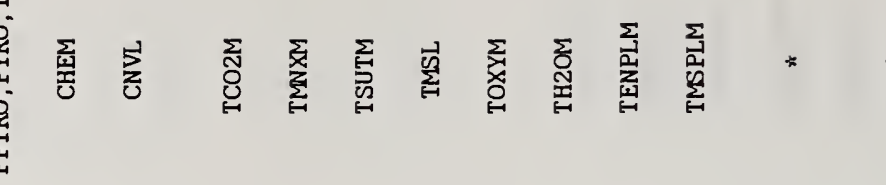

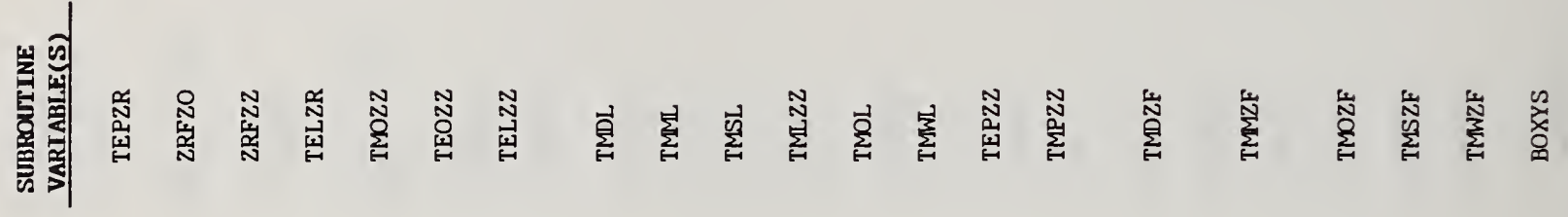

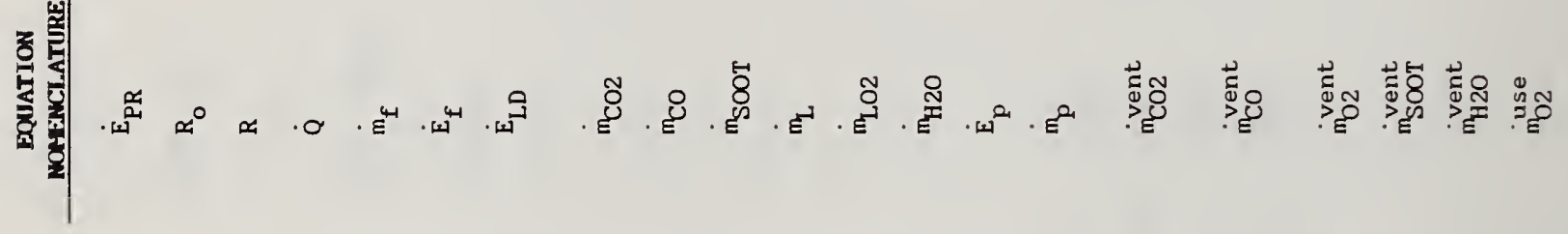

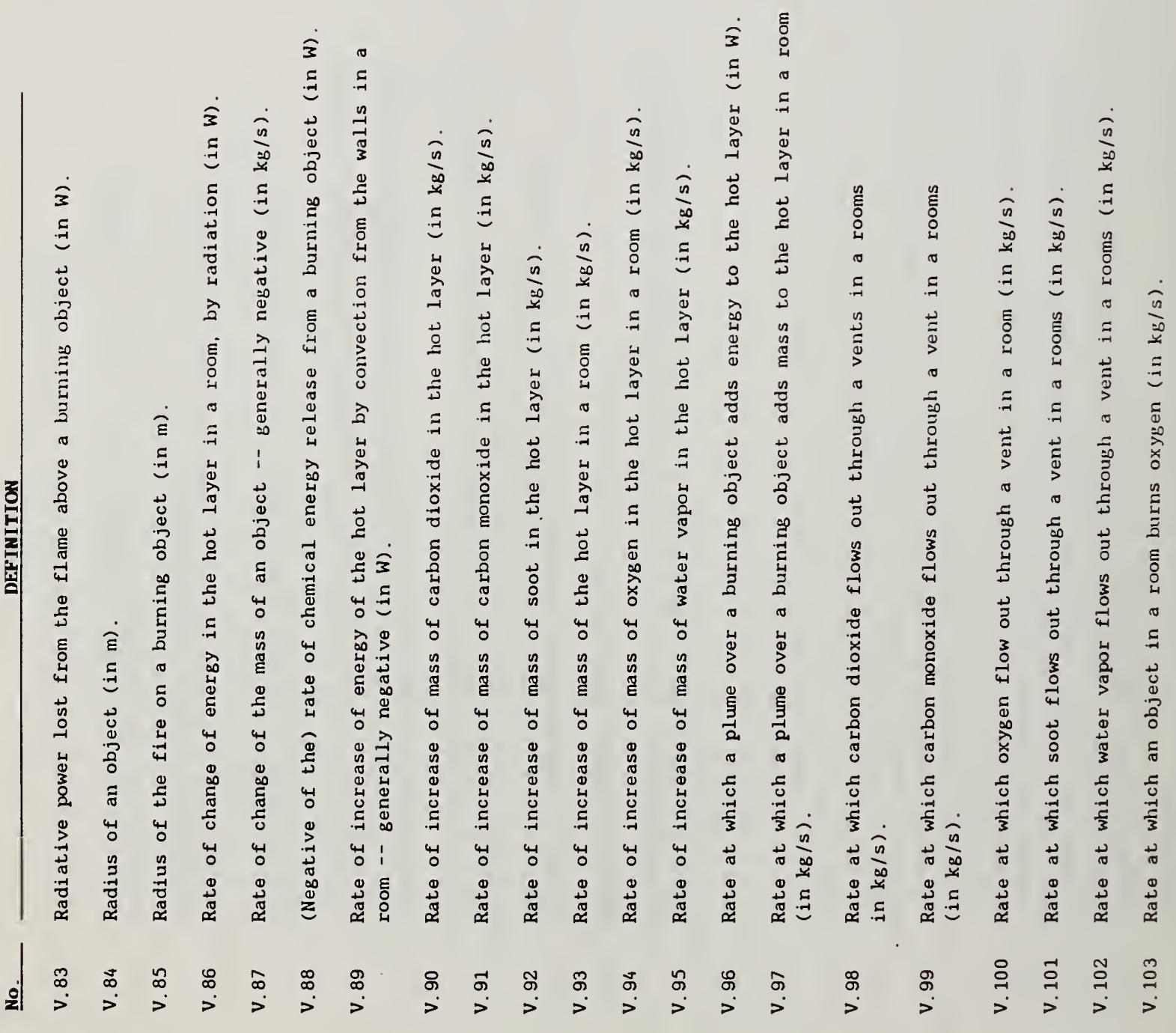




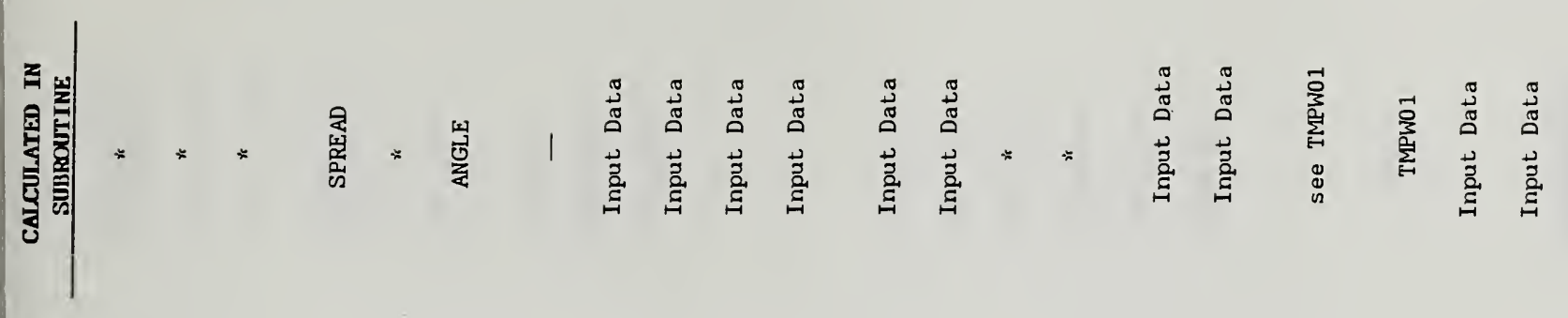

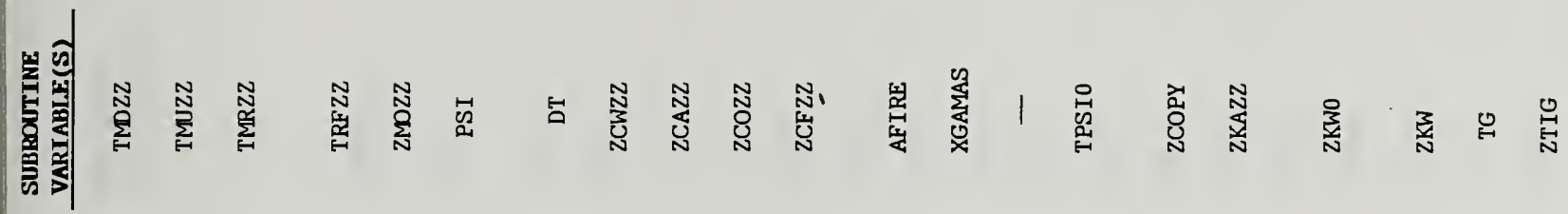

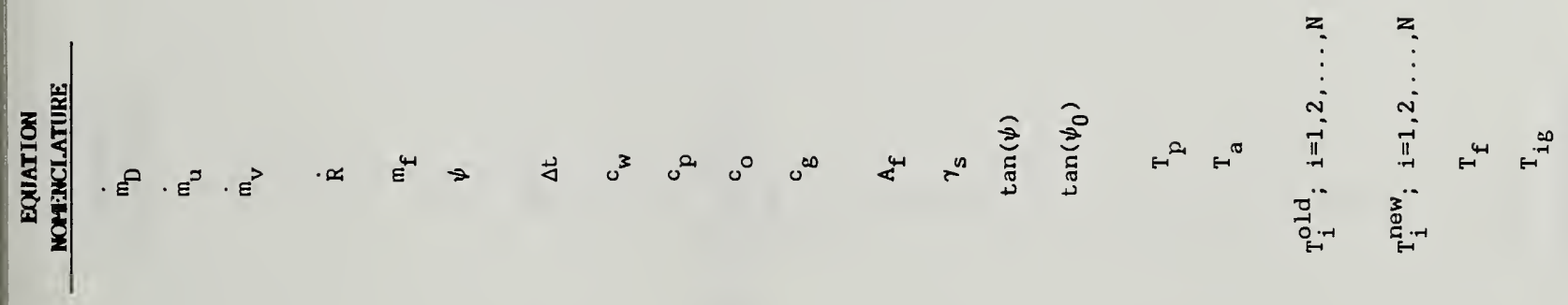

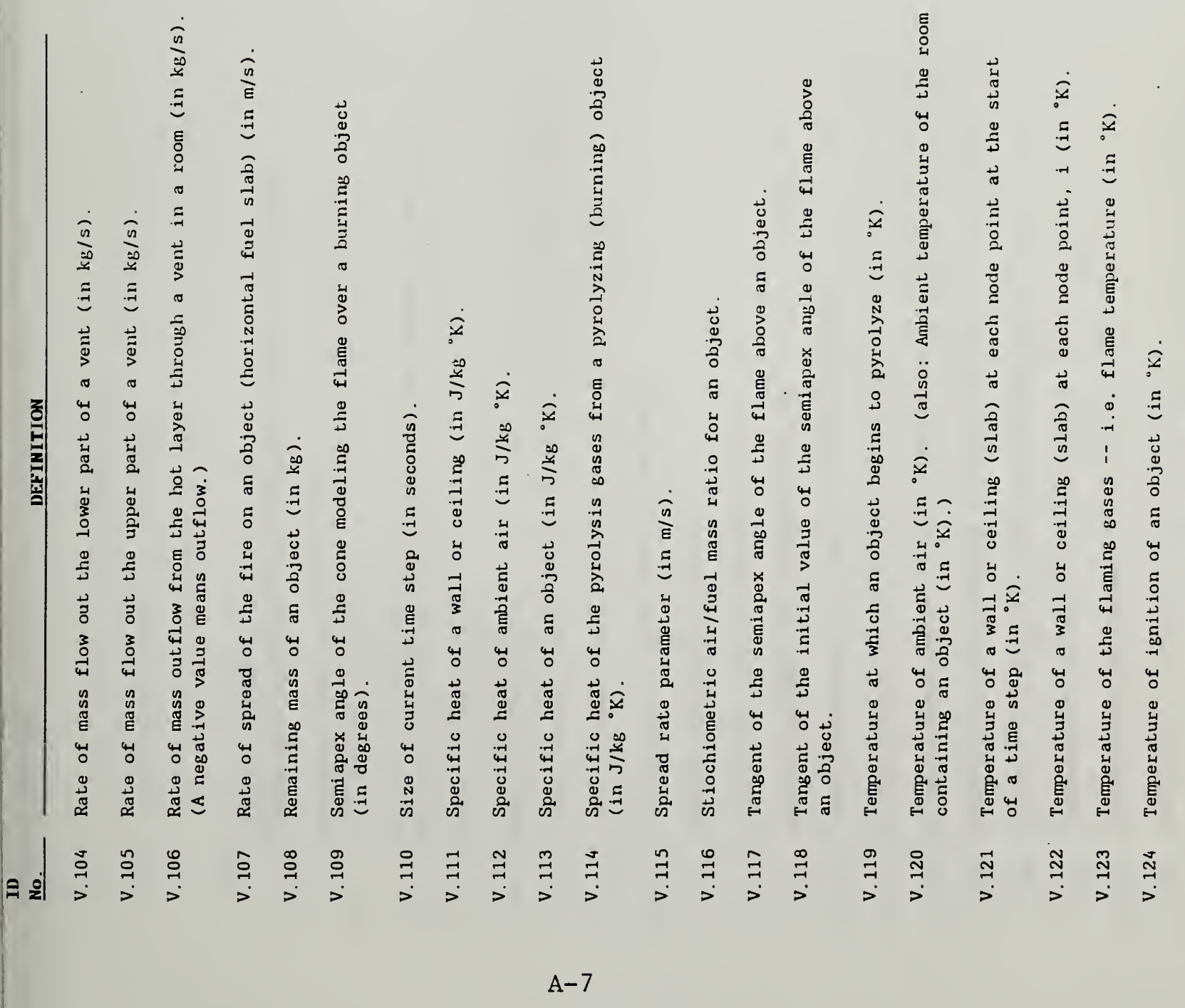




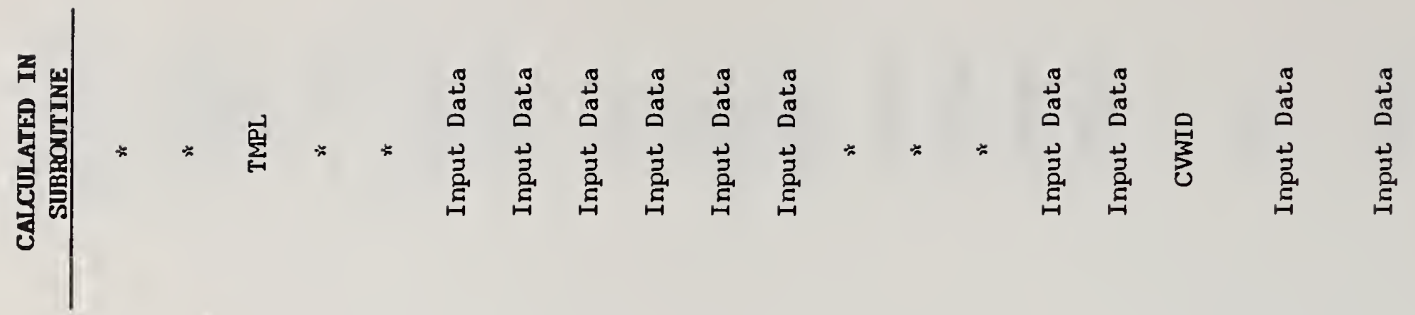

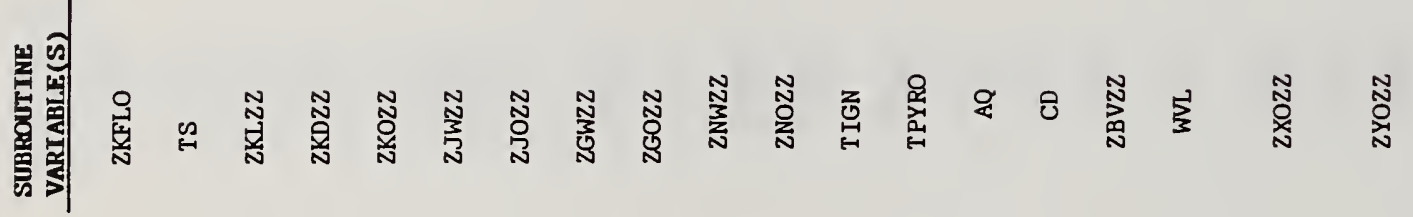

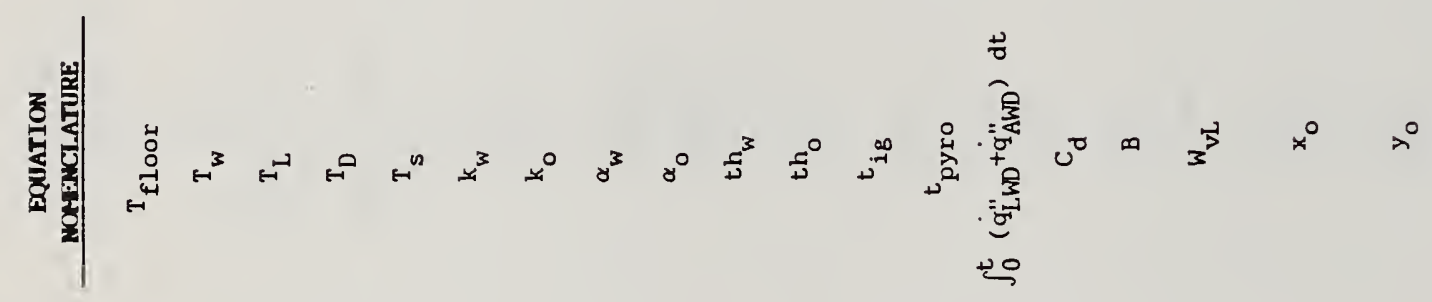

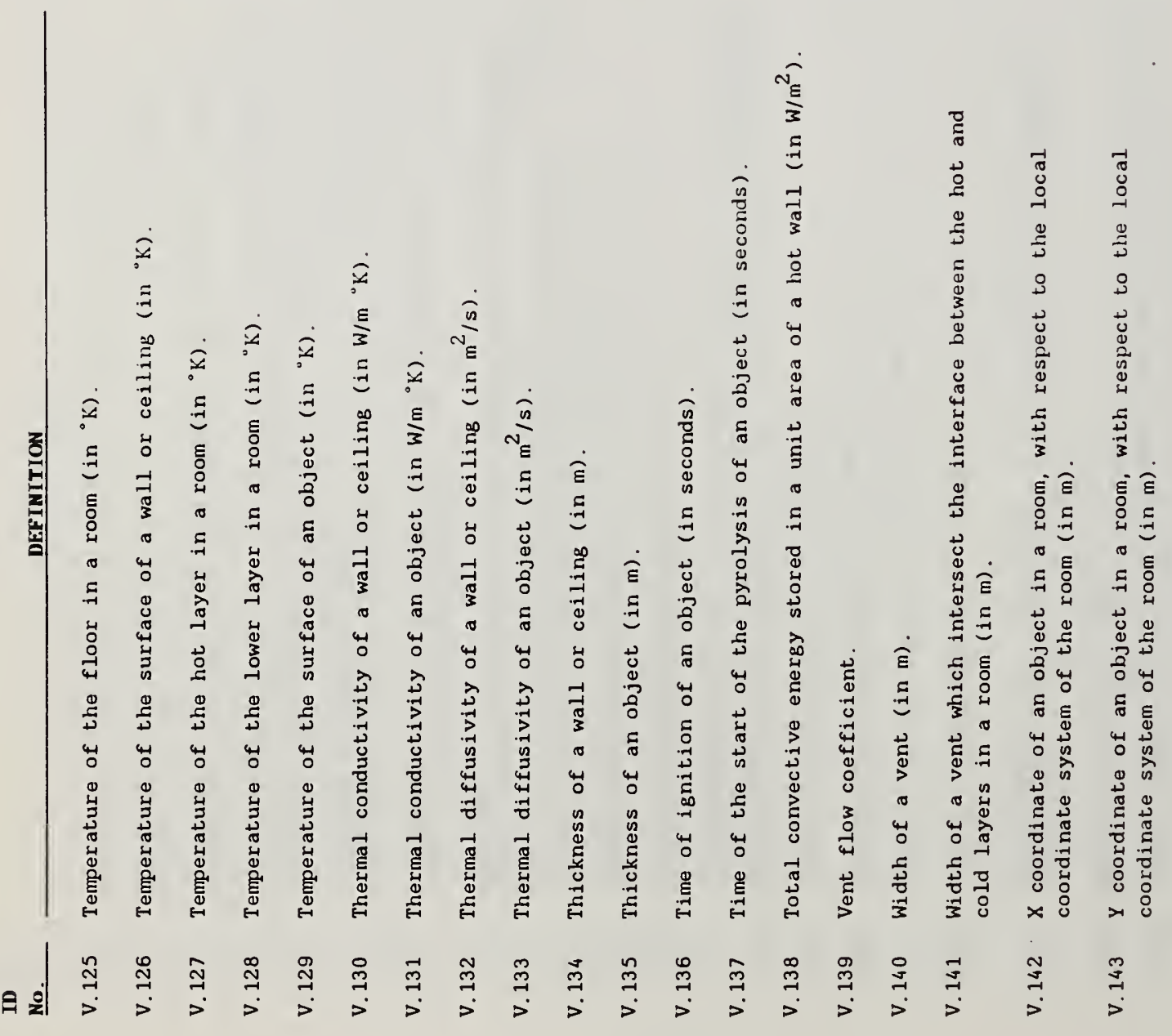




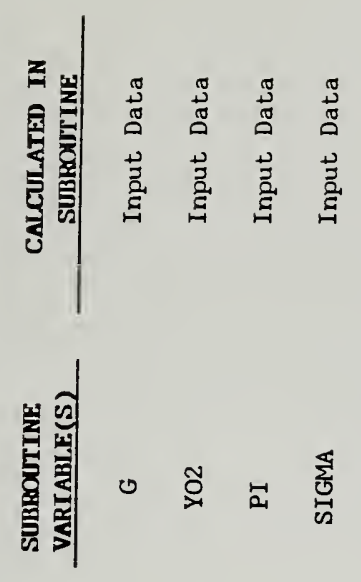

. $\ldots$

| 


$$
\text { A }-10
$$




\section{APPENDIX B}

LISTING OF ALGORITHM/SUBROUTINE WRITE-UPS

B-1 
1. Algorithms Related to the Burning Object

\begin{tabular}{|c|c|c|}
\hline $\begin{array}{c}\text { Subroutine } \\
\text { Name } \\
\end{array}$ & Output(s) & Input (s) \\
\hline ANGLE & V. 109 & V. $85, V .36$ \\
\hline BURN & V. 55 & V.26,V.3,V.61,V.97 \\
\hline CHEM & V. 88 & V.112,V.30,V.120,V.119,V.55,V.3T \\
\hline DXDPRD & V. 56 & V. $46, V .61$ \\
\hline FLUX & V. 67 & $\begin{array}{l}\text { V. } 31, V .1, V .77, V .80, V .78, V .108, V .85, \\
\text { V.146 }\end{array}$ \\
\hline HEIGHT & V. 36 & V. 26, V. 118, V. 55, V. 61, V. 85 \\
\hline MNXPRD & V. 57 & $V .45, V .61$ \\
\hline PFLUX & V. 67 & V. 82, V. 13, V. $28, V .129$, V. 147 \\
\hline PPYRO & V. 61 & V.31,V.67,V.85, V. 146 \\
\hline PULRAD & V.85 & V.8,V.39,V.136,V.15 \\
\hline PYRO & V. 61 & V. 31, V. 8, V. 67, V. $108, V .85, V .146$ \\
\hline SPREAD & V. 107 & V.115, V.123,V.8,V.85, V. .67, V.147 \\
\hline SUTPRD & V. 58 & V. $48, V .61$ \\
\hline TMGAS & V. 61 & V. 15, V. 69, V. 7, V. 6 \\
\hline WTRPRD & V. 59 & V. $47, V .61$ \\
\hline
\end{tabular}

2. Algorithms related to Conduction Heat Transfer

Subroutine

Name

Output(s)

Input (s)

$\begin{array}{ll}\text { TMPW01 } & \text { V.122 }\end{array}$

V.11,V.81,V.79,V.11,V.15,V.64,

V.110,V.120,V.128,V.134,V.130,

V.132,V.111, V.16,V.2, V.147,

V.63,V. 20, V. 121 
3. Algorithms related to Convection Heat Transfer

Subroutine

Name

CBLOCK

CNVF

CNVI

CNVW01
V. 12

V. 86

Output(s)

V. 14

V. 11
Input (s)

V. 61, V. 85, V. 129, V. 144, V. $146, V .112$, V. $123, \mathrm{~V} .72$

V.128,V.125,V.21,V.22,V.72,V.144

V. 21, V. 22, V. $20, V .68$, V. $25, V .11$, V.138,V. 5, V. 141

V. 126, V. 127, V. 120, V. 66, V. 62

4. Algorithms related to the Hot Layer

\section{Subroutine}

Name

ABSRB2

DXDCNC

LAYDPT

MNXCNC

OXYCNC

POWL

SUTCNC

TCO2M

TH2OM

TMNXM

TMPL

TMSL

TOXYM

TSUTM

WTRCNC
Output(s)

V. 2

V. 41

V. 20

$\mathrm{V}: 40$

V. 43

V. 68

V. 44

V. 90

V. 95

V. 91

V. 127

V.93

V. 94

V. 92

V. 42
Input (s)

V. 44

V. 49, V. 54

V.112;V.17,V. 33,V.120,V.21,V. 22, V. 25

V.49,V. 54

V. 52, V. 54

V. 89, V. 86, V. 9, V. 10

V. 53, V. 54

V. $56, V .61, V .97, V .98$

V. 59, V. 102

V. 57, V. 99

V. 120, V. 112, V. 25, V. 54

V.97,V.106

V. 103, V. 61, V. 97, V. 100

V. $58, V .101$

V.51,V.54 
5. Algorithms related to the Plume

Subroutine

Name

OXYBRN

PLMHT

TENPLM

TMSPLM

V.97
Input(s)

V.43,V.116,V.55

V. $38, V .33, V .20$

V. 120, V. 119, V. 112, V. $88, V .29$, V. 61 , V. 97

V. 71, V. 17, V. 120, V. $88, V .61, V .37$ V. 85, V. $146, V .144, V .112$

7. Algorithms related to the Vent

Subroutine

Name

Output(s)

CVWID

VNTCVR
V. 141

V. 5
Input (s)

V. $140, V .23, V .34, V .20$

V. $140, V .23, V .34, V .20$ 
1. PUBLICATION OR REPORT NO. NBSIR-87/3607
2. Performing Organ. Report Nof 3. Publication Date

August 1987

4. TITLE AND SUBTITLE

A Catalog of Compartment Fire Model Algorithms and Associated Computer Subroutines

\section{5. $A \cup T H O R(S)$}

David W. Stroup

6. PERFORMING ORGANIZATION (If joint or other thon NBS, see instructions)

NATIONAL BUREAU OF STANDARDS

DEPARTMENT OF COMMERCE

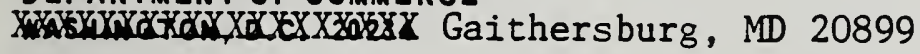

9. SPONSORING ORGANIZATION NAME AND COMPLETE ADDRESS (Street. City, Stote, ZIP)

7. Contrace Grant No.

8. Type of Report \& Period Covered

10. SUPPLEMENTARY NOTES

Document describes a computer program; SF-185, FIPS Software Summary, is attached. 11. ABSTRACT (A 200-word or less factual summary of most significant information. If document includes a significant
bibliography or literoture survey. mention it here)

The Compartment Fire Modeling Research group of the Center for Fire Research, National Bureau of Standards has been charged with the development of a "benchmark" compartment fire model. As part of this activity, a catalog of available fire model algorithms has been compiled. The catalog contains algorithms which calculate various physical/chemical fire phenomena. The description of each algorithm includes the input(s), output(s), and calculations performed. In addition, each algorithm has a computer subroutine written for it in FORTRAN 77. The variables used as input and output throughout the catalog are cross-referenced. This enables a catalog user to determine which routines would be required to calculate a particular fire phenomena. Updates and revisions will be issued periodically.

2. KEY WORDS (Six to twelve entries; alphabetical order: capitalize only proper names; and separate key words by semicolons) algorithms; building fires; cataloging; combustion physics; compartment fires; computer programs; fire chemistry; fire models; mathematical models; zone models 3. AVAILABILITY

X] Unlimited

14. NO. OF PRINTED PAGES

For Official Distribution. Do Not Release to NTIS

Order From Superintendent of Documents, U.S. Government Printing Office, Washington, D.C.
20402 . 235

XX Order From National Technical Information Service (NTIS), Springfield, VA. 2216I 


